\title{
Movements of the Posttraumatic Flâneur in Marker, Resnais, and Varda
}

\section{Bonnie Susan Gill}

\author{
Montclair, New Jersey
}

\author{
B.A., Boston University, 2006 \\ M.A., The American University of Paris, 2011
}

A Dissertation presented to the Graduate Faculty of the University of Virginia in Candidacy for the Degree of Doctor of Philosophy

Department of French

University of Virginia

April 2016 


\section{Table of Contents}

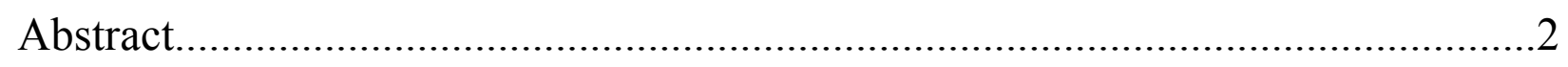

Introduction. The posttraumatic flâneur.................................................................4

Chapter One. Tracing Hiroshima mon amour's uncanny paths............................42

Chapter Two. Redirecting the gaze in Sans toit ni loi..........................................95

Chapter Three. Chasing the cats of Chats perchés...............................................142

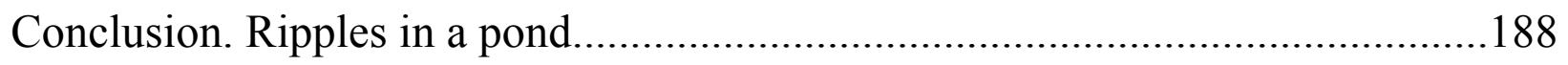

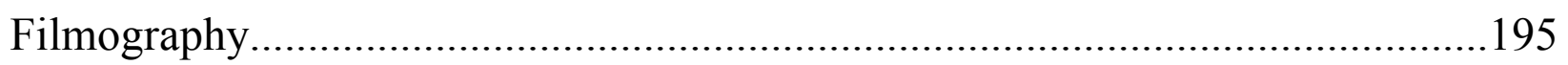

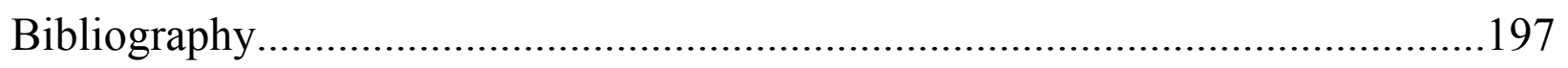




\begin{abstract}
Movements of the Posttraumatic Flâneur in Marker, Resnais, and Varda examines select films by three well-known French filmmakers (Chris Marker, Alain Resnais, and Agnès Varda) in order to identify and analyze the intersection of trauma with the figure of the flâneur in each. Given identifiable shape in the $19^{\text {th }}$ and early $20^{\text {th }}$ century writings of Edgar Allan Poe, Charles Baudelaire, and Walter Benjamin, the iconic flâneur tends to wander alone, thinking and observing, with no destination in mind and no fixed path. The flâneurs examined in the subsequent chapters walk beneath the shadow of a large-scale historical trauma that has permeated the national consciousness to such an extent that even years later it cannot be ignored. I therefore term these figures posttraumatic flâneurs: descendants of Baudelaire's man of the streets, they have no goal in mind and no fixed path and yet, in observing and thinking deeply about the world through which they move, they eventually arrive at a new, more functional place of being. In the case of Elle, the protagonist of Alain Resnais' Hiroshima mon amour (1959), the flâneuse reconciles with her past self, while Mona of Agnès Varda’s Sans toit ni loi (1985) reclaims the ability to look, rather than always being the object of the gaze. And the central character of Chris Marker's Chats perchés (2004) finds humor and hope amidst the darkness.

My identification of the posttraumatic flâneur comes from a close analysis of these three films (Hiroshima mon amour, Sans toit ni loi, and Chats perchés) with particular attention given to the cinematographic means by which each filmmaker imbues his or her film with traces of the sociopolitical and/or national discourses of the time of production. Further, I explore how French film continues to act as a reliable interpreter of the French national consciousness, which has many popular and intellectual outlets but which has historically excelled at expression through
\end{abstract}


film. The presence of a posttraumatic flâneur in these films indicates a productive negotiation between the malaise resulting from a distant but lingering trauma and the possibility of moving on. 


\section{Introduction}

\section{The posttraumatic flâneur}

"Where are the cats?" The question comes from the intertitles of Chris Marker's 2004 film Chats perchés and epitomizes the central figure's intent to track down a cartoon cat graffito that has become, within the context of the film and on the streets of Paris, a harbinger of humor, hope, and peace. The need for these is urgent: the framework of the film portrays a world in which discontent, animosity, and memories of terrorist acts - including the September $11^{\text {th }}, 2001$ attacks in the United States - are uncomfortably present. The central figure of Marker's film therefore takes to the streets, setting off on a quest to inject some measure of lightness into the surrounding gloom. In doing so he borrows the mantle of a long-heralded figure in French literature and culture who also walked the streets: the flâneur. Given identifiable shape in the writings of Charles Baudelaire, the $19^{\text {th }}$ century flâneur tends to wander alone, thinking and observing, with no destination in mind and no fixed path. Then, his thoughts seemed to be largely centered on the city through which he moved, its strange modern landscapes and extraordinary people. Now, however, the shock of modernity has been replaced by something else: the shock of violence. The flâneurs examined in the subsequent chapters walk beneath the shadow of a large-scale historical trauma that has permeated the national consciousness to such an extent that even years later it cannot be ignored. Their movements indicate a productive relationship between trauma and flânerie, the junction of which forms the framework for this inquiry.

An analysis of a number of films made by prominent French filmmakers in the last halfcentury has revealed this intersection of trauma and the flâneur. France has such well-established 
ties to its national cinema that French films can become a microcosm in which questions of national importance - in this case immigration, terrorism, racism, and the respective aftermaths of the Nazi Occupation and the Algerian War - are explored. How can a nation respond to such traumas? The question is vast, but by examining it within the context of film it becomes possible to pinpoint at least some tentative answers. The central figures of the films discussed below are all affected by a large-scale national trauma: Elle lives in a France still recovering from being occupied by Nazi Germany in World War II; Mona's France is dealing with the repercussions of the Algerian War, and the Speaker of Chats perchés moves through streets haunted by terrorism. ${ }^{1}$ Each also has a more proximate source of suffering: Elle mourns the loss of a forbidden lover years ago; Mona is repeatedly rejected by those around her; the Speaker is discouraged by the modern political process and the general lack of meaningful communication he observes in contemporary Parisian society. In the following chapters, I argue that by taking to the streets each finds some measure of relief and a means to negotiate with, if not completely eradicate, his or her malaise. I term these figures posttraumatic flâneurs: descendants of Baudelaire's man of the streets, they have no goal in mind and no fixed path and yet, in observing and thinking deeply about the world through which they move, they eventually arrive at a new, more functional place of being. In the case of Elle, the protagonist of Alain Resnais' Hiroshima mon amour (1959), she reconciles with her past self, while Mona of Agnès Varda's Sans toit ni loi (1985) reclaims the ability to look, rather than always being the object of the gaze. And the central character of Marker's film finds humor and hope amidst the darkness. He finds the cats.

\footnotetext{
${ }^{1}$ I refer to the unseen, unheard narrator-figure of Chats perchés as the "Speaker." There is a definite voice and personality behind this narrator but (s)he cannot be precisely identified with Marker, though the filmmaker is almost certainly the one wielding the camera and making editorial decisions most of the time.
} 
My identification of the posttraumatic flâneur comes from a close analysis of these three films (Hiroshima mon amour, Sans toit ni loi, and Chats perchés) with particular attention given to the cinematographic means by which each filmmaker imbues his or her film with traces of the sociopolitical and/or national discourses of the time of production. The three filmmakers, Alain Resnais (1922 - 2014), Agnès Varda (b. 1928), and Chris Marker (1921 - 2012), were members of the Left Bank group of the French New Wave movement, and their films tend to be formally innovative and visually stimulating. While not the only examples of the appearance of the posttraumatic flâneur, these films offer particularly strong central protagonists whose motivations for walking can easily be grasped. Furthermore, the use of new filmic techniques, a more lenient approach to style and narrative structure, and the possibility of on-location filming that are characteristic of New Wave filmmakers' approaches to light, motion, and sound are particularly appropriate to portraying the in-the-streets experience of the flâneur.

My use of the term "posttraumatic flâneur" echoes Joshua Hirsch, who coins the term "posttraumatic film" in his 2004 study of Holocaust films as "a cinema that not only represents traumatic historical events, but also attempts to embody and reproduce the trauma through its form of narration." Hirsch is concerned with the difficulties of "trying to represent the unrepresentable;" his family history impelled him to study films about the Holocaust, wanting to "understand them better" in order to understand his own as well as the historical past. ${ }^{3}$ Hirsch is struck, in his survey of films that include Resnais' Nuit et brouillard (1955) as well as Claude Lanzmann's Shoah (1985), by the constant movement either of the camera (especially in the former) or of the characters, who constantly walk and wander as they consider their own pasts

\footnotetext{
${ }^{2}$ Joshua Francis Hirsch, Afterimage: Film, Trauma, and the Holocaust (Philadelphia, Temple University Press, 2004), xi. He continues: "posttraumatic cinema is defined less by a particular image content - a documentary image of atrocity, a fictional image of atrocity, or the absence of an image of atrocity - than by the attempt to discover a form for presenting that content that mimics some aspects of posttraumatic consciousness itself, the attempt to formally reproduce for the spectator an experience of suddenly seeing the unthinkable.” Ibid., 19.

${ }^{3}$ Ibid., $\mathrm{x}$.
} 
and experiences. In the present study, I identify this walking and wandering as an essential component of the drive to better understand the past, both on an individual and a collective (i.e. national) level. Further, I hope to explore how French film continues to act as a reliable interpreter of the French national consciousness, which has many popular and intellectual outlets but which has historically excelled at expression through film. The presence of a posttraumatic flâneur in these films indicates a productive negotiation between the malaise resulting from a distant but lingering trauma and the possibility of moving on.

\section{Destruction, survival, and artistic representations}

At the beginning of Unclaimed Experience: Trauma, Narrative, and History Cathy Caruth unpacks a story used by Sigmund Freud to explore the repetitive compulsion of traumatic experience. In the story the hero, Tancred, kills his lover Clorinda and then wounds her again by striking a tree in which her soul has been entrapped. Hearing her voice ring out from the tree, Tancred is stunned; Caruth suggests that his shock arises from "the enigma of the otherness of a human voice that cries out from the wound, a voice that witnesses a truth that Tancred himself cannot fully know." ${ }^{4}$ The trauma of having twice killed his lover is compounded by that of not quite understanding what has happened, or why. Freud has turned to literature in his theoretical exploration, Caruth suggests, because literature can help us assess "the complex relation between knowing and not knowing." What has happened - the trauma, the wound - cannot be fully known except by the victim, but the victim has died, passing beyond the ability to bear witness. Nonetheless an echo of the pain remains. In the case of Tancred it is Clorinda's soul that is able to bear witness to her pain and suffering. Similarly, it is the survivors of a large-scale traumatic

\footnotetext{
${ }^{4}$ Cathy Caruth, Unclaimed Experience: Trauma, Narrative, and History (Baltimore: The Johns Hopkins University Press, 1996), 3.

${ }^{5}$ Ibid.
} 
event - those near, affected by, or even complicit in it - who are available to bear witness to the suffering that echoes through the aftermath. Caruth suggests that literature can provide at least one means of addressing this posttraumatic state by providing a location in which the echo may appear. In the following chapters I argue that film may also act in this capacity, relying on an inherent capability for re-enactment and mimesis to echo the trauma itself as well as the experience of the survivors, witnesses, and other affected parties. Although the examples given in the following chapters focus on individuals, we can also move beyond these protagonists to consider the nation; without trying to generalize from a singular experience, we might still intuit how a nation of individuals might experience a national trauma as it ripples outwards from the source.

Given the scope and discipline of the project, I have chosen to bypass for the most part the psychological (and especially the Freudian) implications of using the word 'trauma,' which have been more than adequately covered in the introduction of any of the texts discussed herein. ${ }^{6}$ Nonetheless the term "trauma" has a distinct meaning in the context of this study. In one of the earliest applications of trauma studies to the humanities Caruth defines trauma in her essay collection Trauma: Explorations in Memory as "a response, sometimes delayed, to an overwhelming event or set of events, which takes the form of repeated, intrusive hallucinations, dreams, thoughts or behaviors stemming from the event,"7 an early definition perhaps overly reliant on the American Psychological Association's Diagnostic and Statistic Manual (DSM) and yet useful in that it presages the use of flashbacks in both literature and film to effectively

\footnotetext{
${ }^{6}$ In particular, see Hirsch; Caruth; or E. Ann Kaplan, Trauma Culture: The Politics of Terror and Loss in Media and Literature (New Brunswick: Rutgers University Press, 2005). I also do not intend to lessen or ignore in any way the psychological or medical implications of a posttraumatic stress disorder (PTSD) diagnosis, which falls outside the scope of this study and my expertise.

${ }^{7}$ Cathy Caruth, Trauma: Explorations in memory (Baltimore: The Johns Hopkins University Press, 1995), 4-5.
} 
demonstrate a survivor's lived experience. ${ }^{8}$ E. Ann Kaplan prefers to acknowledge the complexities of bringing psychological theory, personal anecdote, and academic studies together by insisting on the "sharable" aspects of trauma, including the tendency to dissociate that characterizes both Caruth's and the ADSM's definitions. ${ }^{9}$ Hirsch offers that "trauma originally referred to a physical phenomenon: a violent disruption of the body's integrity" and notes the difference between external and internal (exogenous and endogenous) forms of trauma. ${ }^{10}$ Kaplan's characterization of trauma as a response - delayed or otherwise - to a fearful, unexpected event is especially pertinent to the films in this study, as all of the protagonists discussed below are responding to a pervasive sense of unease that results from the fearful events of the past. One could also consider that each of these protagonists has undergone a "shock," a word also used by Kaplan that has fewer psychological implications attached. However, the idea of receiving a shock does not fully convey the long-lasting effects of the events in question, and the state I am interested in investigating is truly a posttraumatic one in that the individuals repeatedly find themselves confronting, revisiting or flashing back to the site or time of a past event.

It is important to note that it is not the trauma itself that drives these characters into the streets. Rather, it is a sense of discontent that I argue stems in part from the fact that they have, in some cases decades ago, witnessed or been adjacent to an event that has so deeply wounded the nation that it remains always in the background. France's long-standing refusal to acknowledge the Algerian War as anything other than a "peace-keeping" operation is merely one indication of

\footnotetext{
${ }^{8}$ Currently in its fifth edition: American Psychiatric Association. Diagnostic and statistical manual of mental disorders (DSM-5®). American Psychiatric Pub, 2013.

9 See Kaplan's first chapter for a thorough breakdown of Freud's evolving trauma theories as well as what she considers three phases of renewed interest in trauma studies from the 1980s to the present. Kaplan, Trauma Culture, 24-41.

${ }^{10}$ Hirsch, Afterimage: Film, Trauma, and the Holocaust, 8.
} 
the aftermath of such a wound. ${ }^{11}$ None of the protagonists discussed below consciously sets out with the goal of eradicating this posttraumatic trace. Instead, they are reacting to a sense of vague malaise: something is not quite right, although it may well be impossible - or too painful - to identify exactly what. In this, they are again echoing the flâneur, whose excursions were in part driven by a discontent with his otherwise idle existence. Both the $19^{\text {th }}$ century and the posttraumatic flâneur sense that a better, more pleasurable (or at least less painful) state exists outside of their actual and mental walls, even if they do not quite know what form it might take.

Therefore, with the burden of past trauma still present in their day-to-day lives, the protagonists in the following films for one reason or another - often their exact purpose is unclear - take to the streets. Several previous scholars have addressed the question of how trauma permeates literature and/or film, particularly with regard to either character or camera movement. Most usefully, Kaplan explores the intersection of trauma, film, and politics in her 2005 book Trauma Culture: The Politics of Terror and Loss in Media and Literature. She opens her introduction by stating that she intends to write "about the impact of trauma both on individuals and on entire cultures or nations, and about the need to share and 'translate' such traumatic impact."12 Her major themes align closely with several principles on which I structure my argument and analysis: that "trauma produces new subjects, that the political-ideological context within which traumatic events occur shapes their impact, and that it is hard to separate individual and collective traumas." ${ }^{\prime 13}$ In particular Kaplan too is interested in the wider implications of the trauma - not how the immediate victims react or respond to their experience, but rather how those around them, even sometimes quite distant, are also affected. Beginning

\footnotetext{
${ }^{11}$ Jo McCormack, "Social Memories in (Post)colonial France: Remembering the Franco-Algerian War," Journal of Social History 44 no. 4 (2011): 1132.

${ }^{12}$ Kaplan, Trauma Culture, 1.

${ }^{13}$ Ibid.
} 
with a personal anecdote of her experience of 9/11, Kaplan convincingly argues that there are "complex interconnections between individual and cultural trauma" but also, importantly, that "one can also find the single hopeful thread of a catastrophe, namely the perhaps short-lived but real creation of new public-sphere communities as specific crises are 'translated' from group to group." ${ }^{\prime 4}$ Her experience in Lower Manhattan in 2001 led her, a film theorist who in her own estimation believed she "could easily analyze media manipulation,"15 to suddenly sense trauma's aftereffects, "to understand in ways [she] had only theorized before what collective trauma felt like." ${ }^{16}$ She heard, saw, and smelled the fear and sadness around her. In particular, she notes that she "felt the togetherness especially walking around Union Square," $"$ where she and other members of the citywide community were drawn to memorialize and share and express themselves. Similarly, an inexplicable but certain desire or even need to move, walk, or just be elsewhere in response to something so vastly affective is expressed by the characters in the films I study. The protagonists discussed in the following three chapters are individual members of a larger community of those who share, by default, an experience - however distant - of the largescale trauma that looms somewhere in their past. However, rather than focus on how representations impact the readers and viewers of works as Kaplan does, my goal is to delve more deeply into the works, examining the protagonists themselves. Kaplan prefers the former as a way to examine what she (following Hirsch and Martin Hoffman) calls vicarious trauma, an effect experienced by those exposed to others' traumatic recollections (often therapists). This empathetic response, however, can also be considered as applying to the protagonists in the

\footnotetext{
${ }^{14}$ Ibid., 2 .

${ }^{15}$ Ibid., 5 .

${ }^{16}$ Ibid., 9 .

${ }^{17}$ Ibid.
} 
following chapters, especially those who are not in particularly close proximity (in time or space) to the actual event.

As Caruth shows, the effect of these films on the viewer goes beyond the possibility of experiencing a vicarious trauma that then aids in understanding the survivor's state. Rather, the viewing of films that include intimations or representations of violence is particularly appropriate because both literature and trauma are interested in and reliant upon a careful balance between knowledge and incomprehension:

It is the moving quality of this literary story [i.e. Tancred and Clorinda], I would suggest - its striking juxtaposition of the unknowing, injurious repetition and the witness of the crying voice - that best represents Freud's intuition of, and his passionate fascination with, traumatic experiences. If Freud turns to literature to describe traumatic experience, it is because literature, like psychoanalysis, is interested in the complex relation between knowing and not knowing. And it is, indeed at the specific point at which knowing and not knowing intersect that the language of literature and the psychoanalytic theory of traumatic experience precisely meet. ${ }^{18}$

The inability or unwillingness to completely expose a particular experience (due to the trauma that such an exposure would elicit) lies akin to literature's interrogation of both the known and the unknown - Tancred's repeated act and the voice that bears witness, or stories of the collapse of the World Trade Center and the unprompted acts of community that followed. Despite a profound unwillingness to relive it, the trauma cannot be completely ignored but rather remains at best just below the surface. Caruth describes this as "the oscillation between a crisis of death and the correlative crisis of life, ${ }^{, 19}$ for if the event itself is a crisis, so too is the act of having survived it.

\footnotetext{
${ }_{18}^{18}$ Caruth, Unclaimed Experience, 3.

${ }^{19}$ Ibid., 7 (italics original).
} 
In each of the cases Caruth examines she finds parallels between what is known to be true and what might be better left unacknowledged, for the sake of those irreparably touched by it. ${ }^{20}$ In particular, her reading of Hiroshima mon amour suggests that the film "is a matter not only of what we see and known but also of what it is ethical to tell." ${ }^{, 21}$ As the narrative unspools, "the act of seeing, in the very establishing of a bodily referent, erases, like an empty grammar, the reality of the event;" 22 once the trauma is seen, it somehow also ceases to be quite as real, as the new knowledge replaces the lack that may have acted both as the most immediate (because unaltered) truth and as a sort of protective covering. Telling a story thus becomes, Caruth argues, a "necessary betrayal of the particular past." 23 Yet Hiroshima functions and succeeds in that:

a new mode of seeing and of listening - a seeing and a listening from the site of traumais opened up to us as spectators of the film, and offered as the very possibility, in a catastrophic era, of a link between cultures. What we see and hear, in Hiroshima mon amour, resonates beyond what we can know and understand, but it is in the event of this incomprehension and in our departure from sense and understanding that our own witnessing may indeed begin to take place. $^{24}$

Like Caruth, I want to investigate the intersection between the traumatic event and the stories that are told about it, and in particular the ways in which the stories are in fact essential to the trauma - how its continued existence comes to rely upon the history that is crafted around it. Indeed the experiences of those around it - victims as well as survivors - are also reliant upon the story being told, in the balancing of what happened, what is known, with what remains beyond comprehension. The films included in this study are also telling stories about traumatic events and victims and survivors, and are thus productive spaces in which to continue Caruth's

\footnotetext{
${ }^{20}$ Caruth's examples include Alain Resnais' Hiroshima mon amour as well as Freud's Beyond the Pleasure Principle and Moses and Monotheism, a reading of Freud's The Interpretation of Dreams by Lacan ("Tuché and Automaton"), and the intersecting discourses of Paul de Man, Immanuel Kant, and Heinrich von Kleist on falling and the body ("The Resistance to Theory," Critique of Judgment, "On the Marionette Theatre").

${ }^{21}$ Ibid., 26.

${ }^{22}$ Ibid., 29.

${ }^{23}$ Ibid., 30 .

${ }^{24}$ Ibid., 56.
} 
discussion. Rather than look at texts that explicitly refer to trauma, however, I turn to those in which a central trauma has been largely masked or concealed. Even in Hiroshima, where the atomic bomb looms massive over the stage, there is also the question of the Nazi occupation of France, a national trauma only obliquely referred to within the film despite being essential to the film's narrative premise. Similarly France's war with Algeria and the resulting immigration issues only vaguely appear in Agnès Varda's Sans toit ni loi despite their undeniable presence in the political background in which the film was made and takes place. Chris Marker's Chats perchés also takes place against a backdrop of a terrorism threat only touched upon within the narrative. Therefore, while I agree with Caruth in her identification of the story/trauma entanglement, I then turn from this in order to explore what happens once this intersection occurs. If trauma both "defies and demands our witness," as Caruth claims, I want to explore the ways in which this paradox manifests itself within the bodies of the characters of the film.

Like Caruth, Rudolph Binion is interested in why and how we feel the often unconscious "need to repeat, to re-enact, to relive an unbearable experience." $" 25$ The reliving of a trauma is so common, so understandable, Binion writes, that we rarely question why it happens; his goal is therefore to more properly recognize and acknowledge the process of repeating it - to make it more conscious. He too is interested in the intersection between knowing and not knowing, hoping to turn our collective interest more towards the former. To do so he examines everything from Greek mythology through the Romantics to pre-Freudian modern works, with a particular focus on episodic reliving (flashbacks). His case studies include Freud's journey towards the identification of the repetition compulsion as well as several historical examples and a series of

\footnotetext{
${ }^{25}$ Rudolph Binion, Traumatic Reliving in History, Literature and Film (London: Karnac Books, 2011), xi.
} 
literary works each of which is informed by if not centered on a traumatic reliving. ${ }^{26}$ Most relevant to the task at hand, however, is his discussion of several films that range from Orson Welles' A Touch of Evil (1958) and Alfred Hitchcock's Vertigo (1958) to Christopher Nolan's Memento (2000) and George Lucas'Star Wars (2005). Binion is interested in the guilt implied in the process of reliving, though it is rarely (in his estimation) a central consideration of these films. Rather, Binion's focus on reliving means that the stories he studies are very much focused on the trauma itself and on the various means the characters choose or are subject to as they recreate and repeat it, with little attention paid to the other victims and/or survivors of the event. Further, the traumas in question are small-scale, usually murders or assaults, and experienced individually. Like Caruth Binion cites Resnais’ Hiroshima as an apt example of traumatic reliving effectively portrayed on screen, but on the whole his chapter reads like a catalog of examples rather than an investigation of why or how such relivings might reflect the film's effect or the society in which it was made. Little thought, in other words, is given to the films' intersection with the actual world. Nonetheless Binion's index of examples serves to highlight the many ways in which film may succeed as one of many art forms involved in a larger discourse about trauma, society, and individual and collective response, and usefully demonstrates that trauma tends to intrude on those who experience it in unexpected ways. Across his range of examples it seems evident that someone who has been subject to trauma will eventually in some way react to it; if not by reliving it, then through some other form of response.

Other recent authors have considered the question of non-actualized movement (i.e. a movement conceptualized primarily in time rather than in space) as a response to a recent or

\footnotetext{
${ }^{26}$ These include: Euripedes, Ion; Dante, The Divine Comedy; Racine, Athaliah; Edgar Allan Poe, Ulalume; Herman Melville, Moby Dick; Henrik Ibsen, Rosmersholm (with asides on Ibsen's Little Eyolf and When We Dead Awaken as well as a call back to his previous work on repetitive reliving in Sophocles' Oedipus the King).
} 
imminent trauma. In a recent essay collection on "culture(s) of morbidity" Stephanie Siewert and Antonia Mehnert identify the "'close alliance" of morbidity and productivity" in culture and cultural representations, interrogating the ways in which art works to contextualize and problematize historical events (real or imagined). ${ }^{27}$ Siewert in her introduction identifies "morbid" as "an expression of transience, which not only spotlights the decay of life but moreover authors and authorizes the drive of renewal and the celebration of the instantaneousness of being in the face of death., ${ }^{28}$ Although the movement referred to is primarily one of life to death, this focus on the idea of renewal brings into play the act of moving forward or moving onward, not only figuratively through time (transience) but actually in space (translation), for one could argue there is nothing more indicative of the life drive than continued movement, the ability to keep going. In particular, the final essays in the collection suggest that amidst the complex aesthetics of contemporary culture film and literature increasingly turn to new ways of "deal[ing] with the inconceivability of death. . . foremost characterized by an aesthetic distance which creates a safe space of encounter. ${ }^{, 29}$ While the films in this project deal with traumas that threaten only distant deaths, rather than one's own imminent demise, they too tend towards creating an aesthetic distance, in no small part due to the films' high-register techniques (i.e. Resnais' shot angles, the twelve connected panning shots in Varda, or Marker's montage style, to give just a few examples). The essay collection also offers examples of scholarly interest in the physical sensation of trauma and artistic translations of this pain. The protagonists featured in Sandra Poppe's essay on "The Aesthetics of Death and Mourning in American Literature and Film," for example, tend to sense their losses in their bodies, expressing

\footnotetext{
${ }^{27}$ Stephanie Siewert and Antonia Mehnert, ed, Morbidity of Culture: Melancholy, Trauma, Illness and Dying in Literature and Film (Frankfurt: Peter Lang, 2012), 7.

${ }^{28}$ Ibid (italics original).

${ }^{29}$ Ibid., 18.
} 
their otherwise unquantifiable emotions via writing or acting on stage. In particular Poppe considers the physical sensations associated with death and especially grief, noting the human tendency to physically feel their sadness and to attempt to manage the sensation through action (usually of an artistic bent.) Poppe concludes by identifying a tendency towards "a new conciliation with death and grief - at least in literature and film." ${ }^{, 30}$ Such a conclusion is beyond the scope of this dissertation, which considers only a small subset of films produced in France by a very select group of filmmakers, but I too hope to demonstrate a certain movement towards reconciliation with traumatic national events; although no full understanding will or even could be reached, the films in this project are, in my view, attempts to recognize and respond to national trauma in ways that if not entirely definitive - for how could one definitively respond to such trauma in any case? - but at least partially assuaging.

The term "posttraumatic" has migrated from psychology to film studies as a useful descriptor for a cinema that incorporates violent, disturbing, or otherwise painful events into the narrative or subject matter with the intent to engage on an artistic level with the audience. Joshua Hirsch considers Resnais' Nuit et brouillard the first example of posttraumatic film "not only because of its subject matter and formal innovation, but also because of its extremely wide distribution and profound international impact on both the broad public and intellectuals." ${ }^{31}$ Nuit et brouillard thus constitutes a "radical break" from previous films - particularly concentration camp documentaries of the same time period - due to its use of "reflexive, modernist, poetic" techniques, ${ }^{32}$ true to Resnais' tendency to create films in which "the world is perceived,

\footnotetext{
${ }^{30}$ Ibid., 117.

${ }^{31}$ Hirsch, Afterimage: Film, Trauma, and the Holocaust, 28.

${ }^{32}$ Ibid., 41.
} 
distorted, and given meaning by the mind." ${ }^{, 33}$ Hirsch continues (and I would agree) that "for Resnais, the overwhelming historical traumas of the recent past rendered classical historical narrative ineffective; they demanded narratives constructed on the subjectively fragmented terrain of memory. ${ }^{, 34}$ Also useful is Hirsch's interest in two different aspects of Nuit et brouillard's self-awareness, both the formal self-reflexivity seen in the film's emphasis on its own film-ness (Hirsch notes for example the black and white to color transitions, the precise traveling shots, and the commentary) as well as its historical self-consciousness (i.e. its tendency to question the historical reality of certain artifacts that appear onscreen). The former is often seen in post-New Wave narrative films as well as documentaries, but the latter is less common an indication to the audience not just that the film is a film, but that its role as a historical marker should remain in question. ${ }^{35}$ The film essentially cautions the audience that it will itself become an artifact, as indeed it inherently must. After Nuit et brouillard, Hirsch suggests, posttraumatic narration could and did get translated into fiction films, including (among Holocaust films) The Pawnbroker (Sidney Lumet, 1965), which incorporates an early example of the posttraumatic flashback, and Hiroshima mon amour (Resnais, 1959), in which flashbacks are essential both to the narrative and the transmission of the trauma (to whatever extent possible) to the audience. Indeed Hirsch's analysis is highly reliant on the flashback as the central device through which a posttraumatic experience is elicited, though one might also include alternating shots, dream sequences, or any number of other cinematic techniques.

\footnotetext{
${ }^{33}$ Ibid., 42. Amongst Resnais' techniques Hirsch includes the film's poetic commentary (by Jean Cayrol), a modernist score, and the "formal rigor" of the film as a whole. Hirsch chooses to "read" the films in his project using the narrative terms of Gerard Genette (tense, mood, voice, etc.); rather than review these here I direct interested readers to Chapter Two of his book for a thorough discussion of these structures as seen in Nuit et brouillard and elsewhere.

${ }^{34}$ Ibid.

${ }^{35}$ On reflexive documentaries see Bill Nichols, Representing Reality: Issues and Concepts in Documentary (Bloomington: Indiana University Press, 1994).
} 
Meanwhile, although she does not explicitly use the term "posttraumatic," Kaplan's study looks at the aesthetics of trauma via several World War II narratives that center on a "belated" recreation of particular memories. She addresses in particular how politics (often unconsciously) affects filmic representations of trauma, thereby establishing (or "translating," to use her term) the event to the collective, spreading the experience among a wider audience. In each case she brings up questions of collective memory (or forgetfulness) and cultural representations in image or word that are inflected by the predominant surrounding discourses. However, Kaplan's analyses tend toward the historical, as befits her interest in the viewership or readership of these works; for example, her analysis of Hitchcock's Spellbound (1946) focuses largely on how the production of the film reflects the unconscious political concerns of that post-World War II time period, and how the film's genre (melodrama) allows a deliberate mimicking of trauma symptoms in order to draw the viewer's attention to questions of psychoanalysis. Kaplan's selection of works, from Marguerite Duras' novel La Douleur to Werner Herzog's Where the Green Ants Dream (1984) to photojournalism in Rwanda and Iraq, allow her to access a wide range of artistic and cultural representations, and she successfully argues for the insertion of political discourses into these varied visual media formats.

Mine is hardly the first attempt to look at the myriad ways in which historical traumas insinuate themselves into the fissures of society. Scholarly interest in the aftereffects of traumatic events spans a number of recent decades and became particularly essential following World War II. As Kaplan notes: "Trauma studies originated in the context of research about the Holocaust. This event was of such a magnitude as to warrant the use of trauma in its historical (one might say 'classical') form." ${ }^{36}$ More recently, an issue of Screen in 2001 was devoted to "Trauma and Screen Studies" and featured several studies of how trauma and culture collide, including articles

\footnotetext{
${ }^{36}$ Kaplan, Trauma Culture, 1.
} 
by Kaplan, Thomas Elsaesser, and Maureen Turim. ${ }^{37}$ Many of these more recent articles and texts have an interdisciplinary focus, with an eye towards collaborative understanding. As Hirsch usefully notes, following the work of James Berger:

The application of trauma theory to culture may offer at least one method of bridging the apparent gaps between a historical approach to culture and a textual approach; between a focus on the past signified by a historical text and a focus on the text's work of signification in the present; between documentary and fictional modes of representing history; and between individual and collective experiences of history. ${ }^{38}$

These histories must, one gathers, be addressed in some way, and while film (and literature) offer at best partial interpretations and/or responses to trauma, they nonetheless open the event up to a new audience by (re)presenting it in a somewhat comprehensible form. In fact this reproduction in textual or screen format may even be of use to the survivors of the event, for as Caruth suggests there may be a strong need to readdress or revisit what has happened, that "trauma is not locatable in the simple violent or original event in an individual's past, but rather in the way that its very unassimilated nature - the way it was precisely not known in the first instance returns to haunt the survivor later on." 39 Deborah Jensen adds that "trauma, after all, is a phenomenon that is normally made manifest only through displacement of literal memories into symbolic or fragmented form. Trauma allows suffering to be exhibited as symptom, even while the violence that occasioned the trauma is forgotten and unrecognizable." ${ }^{40}$ Trauma may be considered a productive and intriguing area of artistic investigation, but at the same time it potentially allows the line between knowing and unknowing to come into greater focus; by revisiting the event, these works of literature or film also become part of the echo.

\footnotetext{
${ }^{37}$ E. Ann Kaplan, "Melodrama, cinema and trauma," Screen 42, no. 2 (2001): 201 - 205.; Thomas Elsaesser, "Postmodernism as Mourning Work," Screen 42, no. 2 (2001): 193- 201.; Maureen Turim, "The trauma of history: flashbacks upon flashbacks," Screen 42, no 2 (2001): 205 - 210.

${ }^{38}$ Hirsch, Afterimage: Film, Trauma, and the Holocaust, 9.

${ }^{39}$ Caruth, Unclaimed Experience, 4 (italics original).

${ }^{40}$ Deborah Jensen, Trauma and its Representations: The Social Life of Mimesis in Post-Revolutionary France (Baltimore: The Johns Hopkins University Press, 2001), 32 (italics original).
} 


\section{Memory, fantasy, dreams}

Although literature can be a productive site of engagement with concepts of trauma, film offers an even more effective approach, especially for a contemporary audience conditioned to respond easily to visual stimuli. Kaplan includes film's disruption of more "traditional" literary forms among one of modernity's characteristics but, more importantly, film allows for a very visual experience of trauma. ${ }^{41}$ Further, film offers opportunities "to express emotions that sometimes are beyond rational treatment." 42 Binion usefully notes that, given the wide variety of techniques available to a filmmaker, "the medium itself, with its quick cuts, crosscuts, and flashbacks, is simply more hospitable than the novel or the theatre to trauma striking with an abrupt impact and to past trauma stealthily intruding on the present." 43 Hirsch echoes this belief, writing that "in addition to being one of the most influential mass media in the West at the time of the Second World War and its aftermath. . cinema was the medium most closely analogous to both perception and fantasy." 44 film can convey an "indexical aura, which can be used to create a sense of witnessing history" but also "imitates and engages the experience of processing what has been witness through mental imagery, memory, fantasy, and dreams." ${ }^{, 45}$ In other words, film is particularly suited to representations of trauma due to its ability to recreate past events in an accessible manner, either by realistically portraying them or by choosing methods that impart the sense of the event, if not the actuality. If posttraumatic experience is a mixture of a desire to know (closeness) and a desire to escape (distance), then film can mediate between the two by presenting images that are at once deeply affective and yet constructed so as to keep the representation under control.

\footnotetext{
${ }^{41}$ Kaplan, Trauma Culture, 24.

42 Poppe, "The Aesthetics of Death and Mourning," 112.

${ }^{43}$ Binion, Traumatic Reliving, 100.

${ }^{44}$ Hirsch, Afterimage: Film, Trauma, and the Holocaust, 6.

45 Ibid., 6-7.
} 
As befits a continuation of flâneur studies, I focus in particular on a selection of French films. France as a nation is particularly tied to the film industry, with a long history of cinematic innovation and a consistently high level of production often subsidized and supported by the national government. Further, French cinema was the instigator of the 1960s New Wave movement, which advanced the possibilities for what a film could do in terms of its effect on the viewer. French film after the development of the New Wave was particularly well suited to replicating - or at least revisiting - traumatic events; as Hirsch observes, certain modern or postrealist techniques in part "formally repeat the traumatic structure of the experience of witnessing the events themselves. ${ }^{, 46}$ Realist attempts to replicate trauma would be lacking in taste at best and intolerable at worst - one need only look at Alain Resnais' experience in filming Nuit et brouillard to recognize the near impossibility of recreating such an event as the World War II Nazi labor and concentration camps.

Generally identified as taking place from 1959 to 1964, the New Wave marks a reinvigoration of the seventh art in France following the war years and has been productively discussed as a reaction to the prevailing political, social, and economic conditions in France in the late 1940s and 1950s. ${ }^{47}$ New Wave films, although still widely regarded and studied as classics in many contexts, are generally considered to be of the moment - in other words, films that could not have been made before the post-war upheavals and which, although certainly influential, have rarely been made since. After the burst of reactionary creativity in the first half of the 1960 s, French film did largely return to a more traditional narrative structure. ${ }^{48}$ Successive

\footnotetext{
${ }^{46}$ Ibid., 3.

${ }^{47}$ Most recently: Richard Neupert, A History of the French New Wave Cinema (Madison: University of Wisconsin Press, 2002); Michel Marie, The French New Wave: An Artistic School, trans. Richard Neupert (Malden: Blackwell Publishing, 2003); Jean Douchet and Cédric Anger, French New Wave, trans. Robert Bonnono (New York: Distributed Art Publishers, 1999).

48 "Bertrand Tavernier, a former Positif critic, did not hesitate to ask Jean Aurenche and Pierre Bost [both of the 'cinéma de qualité' tradition] to collaborate on the scripts for his films, beginning with L'Horloger de Saint-Paul
} 
French films have largely maintained their distance from the blockbuster style of mainstream Hollywood and are still known for being technical and cerebral, ${ }^{49}$ but never again has French cinema presented the kind of large-scale innovation that suffused the cinematic landscape in Paris at that time. Critical scholarship invariably identifies the period as a crucial one for cinematic production both in France and worldwide. Richard Neupert suggests that the movement reflects "a complex network of historical forces, including all films made by young directors exploiting new modes of production as well as unusual story and style options" and should be considered "a time period during which social, technological, economic, and cinematic factors helped generate one of the most intensely creative movements in film history." ${ }^{, 50}$ Michel Marie writes that "the New Wave completely altered France's cinematic landscape, provoking a number of psychological 'shocks' felt across the world, as national cinemas discovered these films and greeted them with a mixture of amazement and discomfort." ${ }^{, 51}$ But the period was undeniably short-lived. For a multitude of reasons discussed in works by the critics cited above, the innovative outburst only lasted half a decade before French filmmakers largely returned to making films which, although certainly affected by the New Wave advances, were closer in style and form to the films of the pre- and inter-war years than to their immediate precursors. Thus the New Wave, despite its still prominent standing with both film scholars and the casual film viewer, is generally considered to have largely subsided by $1964 .^{52}$

(The Clockmaker of Saint Paul, 1974)." Marie, The French New Wave, 48.; "At the same time [early 1970s] an antiNew Wave current appeared. This had begun rather modestly when Bertrand Tavernier began directing in 1974. As a form of protest, as well as a provocation, he returned to using the scriptwriters of the French quality tradition that Truffaut had damned twenty years earlier. He gave precedence to the formal attitudes of documentary film, which enabled him to maintain his distance from the film." Douchet, French New Wave, 302.

${ }^{49}$ A well-known exception is Luc Besson and his films Léon: The Professional (1994); The Fifth Element (1997); writer for the Transporter and Taken series, Lucy (2014).

${ }^{50}$ Neupert, A History of the French New Wave Cinema, xviii.

${ }^{51}$ Marie, The French New Wave, 18.

52 "Today, Paris vu par. . . [1964] appears as both the New Wave's manifesto and testament, for it marked the end of the movement." Douchet, French New Wave, 173. 
However, the development of the New Wave in France allowed for a greater freedom of the part of the filmmakers, who no longer felt constrained by realist expectations. Following the publication in 1954 of François Truffaut's essay, "Une Certaine Tendance du cinéma français," which called for a new style of cinema free from the narrative and aesthetic boredoms of the “cinéma du papa," filmmakers including the Left Bank group of Resnais, Varda, and Marker began to experiment with non-traditional narrative forms and editing techniques. At the same time literature in France was responding to a similar call from Natalie Sarraute who promoted the self-conscious aesthetics of what she considered "L'Ère du soupçon." 53 Lynn Higgins considers the concurrent New Novel movement in part a reaction to "a heightening of sophistication on the part of novelists and readers alike,"54 and while Sarraute herself argued that lazy readers could take refuge in the easy narratives of cinema, Higgins suggests that the New Wave filmmakers were simultaneously responding to a similar craving for experimentation and formal complication. Although it is difficult to characterize New Wave films across the entire movement, Higgins identifies certain common structural elements, including "repetition, circularity, return, refusal (or inability) to achieve closure, spiraling in on themselves, gaps, holes, blank spaces, aporias of all kinds, jumps and cuts, proliferating mises en abyme and figures of infinite regress." ${ }^{, 55}$ In sum, these films often betray "a condition of restless immobility, ${ }^{, 56}$ an unwillingness to settle into narrative rhythms and a fixation on frustrating the expectations of the viewer. Films of this style are constantly on the move, and are therefore a particularly appropriate vehicle for flâneur protagonists.

\footnotetext{
${ }^{53}$ The title of Sarraute's well-known essay, published in 1956. Nathalie Sarraute, L'ère du soupçon (Paris, Gallimard, 1956). Agnès Varda dedicates Sans toit ni loi to Sarraute, though she had not yet met her. See T. Jefferson Kline, ed. Agnès Varda: Interviews (Jackson: University Press of Mississippi, 2014).

${ }^{54}$ Lynn A. Higgins, New Novel, New Wave, New Politics: Fiction and Representation of History in Postwar France (Lincoln: University of Nebraska Press, 1996), 5.

55 Ibid., 15.

${ }^{56}$ Ibid., 12.
} 
Although there were further developments in French (and world) cinema following the short-lived New Wave movement, it is those techniques that are most essential to the project of revisiting trauma. While only one of the films contained in this dissertation is a true "New Wave" film, Resnais, Varda, and Marker all got their start as part of the movement and all continue to make use of techniques that are designed in part to disorient the viewer and draw his or her attention to the form as well as the content of the film. In addition, these three filmmakers are considered part of the Left Bank subgroup of the New Wave innovators, largely for their more overtly expressed political interests. As I am in part interested in the intersections of these films with the political conditions of their production and reception, these highly engaged filmmakers seem an appropriate place to begin my investigation. There are several other films that would have been productive choices to analyze, including Resnais' Muriel (1963), Varda's Cléo de 5 à 7 (1962), or Marker's Le joli mai (1962), all of which incorporate the Algerian War into the context of the narrative. However, as evident from the release dates of those films, the conflict was only barely past (if at all) and therefore remains very much in the foreground of each of the films. Of course filmmakers in 1962-3 would be interested in Algeria. What is so interesting about Sans toit ni loi's response to that particular trauma is that the event is still there in the background, even twenty years later. Meanwhile, Hiroshima takes place a dozen years after the Occupation and the bombing of Hiroshima; and while Chats perchés is very close in time to the 2001 terrorist attacks, it also addresses the terrorist subway bombings from the mid1990s, a decade prior. In addition, while many characters in the films listed above deal with their exposure to trauma through movement - especially Cléo - the films in the following chapters have easily identifiable central protagonists whose movements become an indelible element of the narrative. 


\section{Taking a tortoise for a walk ${ }^{57}$}

Amidst these studies on trauma and its recreations in literary or filmic form one finds a persistent recognition of the need to react - whether survivor, observer, or only vaguely affected by a traumatic event, people universally are moved to respond in some way. One response that repeatedly appears is the urge to physically move, often away from the location of the event, in order to escape, to find distraction, or simply to achieve a physical and thereby also mental/emotional distance. Indeed this desire to vacate the scene of a trauma may be an essential element of the event itself: as Caruth notes, "in Freud's own theoretical explanation of trauma, in the example of the accident, it is, finally, the act of leaving that constitutes its central and enigmatic core." ${ }^{, 58}$ The posttraumatic flâneur considered here, however, is many years removed from the shock of the event. The impulse to move, therefore, is due to the enduring presence of discontent, a malaise that drives both the $19^{\text {th }}$ century flâneur attempting to occupy his otherwise idle mind and the posttraumatic flâneur still looking to return to a state in which the shock of the past no longer intrudes into the present.

The flâneur is an easily recognizable figure in French literary history, and has recently been acknowledged as a useful means to discuss a variety of contemporary inquiries, including postmodern cityscapes, architecture, and even popular health and fitness. ${ }^{59}$ Certain motifs return again and again in studies of the flâneur, but I will focus on three in particular: the anonymity of the individual within the crowd; the dichotomy between observing and being observed; and the shock of modernity. Each of these themes can be identified in Edgar Allan Poe's 1840 short story "The Man of the Crowd"; Charles Baudelaire's essay "Le peintre de la vie moderne"

\footnotetext{
57 "In 1839 it was considered elegant to take a tortoise out walking. This gives us an idea of the tempo of flânerie in the arcades." Walter Benjamin, The Arcades Project, trans. Howard Eiland and Kevin McLaughlin (Cambridge: The Belknap Press of Harvard University Press, 1999), 422.

${ }^{58}$ Caruth, Unclaimed Experience, 22 (italics original).

${ }^{59}$ A recent Google search turns up terms like "academic flâneur," "rocker flâneur," "phenomenological flâneur," and "surrealist flâneur" in addition to the usual "Parisian" or "Baudelairian" sort.
} 
(1863), dedicated to the subject of the artist Constantin Guys and referring back to Poe's story;

Walter Benjamin's reading of Baudelaire and observations in Das Passagen-Werk (written 19271940); and subsequent readings of these three touchstone works on the flâneur and flânerie. ${ }^{60}$

Regardless of alternate readings of the characteristics of the flâneur figure, these elements remain clearly identifiable across this range of works. ${ }^{61}$ Emotionally distant, although physically present, the flâneur observes his milieu through the eyes of one who is not really a part of the crowd. He is surrounded by the crowd, and moved by it, but also moves through it, his awareness lifting him above the sway and into a realm of greater observation.

It is in Baudelaire's reading of Poe that the concept of the Second Empire flâneur best materializes. Poe's story describes a man who spies a face that interests him through a café window and decides to follow it, eventually spending all night in pursuit of a man who seems to have no purpose, no goal, and no fixed path. Very little of either character is revealed, and no contact is made; eventually the story ends with the observer noting of the observed: "He refuses to be alone. He is the man of the crowd. It will be in vain to follow; for I shall learn no more of him, nor of his deeds." ${ }^{, 62}$ Here both figures remain anonymous, and the dialectic between seeing and being seen begins to be established. In his essay Baudelaire further develops these motifs, summarizing Poe's story (which he translated in 1857 for Nouvelles Histoires Extraordinaires) as follows:

In the window of a coffee-house there sits a convalescent, pleasurably absorbed in gazing at the crowd, and mingling, through the medium of thought, in the turmoil of thought that surrounds him. But lately returned from the valley of the shadow of death, he is

\footnotetext{
${ }^{60}$ Baudelaire's poem "Rêve Parisien" in the 1860 publication of Fleurs du mal is also dedicated to Constantin Guys; one might also turn to his "À une passante" from the same edition for another evocation of beauty and motion.

${ }^{61}$ Scholars differ on the exact parameters of a proper flâneur: for example, Martina Lauster calls Benjamin's reading of Baudelaire and Poe "flawed," suggesting that "Benjamin's idea of the flâneur is not only of limited value for an understanding of nineteenth-century urban experience, but can be seen positively to hamper it." Martina Lauster, "Walter Benjamin's Myth of the "flâneur"," The Modern Language Review 102 no. 1 (2007): 139.

${ }^{62}$ Edgar Allan Poe, "The Man of the Crowd," The Complete Tales and Poems of Edgar Allan Poe (New York: Race Point Publishing, 2014), 420.
} 
rapturously breathing in all the odours and essences of life; as he has been on the brink of total oblivion, he remembers, and fervently desires to remember, everything. Finally he hurls himself headlong into the midst of the throng, in pursuit of an unknown, halfglimpsed countenance that has, on an instant, bewitched him. Curiosity has become a fatal, irresistible passion!"63

In this description we see already Baudelaire's interest in the relationship between the individual -meaning the convalescent, but also the unknown "half-glimpsed countenance" - and the throng of people, the singular thought mingled with the surrounding turmoil. In addition, Baudelaire notes the allure of observation, which becomes a "bewitching," "irresistible" force; this observer needs to know more, whatever the cost. Therefore his flâneur does, in fact, enter the crowd. Poe's narrator also imagines that he can, as the hour grows late, "frequently read, even in that brief interval of a glance, the history of long years" as he gazes upon the faces that pass. ${ }^{64}$ Even if mistaken, this intensity of gaze, the desire to know what lies behind it, is characteristic of the flâneur who imagines the connections, the stories behind the faces (and places) that pass. Yet is the convalescent observer really the flâneur? It is true that he wanders the streets all night, but he is hardly without purpose: he wants to know more about the stranger, he is curious. The old man, the fiend in the crowd, is decidedly more flâneur-like in his movement and better represents how the figure is later characterized; it is he who "force[s] his way to and fro, without aim, among the host of buyers and sellers, ${ }^{65}$ even retracing his steps and completely oblivious to his pursuer.

Whether he refers to the convalescent, the mysterious figure, or some amalgamation of the two, however, Baudelaire's definition of the flâneur is crisp and clear:

The crowd is his element, as the air is that of birds and water of fishes. His passion and his profession are to become one flesh with the crowd. For the perfect flâneur, for the passionate spectator, it is an immense joy to set up house in the heart of the multitude, amid the ebb and flow of movement, in the midst of the fugitive and the infinite. To be

\footnotetext{
${ }^{63}$ Charles Baudelaire, The Painter of Modern Life and Other Essays, trans. and ed. Jonathan Mayne (London: Phaidon Press Limited, 2003), 7.

${ }^{64}$ Poe, "The Man of the Crowd," 417.

${ }^{65}$ Poe, "The Man of the Crowd," 418.
} 
away from home and yet to feel oneself everywhere at home; to see the world, to be at the centre of the world, and yet to remain hidden from the world - such are a few of the slightest pleasures of those independent, passionate, impartial natures which the tongue can but clumsily define. ${ }^{66}$

In this definition one sees neither the thwarted convalescent of Poe's story nor his prey, but rather some more joyful sort, entirely comfortable amidst the sway of the populace; it is from this description that later discussions of the flâneur take their inspiration.

Once immersed, the flâneur must also be able to switch between an abstract, overall impression and an attention to details, as Poe's narrator describes: “At first my observations took an abstract and generalizing turn. I looked at the passengers in masses, and thought of them in their aggregate relations. Soon, however, I descended to details, and regarded with minute interest the innumerable varieties of figure, dress, air, gait, visage, and expression of countenance." ${ }^{67}$ Where Poe's convalescent is particularly interested in people, Baudelaire's painter prefers to gaze upon the city itself: "He marvels at the eternal beauty and the amazing harmony of life in the capital cities, a harmony so providentially maintained amid the turmoil of human freedom. He gazes upon the landscapes of the great city - landscapes of stone, caressed by the mist or buffeted by the sun." ${ }^{, 68}$ All of these marvelous vistas Baudelaire eventually qualifies as la vie moderne, "that quality which you must allow me to call 'modernity'; for I know of no better word to express the idea I have in mind." ${ }^{69}$ He later elaborates: "By 'modernity' I mean the ephemeral, the fugitive, the contingent, the half of art whose other half is the eternal and the immutable. Every old master has had his own modernity. . It is doubtless an excellent thing to study the old masters in order to learn how to paint; but it can be no more than

\footnotetext{
${ }^{66}$ Baudelaire, The Painter of Modern Life, 9.

${ }^{67}$ Poe, "The Man of the Crowd," 415.

${ }^{68}$ Baudelaire, The Painter of Modern Life, 11.

${ }^{69}$ Ibid., 12.
} 
a waste of labour if your aim is to understand the special nature of present-day beauty." ${ }^{, 70}$ What the flâneur observes is precisely this modernity, the passing faces and places that offer beauty to the discerning, attentive eye.

This landscape of stone, however, was more shocking than amazing to Benjamin. Where Baudelaire sees the childlike, as if "that illness had left our spiritual capacities pure and unharmed,"71 Benjamin sees a reprobate:

The masses in Baudelaire. They stretch before the flâneur as a veil: they are the newest drug for the solitary. - Second, they efface all traces of the individual: they are the newest asylum for the reprobate and the proscript. - Finally, within the labyrinth of the city, the masses are the newest and most inscrutable labyrinth. Through them, previously unknown chthonic traits are imprinted on the image of the city. ${ }^{72}$

Not only is anonymity desirable, it becomes a veritable craving. Indeed Benjamin found the Arcades of Paris, however entrancing, to be just another indication of the proliferation of "phantasmagorias," lamenting that "humanity will be prey to a mythic anguish so long as phantasmagoria occupies a place in it." ${ }^{, 73}$ He reads the gaze of the flâneur as betraying "a profound alienation," and suggests that "the crowd is the veil through which the familiar city is transformed for the flâneur into phantasmagoria. This phantasmagoria, in which the city appears now as landscape, now as room, seems later to have inspired the décor of department stores, which thus put flânerie to work for profit. In any case, department stores are the last precincts of flânerie.",74 Lauster adds, reading Benjamin, that "As an observer and connoisseur of market

\footnotetext{
${ }^{70}$ Ibid., 13.

${ }^{71}$ Ibid., 8 .

72 Benjamin, The Arcades Project, 446. While Baudelaire's ode to the flâneur (in a section of the essay subtitled "The artist, man of the world, man of the crowd, and child") relies on anonymity, it is not exactly this sort of anonymity that has been carried across in later discussions of the flâneur. Baudelaire writes about the painter Constantin Guys, but declines to name him, instead suggesting that "when he learnt that I had it in mind to write an appreciation of his mind and his talent, he begged me - very imperiously, I must admit - to suppress his name, and if I must speak of his works, to speak of them as if they were those of an anonymous artists." Baudelaire, The Painter of Modern Life, 5.

${ }^{73}$ Benjamin, The Arcades Project, 15.

${ }^{74}$ Ibid., 21.
} 
fluctuations and as someone at the same time on a reconnaissance mission in the consumer's realm, the flâneur possesses the perceptiveness to register all the signs of commodification." ${ }^{, 75}$ Benjamin's dismay at the commodification of society lives within the experience of the flâneur, who cannot step into the streets without being confronted with signs of an upsetting modernity. His flâneur, therefore, is one who observes and is overcome by an economic landscape, somewhat different from Baudelaire's more artistically-minded wanderer.

Beyond his shock at the ubiquity of consumerism, an additional preoccupation of Benjamin in his musings on the flâneur is an engagement with the past, especially the past as it has been told in story form or put down in a book. Benjamin ties the ambulatory experience of the flâneur to this way of telling the past via narration, words, writing that:

That anamnestic intoxication in which the flâneur goes about the city not only feeds on the sensory data taking shape before his eyes but often possesses itself of abstract knowledge - indeed, of dead facts - as something experienced and lived through. This felt knowledge travels from one person to another, especially by word of mouth. But in the course of the nineteenth century, it was also deposited in an immense literature. . . The study of these books constituted a second existence, already wholly predisposed toward dreaming; and what the flâneur learned from them took form and figure during an afternoon walk before the aperitif. ${ }^{76}$

The flâneur, then, is more or less codifying history through his walk, acting out a similar sort of living-through by wandering through the streets as he has wandered through literary representations of the past. As we will see in the following chapters, the protagonists of the chosen films are also preoccupied with the past, and often seem to bring the past into their wanderings, either through flashback (Elle), repeated action (Mona), or clarification (Marker's Speaker). They are also, like Baudelaire's flâneur, keen observers of their surroundings, including the other people they encounter. However, the wanderer him- or herself must eventually recognize that $\mathrm{s} /$ he also becomes part of the surroundings, a potentially equally

\footnotetext{
${ }^{75}$ Lauster, "Walter Benjamin's Myth,” 140.

${ }^{76}$ Benjamin, The Arcades Project, 417.
} 
fascinating figure among the many in the crowd. Benjamin refers to this need for equilibrium as the "dialectic of flânerie": "on the one side, the man who feels himself viewed by all and sundry as a true suspect and, on the other side, the man who is utterly undiscoverable, the hidden man."77 The flâneur is inherently anonymous, an observant individual in the crowd, and yet there are moments in which he too is seen. Benjamin reads this moment of recognition negatively, as the flâneur becomes suspect; for Poe, on the other hand, the glimpse of another's face is an impetus for ravenous, healthy curiosity, and for Baudelaire, an instant of joyful communion with the infinite.

Like the concept of the New Wave, the flâneur holds great sway over the imagination of scholars, although both have been somewhat sentimentalized. ${ }^{78}$ The word flâneur has been used in both French and English-language scholarship to denote a certain kind of pensive, intellectual person of the crowd whose journeys through the urban streets have become a useful motif in describing cities, understanding modernity, and analyzing the imbrication of physical activity with intellectual pursuits. As Giampaolo Nuvolati puts it, the word flâneur has been used "since the late nineteenth century to designate writers, poets and intellectuals that critically observed people's behavior while strolling among the crowd."79 John Rignall adds that "the Flâneur is at once an observed historical phenomenon, a type among inhabitants of nineteenth century Paris, the representation of a way of experiencing metropolitan life, a literary motif, and an image of the commodity in its relation to the crowd." ${ }^{80}$ Considering the less deliberate aspects of the figure, Raymond Lucas describes the flâneur as a "meandering, aimless 'Man Without

\footnotetext{
${ }^{77}$ Ibid., 420.

${ }^{78}$ One of the major organizing questions of Marie's book is: "why has this myth [of New Wave coherence] survived for so long since the 1960s?" Marie, The French New Wave, 1.

${ }^{79}$ Giampaolo Nuvolati, "The Flâneur: A Way of Walking, Exploring and Interpreting the City," Walking in the European City, ed. Timothy Shortell and Evrick Brown (Farnham: Ashgate, 2014), 21.

${ }^{80}$ John Rignall, "Benjamin's flâneur and the problem of realism," The Problems of Modernity, ed. Andrew Benjamin (London: Routledge, 1989), 113.
} 
Qualities" "who is notable for displaying "modes of distracted attention in traversing the city,"81 while Chris Jenks suggests that "the flâneur, though grounded in everyday life, is an analytic form, a narrative device, an attitude towards knowledge and its social context. It is an image of movement through the social space of modernity." 82 Beatrice Hanssen highlights the ubiquity of the practice and its subsequent ritualization among the populace and eventually the intellectual class: "Flânerie - of course - was an urban art form, a leisure habit, made famous by dandies, such as the poet Baudelaire, not the healthy exercise of strolling or walking, spazieren, prescribed by doctors as a means to ward of melancholy. . . flânerie involved the gregarious if defiant encounter with passers-by, a social ritual of the bourgeois upper class. ${ }^{, 83}$ All of these definitions trace out the image of a pensive figure, surrounded by others but largely alone, usually metropolitan and, most importantly, always on the move. ${ }^{84}$

In recent decades a renewed interest in the flâneur figure has developed, in particular with regard to a post-modern understanding of public spaces and practical applications of the observation-through-motion model. Chris Jenks uses the flâneur to explore urban space, suggesting that "space has to be conceptualised in order to be experienced and understood, our

\footnotetext{
${ }^{81}$ Raymond Lucas, "Inscribing the city: a flâneur in Tokyo," Anthropology Matters 6 no. 1 (2004), 1.

${ }^{82}$ Chris Jenks, "Watching Your Step: The history and practice of the flâneur," Visual Culture (London: Routledge, 1995), 148.

${ }^{83}$ Beatrice Hanssen, ed. Walter Benjamin and The Arcades Project (London: Continuum, 2006), 3.

${ }^{84}$ It was of course nearly impossible for a woman to "take to the streets" in earlier eras - a female street-walker was much more likely to be a prostitute than a woman of leisure out for a pensive stroll. Although my project features two female lead characters, they are subject to the (somewhat) more tolerant societal norms of the $20^{\text {th }}$ century and their flânerie does not automatically lead to assumptions of lewd behavior, at least not to the same extent that it would have a century earlier. For the most part, therefore, I bypass the question of social propriety and the flâneuse in the present study. Nevertheless it is true that both Elle and (especially) Mona are subject to certain assumptions due to their presence as lone females in the streets: Elle deals with the unwanted advances of a man in a café she visits, while Mona is subject to countless leers, several sexual encounters where her consent is not made explicit, and one (off-screen) rape. Mona also encounters a prostitute at one point, so there is at least some awareness in the film of the distinction drawn between the two roles. For a thorough analysis of the flâneuse see: Catherine Nesci, $L e$ Flâneur et les flâneuses: les femmes et la ville à l'époque romantique (Grenoble: ELLUG. 2007).; Aruna D'Souza Aruna and Tom McDonough, ed., Invisible Flâneuse?: Gender, Public Space and Visual Culture in NineteenthCentury Paris (Manchester: Manchester University Press. 2006).; Deborah L. Parsons, Streetwalking the Metropolis: Women, the City and Modernity (London: Oxford. 2000).
} 
'sites' are informed by the predisposed character of our 'sight'." ${ }^{85}$ In particular, Jenks argues that by default modern institutions (including “prisons, factories, schools, and the armed services”) inevitably result in populations that are "spatialised, divided, subdivided, clustered and, therefore, more readily processed. ${ }^{, 86}$ In order to establish alternate meanings of these sites and clusters, Jenks insists, the act of observation can play an important sociological role; in other words he wants "to reconstitute the analytic force of the flâneur." ${ }^{, 87}$ He uses the figure "to "move' from real products of modernity, like commodification and leisured patriarchy, through the practical organisation of space and its negotiation by inhabitants of a city, to a critical appreciation of the state of modernity and its erosion into the post-[modern]." 88 Jenks' goal, ultimately, is to tie the flâneur to a kind of alternative geography that in his view helps clarify the designations often too readily given to certain, often lower-income neighborhoods; the flâneur thus, via his/her fascination and estrangedness, represents a "reflexive recognition [that], being interchangeably magnetic and repulsive, is both upholding of its difference and despecularising of its content." 89

Giampaolo Nuvolati is particularly interested in the contradictions of the flâneur and the ways in which the flâneur can be reimagined in a contemporary setting, including for example modern-day students or the writer of a tourist guidebook who uses personal experience to create recommendations. Nuvolati's essay, in a collection called Walking in the European City, identifies the re-emergence of the concept of the flâneur in modern and post-modern scholarship and therefore can be considered a useful survey of the landscape into which this dissertation fits. In it, he lays out a series of other flâneur-like figures, including "tourists, travelers, social

\footnotetext{
${ }^{85}$ Jenks, "Watching Your Step," 144.

${ }^{86}$ Ibid.

${ }^{87}$ Ibid., 145.

${ }^{88}$ Ibid., 148.

${ }^{89}$ Ibid., 158.
} 
scientists, hippies and other figures performing a sort of flanerie in the urban context,"90 a useful list to consider when analyzing the protagonists chosen for the dissertation. Nuvolati also calls our attention to the wide variety of possible motives for a contemporary flâneur, writing that as "urban animals par excellence and trained at the difficult school of modern metropolitan existence, flâneurs embody many things: the wanderlust typical of individuals trapped by territorial, ideological, and professional constraints; rebellion against mass consumerism, especially fast-food tourism; the desire to enjoy life at a slower pace; the cultivation of sensitivity as a form of knowledge." ${ }^{91}$ He continues: "Relocated from the Parisian arcades to contemporary suburbs and commercial malls, the use of the concept of flâneur seems to reflect the modern sense of bewilderment, as well as the craving for new relationships with both places and their inhabitants." 92 It is particularly this latter that drives the protagonists in the films chosen for this dissertation, and to this list I would add that their bewilderment stems not just from their confrontation with a modern lifestyle (as Nuvolati somewhat implies) but also from a persistent fear looming in the background. Most importantly, Nuvolati emphasizes the use of "flânerie for understanding the city" and his insistence on "walking" as "the first and fundamental step in order to get body contact with places, to merge the sensitive approach to the city with the more thoughtful one.",93

Meanwhile, recent scholarship has turned to the flâneur as a useful metaphor for careful observation in a post-modern setting, especially in alternate, non-literature-based disciplines. Raymond Lucas uses the flâneur as a way to conceptualize contemporary architectural theories, particularly honing in on the creative aspects of drawing and notation as representational tools.

\footnotetext{
${ }^{90}$ Nuvolati, "The Flâneur: A Way of Walking," 21.

${ }^{91}$ Ibid., 22.

${ }^{92}$ Ibid.

${ }^{93}$ Ibid., 29, 23.
} 
Citing Francesco Careri, he traces a genealogy "from the Dada anti-art movement, through

Surrealism, the Situationists and Fluxus movements to the work of Robert Smithson and Richard Long." 94 Flânerie thus becomes established as an artistic tool, a method among others for eliciting beauty from the surroundings. He suggests that a contemporary flânerie exists as a sort of mutual gaze: "the urban walk perpetuates its memory in the walkers and those traces left behind, be they representations, reconfigured maps, or the memories of participants who may or may not have been passers-by. . . After all the flâneur walks to be observed, as well as to observe others." "95 Miranda Gill considers the flâneur in her/her status as "urban spectator," part of the observing crowd that made up a culture of "omnipresent exhibition associated with the notion of the Parisian menagerie" in her study of $19^{\text {th }}$ century eccentricities in Paris, ${ }^{96}$ and draws associations with elements of animality, danger, and the underworld, a "Paris inconnu."97 Christian Hermansen Cordua reads Baudelaire's flâneur in particular as an indicator of beginnings of the modern city, essential in developing an understanding of the city that is dominated by "an aesthetic understanding" of one's surroundings". 98 And Kerry Mallan finds a "neo-flâneur" in children's literature, suggesting that "the changes wrought by postmodernity and globalization, particularly tourism and consumption" are responsible for a disruption of the experience of flânerie and a tendency towards becoming "comic tourist-flâneurs" instead. 99 These examples are only a few selections from the wide variety of recent flâneur-related articles;

\footnotetext{
${ }^{94}$ Lucas, "Inscribing the city," 4.

${ }^{95}$ Ibid., 5.

${ }^{96}$ Miranda Gill, Eccentricity and the Cultural Imagination in Nineteenth-Century Paris (New York: Oxford University Press, 2009), 137.

${ }^{97}$ Ibid, 176.

${ }^{98}$ Christian Hermansen Cordua, ed., Manifestoes and transformations in the early modernist city (Burlington: Ashgate Publishing, Ltd., 2010), 86.; Cordua also gives the examples of Flaubert: "Flaubert's flâneur, Frédéric in Sentimental Education, is dissociated from society, estranged, and his wanderings seem aimless of both destination and purpose" (87); and Balzac: "Balzac's flâneur is more than an aesthete, a wandering observer, he is also purposive, seeking to unravel the mysteries of social relations and of the city, seeking to penetrate the fetish"' (Harvey qtd. in Cordua 89).

${ }^{99}$ Kerry Mallan, "Strolling Through the (Post)modern City: Modes of Being a Flâneur in Picture Books," The Lion and the Unicorn 36 no. 1 (2012): 56, 72.
} 
though parameters have changed somewhat, the image of a pensive, solitary walking figure clearly still captures the imagination and thoughts of current generations of scholars. Considering flânerie, as Nuvolati does, as "based on four main human activities: walking, observing, thinking and creating" allows us to create a relatively stable definition from which to expand our understanding of this figure constantly in motion. ${ }^{100}$ Without conforming to a preset typology, each of the protagonists discussed below embodies several aspects of the flâneur as conceptualized by Benjamin and Baudelaire and can be productively considered a descendant of sorts of the $19^{\text {th }}$ century dandy, pensive and constantly compelled to move.

\section{Movements and paths}

Even given the academic setting and goal of this proposed study, it remains difficult to analyze representations of trauma from such an outsider perspective. I do not intend any disrespect to the extreme traumas of the Holocaust, the bombing of Nagasaki, the French war in Indochina, etc. by choosing to focus on only a select few historical events. Nor am I, like Hirsch, currently interested in the "vicarious trauma" that may result from a viewing of films that contain within them representations of trauma; while a valuable query, this psychoanalytical approach is not part of the current study. Instead, like Kaplan, I intend to investigate "the increasing importance of 'translating' trauma - that is, of finding ways to make meaning out of, and to communicate, catastrophes that happen to others as well as to oneself." ${ }^{101}$ Like her, I suggest that "art, perhaps paradoxically, is one such way." ${ }^{102}$ In each of the films that follow we see the development of a posttraumatic flâneur, an individual who lives amidst the lingering aftereffects of a distant but ever-present traumatic historical event. While these traumas do not explicitly

\footnotetext{
${ }^{100}$ Nuvolati, "The Flâneur, A Way of Walking," 23.

${ }^{101}$ Kaplan, Trauma Culture, 19.

102 Ibid.
} 
drive the characters' movements, I argue that flânerie can be productively analyzed as a potentially cathartic response to their otherwise inexplicable malaise. Although each protagonist also experiences a more proximate trauma, these too are linked to the past event: Elle's sorrow over her former lover is linked to the fact that he was a member of the German army who was occupying France; Mona's rejection by society is related to how she is perceived as a stand-in for the North African immigrant population and the environment of distrust stemming from the Algerian War; the Speaker's dejection over a lack of communication stems from the fear and panic of terrorism that surrounds him. Each chapter will demonstrate the connections between a posttraumatic state and the impulse to translate this trauma into movement.

In Chapter One, therefore, I begin with a study of Alain Resnais' Hiroshima mon amour (1959), a film produced in 1957, released in 1959, and closely based on a script by Marguerite Duras. Hiroshima mon amour portrays the experience of a middle-aged French actress (Elle) who meets a Japanese man in Hiroshima and, through his conversation and physical presence, contemplates her past relationship with a German soldier in France during the Occupation. Elle finds modernity - as represented by the city - to be comforting; she uses the streets of Hiroshima as a means of escape, looking for refuge in street signs, in tourist shops, in cafés. Like Poe's mysterious stranger, Elle rushes through the streets, looking for something unknown perhaps even to her, retracing her steps, entirely purposeless. She is followed by Lui, who has glimpsed her - we do not exactly know how - and become fascinated by her, wanting to know who she is and why she moves so restlessly through the crowds. The parallels with Poe's story are not exact, of course, but the echoes are there. Through a discussion of the uncanny elements of the film and the parallels that exist between film, museum, and memory, the chapter investigates nonlocatable movement, the kind of movement that is purposefully unmapped. Indeed, the chapter 
argues that having a lack of direction in both time and space may be a particular key to appreciating and understanding Elle's experience and, by extension, the film itself. Elle's ability to accept the past and move beyond her traumatic memories relies on an acceptance of the uncanny, a recognition and welcoming of the familiar aspects of her new lover that are nonetheless so very strange. The movements discussed in this chapter are also uncanny, unexpected but not unwelcome; Elle's dilemma is that she must both walk away and yet constantly return to the same memories, time, and even place of her pain.

Chapter Two focuses on a protagonist, Mona, who also spends a large portion of the film in motion, on the march across the frigid landscape of the French countryside in Agnès Varda's Sans toit ni loi (1985). Movement in this film tends to go in strange directions, with Mona walking from right to left across the screen, the camera never quite in sync, and the viewer's gaze repeatedly distracted away from Mona and towards her topsy-turvy surroundings. The film was made in 1985, and is partially based on Varda's experiences meeting with the homeless population in the areas she filmed. Mona is an object of fascination, both for the people she meets and for scholars. However, equally important is what she observes around her, particularly the problems with homelessness and poverty that stem in part from France's immigration policies and the aftermath of the Algerian War. Mona represents a reimagining of Benjamin's dialectic of flânerie, in which she becomes both suspect and yet utterly undiscoverable. The chapter suggests that turning the gaze (of the viewer, but also of the other characters in the film) away from Mona exposes France's ongoing political and social issues by forcing them, and us, to look in another direction and to recognize the inadequacies of the national response to the Algerian war and the immigration policies that followed. 
All three protagonists discussed in these chapters find comfort in anonymity. Elle and Mona both prefer to keep their identities - by which I mean not their names, necessarily, but their inner selves, their desires and fears and pasts - as secret as possible. Both slowly, though not completely, lose their anonymity over the course of their journeys. The identity of the Speaker of Chris Marker's Chats perchés (2004), however, is never revealed, and the third chapter will demonstrate how anonymity becomes an essential aspect of group movements. In part a response to the terrorist attacks of September $11^{\text {th }} 2001$, the 2004 film is largely concerned with political and social collectivities and mass movements, as well as the self-reflexivity of filmmaking. The chapter follows the unseen protagonist of the film, a camera-eye with a witty repartee who tracks protest movements in Paris in the early 2000s. A fantastic example of Marker's unique filmmaking style, Chats perchés offers an in-the-streets look at how group movements do or do not function, constantly reinforcing the constructedness of both image and message. The chapter explores the film's emphasis on collective and artistic movements as essential elements of contemporary political discourse, suggesting that Marker's alter egos (a camera and a cat) are effective foragers of hope and peace in an otherwise tumultuous Paris.

Thus this study offers an analysis of selected works portraying the different kinds of movement that develop, in these films, as eventual responses to trauma. These protagonists have experienced personal, close-range traumas, but each also inhabits a world in which larger, national traumas continue to cast their shadow. Each chapter will explore the paths, vistas, and landscapes of these walkers, with particular focus on how each manifests the echoes of past trauma in their bodies and minds. As a group, these three protagonists sketch out the beginnings of an outline for a posttraumatic flâneur, a figure who effectively communicates a collective desire to respond to trauma through movement. Their movements are non-exact; there is a 
purpose but perhaps not a specific destination nor a fixed path. They are compelled to move; with trauma at their backs, walking ahead seems a likely and even potentially cathartic response. 


\section{Chapter One}

\section{Tracing Hiroshima mon amour's uncanny paths}

The unnamed female protagonist of Alain Resnais' 1959 film Hiroshima mon amour is unpredictable and inaccessible, a woman wandering through the twisted paths of her memory as she moves through the streets and buildings of Hiroshima, Japan. In part, this is because the woman (known as "Elle") has experienced a highly personal trauma which she has fought, body and mind, to hold on to, and yet loses. Fourteen years later, she revisits the moment due to the interference of an unknown man ("Lui") who forces her to access not just the memory of the trauma, but the physical pain of the experience. By recreating the emotional circumstances of the original trauma the woman experiences again the immediate, visceral reaction of her initial loss, and reacts accordingly. Though she has long since moved past the trauma - the death of a previous lover - she still struggles with her newly potent emotions, for her descent back into the past evokes not just the trauma of the death but also that of having forgotten what was once so vital. Moved by this painful struggle between remembering and forgetting she becomes a doubled figure, present at once in two cities and two times, fully comfortable in neither.

Yet Resnais' project in the film extends beyond the long-ago love story of a woman in France, for Hiroshima mon amour also deals with a significantly more imposing event, the dropping of an atomic bomb on Hiroshima on August 6, 1945. Hiroshima is the woman's trauma writ large, the reification of her personal loss in a historical event undeniably monumental. Setting Elle's story against the backdrop of a newly revitalized Hiroshima, Resnais interrogates the definitions of memory, history, and commemoration, and the often strange formulation of the stories that get told about the past. Working closely with Marguerite Duras, who wrote the 
screenplay, ${ }^{1}$ Resnais suggests that a better understanding of the past may be reached by allowing emotion to play a role, by acknowledging the pain of the past and the odd, even unnatural ways the past manifests itself in the present. As Elle journeys simultaneously through Hiroshima and her memories she is accompanied by a sense of familiarity, as if she has seen and experienced it all before, but also a sense of strangeness, as if she is haunted by the ghosts of the past - both hers and those of the bombed-out city. This doubled experience also plays out in the concurrent, often paradoxical sensations she experiences as fascination mixes with fear, life with death, desire with guilt, past with present. This chapter will center on the uncanny elements present in the film, and in particular those of bodies, movement, and words, as unexpected but necessary elements of the process of commemoration. ${ }^{2}$ It will then turn to a discussion of Resnais' development of memory as a collection, similar in its construction to museums and even the film itself. In order to be effective each of these processes must incorporate elements of the uncanny, elements that are reflected in Elle's own experience and the viewer's experience of the film. For Elle's path through the past and through Hiroshima is a eerie one: she is a lone voyager who is nonetheless never alone, a flâneur haunted by the living and the dead. She must accept the presence of the past in order to move on.

\footnotetext{
${ }^{1}$ Duras notes in her introduction to the screenplay that there were "conversations presque quotidiennes" between herself and Resnais, occasionally with the input of the conseiller littéraire Gérard Jarlot. Marguerite Duras, Hiroshima mon amour: scénario et dialogue (Paris : Gallimard, 1960), 19.

2 "Uncanny" has accumulated a host of (often psychoanalytic) undertones when used in literature/film analysis. Freud writes: "There are thus two courses open to us: either we can investigate the semantic content that has accrued to the German word unheimlich as the language has developed, or we can assemble whatever it is about persons and things, sense impressions, experiences and situations, that evokes in us a sense of the uncanny, and then go on to infer its hidden nature from what all these have in common. I can say in advance that both these courses lead to the same conclusion - that the uncanny is that species of the frightening that goes back to what was once well known and had long been familiar." Sigmund Freud, The Uncanny, trans. David McClintock (New York: Penguin Books, 2003), 124. This interplay between the familiar and the unfamiliar is the focus of this chapter.
} 


\section{Ghostly figures, haunted words}

Hiroshima mon amour traces the path of a French actress, played by Emmanuelle Riva, as she explores and delineates the city of Hiroshima and the body of her lover, a Japanese architect and politician with whom she spends two nights and one day. The plot of the film, in terms of the action that actually takes place during its diegetic time, is simple: awakening together in the woman's hotel room, the two lovers exchange information about themselves, shower, and get dressed, displaying a sense of ease and the new delights characteristic of a brief affair. The woman, Elle, leaves her hotel room to complete a final day on the set of a film, telling the man, Lui (played by Eiji Okada), that she will not see him again. Later, however, he finds her on set and they spend an afternoon at his home and the evening in a café. Although Elle repeatedly tries to evade him Lui follows her, forcing their continued interaction and, more importantly, the ongoing revelation of Elle's past history. For intermingled with the physical movements of the characters are two supplemental histories: that of Elle's love affair with a German officer during the occupation of France in World War II, and that of the bombing of Hiroshima at the end of the same war. Elle, as a teenager in the French town of Nevers, falls in love with an occupying German soldier and, when he dies, goes through a long period of shame and insanity during which her head is shaved, her family shuts her in a cellar, and she loses contact with the outside world. In a series of conversations with Lui, the details of this difficult past gradually resurface in bits and pieces, flashbacks coaxed forth by the careful questioning of Lui and the parallels that Elle herself constructs between this prior, forbidden love and her equally impossible affair with this Japanese stranger. Meanwhile, Resnais - via Elle's attempt, as a tourist, to see and understand Hiroshima - deconstructs the bombing of Hiroshima as seen by the distant observers whose only contact with the event is through images and memory. Together 
these alternate stories offer a dual meditation on the process of remembering, and telling, a fearful past and how this process of telling becomes necessarily corrupted by emotion, particularly fear, pain, and sadness. Though these emotions alter the perception of the past, they are also essential; only by acknowledging their presence can some measure of comprehension be obtained.

In terms of filmic time, the events that take place in Hiroshima - the story of Elle and Lui - occur in the film's present (1959) while the story of Elle and the German takes place entirely in the past (1944-45). The conversation about Hiroshima that opens the film, however, exists in an indeterminate time, neither past nor present but rather somewhere in between, one of many elements of time that Resnais manipulates over the course of the film. Intricate investigations of time, memory, and desire are part of what make Hiroshima mon amour popular with film scholars as well as the general public. Lynn Higgins's essay "Myths of Textual Autonomy” in her 1996 study of on the New Wave privileges the formal aspects of the film, suggesting that Hiroshima's "major point of access, which is also its dimension of greatest difficulty" lies in its construction. ${ }^{3}$ Her essay investigates the historiographical, psychoanalytic, and cinematic underpinnings of the film as an intricately, and intentionally, complex investigation into the past and our understanding of it. She writes: 'If the film does systematically try to 'blur the trail,' it does so not out of perverse pleasure but with the serious intent to contest every discourse that it proposes, particularly those by which an understanding of the past is constructed."4 This intentional blurring occurs primarily through the manipulation of tools of narration commonly accepted as routine, including continuities of time and place and stable narrative threads. In particular, Higgins suggests that "chronical linearity is . . . translated into concentric spatial

\footnotetext{
${ }^{3}$ Lynn A. Higgins, New Novel, New Wave, New Politics: Fiction and Representation of History in Postwar France (Lincoln: University of Nebraska Press, 1996), 21.

${ }^{4}$ Ibid.
} 
configurations, so that the present frames, gives birth to, and coexists with the past, yielding a complex mixture of sensation and memory." ${ }^{5}$ This mélange of past and present becomes a narrative tension that remains unresolved, as "the need to forget the traumatic events of Nevers is contested by the necessity of remembering the destruction of Hiroshima. The desire to unburden oneself of the story is frustrated by the impossibility of conveying its intensity." ${ }^{6}$ To further complicate this tension, Higgins argues that the Nevers storyline encourages forgetting "as the healthiest response to a traumatic past,", while the Hiroshima storyline encourages commemoration: "Hiroshima mon amour is aware of the complex nature of sign systems, of time, and of memory. It knows, for example, that the desire to represent horror through a love story must be counterbalanced by an awareness of the danger of forgetting the horror entirely." Thus the film is driven by the double necessity of holding on to while also letting go of the past. Marie-Claire Ropars-Wuilleumier similarly focuses on the telling of stories and the process of historicization in her 1990 essay "History Begets Meaning." She too considers meaning and narrative within the film to ultimately be frustrated, as the film "simultaneously tells an easily understandable story and interposes between that story and its perception a screen of multiple signs resistant to narrativity." Among these are the film's tendency to privilege - or at least make central - its nontraditional form: "The story itself only comes to the film in dislocated pieces, alternating with the duration of an encounter and doubling up its trajectory."10 The incredible trauma of the atomic bomb as a historical event also informs the creation of the film's narrative; "the horror of Hiroshima is not eclipsed, but it becomes the object of a secret

\footnotetext{
${ }^{5}$ Ibid., 23.

${ }^{6}$ Ibid., 21.

${ }^{7}$ Ibid., 32.

${ }^{8}$ Ibid., 22.

${ }^{9}$ Marie-Claire Ropars-Wuilleumier, "How history begets meaning: Alain Resnais' Hiroshima mon amour (1959)," French Film: Texts and Contexts, ed. Susan Hayward and Ginette Vincendeau (London: Routledge, 1990$), 173$.

${ }^{10}$ Ibid., 180.
} 
reflection upon the terms of both enunciation and expulsion of the historical event." ${ }^{11}$ For Ropars-Wuilleumier, the focus of the film is on the process of representation, and on how the past is reconstructed.

In Emma Wilson's 2006 overview of Resnais' body of work, she considers Hiroshima within the thematic structures of parallel and imbricated narratives, eroticism, and musealization. Wilson refers to the film as a "self-conscious documentary" in which "Resnais offers a collage of images of the city and its survivors ... always framed by a return to the lovers in bed and to the doubting words of their dialogue. Our view of Hiroshima, recalled, is impeded like this, made self-conscious, dubious and interrogative." ${ }^{\prime 2}$ This impeded vision of the city also leaks into the storyline, as "the narrative of Nevers and the narrative of Hiroshima work as two parallel, differently scaled histories which make us focus on ways of remembering, and forgetting, in particular through the flesh and materiality." 13 It is also in Wilson that we see the first extensive discussion of Elle's journey itself, the physical act of walking, which Wilson considers an essential element of Elle's process of discovery: "The film follows [Elle] into the streets of the city to see whether in perambulation she may come to a different relation to trauma and the history of Hiroshima. In walking through the city, in the traces of her footsteps, the French woman arguably seeks this creation and undoing of memory." ${ }^{14}$ Elle is thus ultimately a transitory presence; she "wants to know the city, to have material comprehension of its forms, she wants to hold its stones and shadows in her memory, but she remains a tourist. She is a museum visitor, she is an actress in a film in Hiroshima, she is a guest at the Hotel New

\footnotetext{
${ }^{11}$ Ibid., 182.

${ }^{12}$ Emma Wilson, Alain Resnais (Manchester: Manchester United Press, 2006), 50.

${ }^{13}$ Ibid., 54.

${ }^{14}$ Ibid., 60.
} 
Hiroshima, she passes through the city." ${ }^{15}$ Wilson also intriguingly suggests that, while most critics read Hiroshima as focused on the memories of the French actress, there may also be a consideration of the memory - or imagination - of the Japanese man: "Nevers may indeed be his choice of narrative, as well as the space and time of the woman's involuntary memories. The images of Nevers may be his fantasies."16 The film plays on viewer expectations, relying on sensation and affect to revisit the idea of commemoration.

The work of Higgins, Ropars-Wuilleumier, and Wilson is representative of an extensive scholarship on the film, both as an exemplar of the New Wave film movement and as a cinematic and narrative masterpiece. To date, however, there has been little discussion of how certain elements of the film might be considered as otherworldly or uncanny. The uncanny is a particularly useful concept for this film, which follows the path of a woman discovering familiar features in a foreign city and the body of a stranger. The following sections will consider how Resnais' portrayal of the physical bodies of Elle and her two lovers, the movements of these bodies through the landscapes of Hiroshima and Nevers, and the words spoken by Elle both diegetically and extradiegetically can be considered not just a part of the narrative but also elements of the beyond, the unnatural, or the strange. The unusual or unexpected characteristics of these elements help privilege the strangeness of the film and by extension of the process of commemoration on which it centers. As this chapter will show, the tendency to commemorate traumatic historical events in films, museums, and even - perhaps especially - memory depends on a willingness to accept a certain measure of the unnatural, an ability to accept the odd scaffolds within which these past events are encased. Indeed it is this willingness that allows us to move beyond the otherwise ineffable past and into the future.

\footnotetext{
${ }^{15}$ Ibid.

${ }^{16}$ Ibid., 53.
} 


\section{Bodies past and present}

For fourteen years, Elle resists starting out on the emotional journey that she will finally undertake in Hiroshima. In part this is due to her fear of experiencing again the pain she felt at the time. Her past trauma - the death of her German lover as he waits for her to run away with him - centers on her memory of his dying body; seeing him from a distance, Elle rushes to his side and lies next to him for an entire night, later claiming that she "n'arrivai[t] pas à trouver la moindre différence entre ce corps mort et le [s]ien." ${ }^{17}$ When she remembers the moment, it is his body she sees - his twitching hand, the blood on his face, his staring eyes. These corporeal images infuse the film, forcing the viewer like Elle to continually relive a vision of bodily trauma. Beyond the fragmentation, doubling, and estrangement of bodies Resnais also establishes the character of Lui as an amalgam of two opposing forces, life and non-life. Lui acts as a guide and a stimulus to Elle, prodding her to revisit the past and then helping her back into the present. He also, however, projects an other-worldly presence that corresponds, albeit imperfectly, to the dead German soldier of Elle's past. Lui like Elle is a doubled figure, seen both in his present iteration and as a ghost, alternating between the natural and the strange.

Bodies are first made strange in the oft-analyzed opening of the film, in which nearly unidentifiable torsos cling to each other amidst the fallout of an unknown substance that Duras specifies to be either ashes, or rain, or dew, or sweat. ${ }^{18}$ Filmed in extreme close up, the headless torsos appear more as one entity than as two separate people; genders are unrevealed and only with difficulty can one make out the shoulders, elbows, and fingers that hint at the humanity of the figures (Figure 1.1). Resnais films the bodies from multiple angles, playing off the shadows

\footnotetext{
${ }^{17}$ Marguerite Duras, Hiroshima mon amour: scénario et dialogue (Paris : Gallimard, 1960), 100. All quotes from the film are taken from the screenplay published by Gallimard in 1960, in which Marguerite Duras, the screenwriter who is credited with having co-created the film, "se borne à rendre compte des éléments à partir desquels Resnais a fait son film" (20). Any discrepancies between film and screenplay are noted.

${ }^{18}$ Resnais shows three different substances coating the bodies, contributing to the uncertainty.
} 
in and around the various angles and intersections of the torsos; these humans, if humans they are, exist in almost complete darkness, with absolutely no visual or chronological context to their act. Nor do we know whether the bodies cling to each other in love or in death. In the synopsis that accompanies the screenplay, Duras not only insists that the bodies be segmented, but even denies the existence of any character other than the body itself, noting that "ce couple de fortune, on ne le voit pas au début du film. Ni elle. Ni lui. On voit en leur lieu et place des corps mutilés." ${ }^{19}$ Accompanied by the haunting lover's theme of Giovanni Fusco, the entire sequence is both mesmerizing and unsettling.

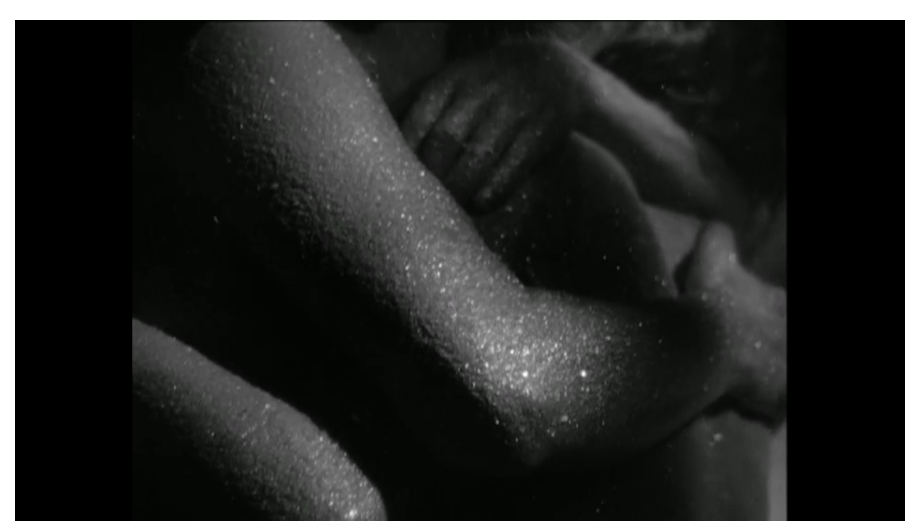

Fig. 1.1

Therefore the first clearly 'present-day' words of the film are quite jarring, as the camera quickly pans up to Elle's face as she remarks to Lui, laughing, “c'est fou ce que tu as une belle peau." ${ }^{20}$ Making light of the skin that has been so hauntingly occupying the frame, Elle (and/or Resnais) completely breaks the spell of the opening images, setting off what will prove to be the most conventional sequence of the film, as the two lovers converse, get dressed, and leave the hotel room together. Elle, telling Lui she does not want to see him again, gets into a taxi and leaves, but later he tracks her down on the set of her film where she lies resting in the shade. Up to this point the film, from the moment of Elle's comment about Lui's skin, remains largely free

\footnotetext{
${ }^{19}$ Duras, Hiroshima mon amour, 9.

${ }^{20}$ Ibid., 36.
} 
of overt interventions by the director, at least in terms of flashbacks, incomprehensible images, or other narrative confusions. ${ }^{21}$ But from this point on, bodies become increasingly strange and disturbing in their portrayal. Human hands are a common image, often situated alone in the frame and sometimes taking on astonishing proportions: as Elle and Lui speak together on the set of the film, they are literally knocked off balance by two production assistants carrying an oversized photograph of a bloody, mutilated hand (Figure 1.2). From here hands regularly appear in both the present-day storyline and Elle's Nevers past and soon prove unavoidable triggers for Elle's memories. ${ }^{22}$ A few examples: Elle and Lui's hands clasped on a café table, with no other parts of the body visible, are juxtaposed with Elle's hands scraping the wall of a cellar, equally disembodied; Lui's hands on Elle's face, urging her to tell her story, are reprised later by Elle's hands on her own face and, even later, by her hands on the face of her German lover. As Elle remembers the cellar, she herself comments on the uselessness of her hands: "Les mains deviennent inutiles dans les caves. Elles grattent. Elles s'écorchent aux murs... à se faire saigner." 23 Immediately afterwards, her hands (in the present) lose their ability to function, and Lui's hands must become hers as he raises her glass to her lips and makes her drink. Alongside these disturbing, disembodied hands Resnais also films legs with torsos cut off by other elements in the frame (as in the museum or the windows of the cellar), missing eyes, and the lost hair of the Hiroshima victims and of Elle herself, whose head is shaved as punishment for her interaction with the occupying German. Seen altogether, the repeated images of partitioned bodies suggest that the disfigurements are universalized, as if the physical losses of the victims are transferred across the collective body of humanity.

\footnotetext{
${ }^{21}$ The notable exception being Elle's momentary flashback on glimpsing Lui's twitching hand in the moments before he wakes up, which will be discussed later in the chapter.

22 "[Jean-Louis] Leutrat notes that one of the main themes of the film, and its visual expression, is '[le thème] de la peau, des mains et les expressions tactiles'." Wilson, Alain Resnais, 48.

${ }^{23}$ Duras, Hiroshima mon amour, 88.
} 


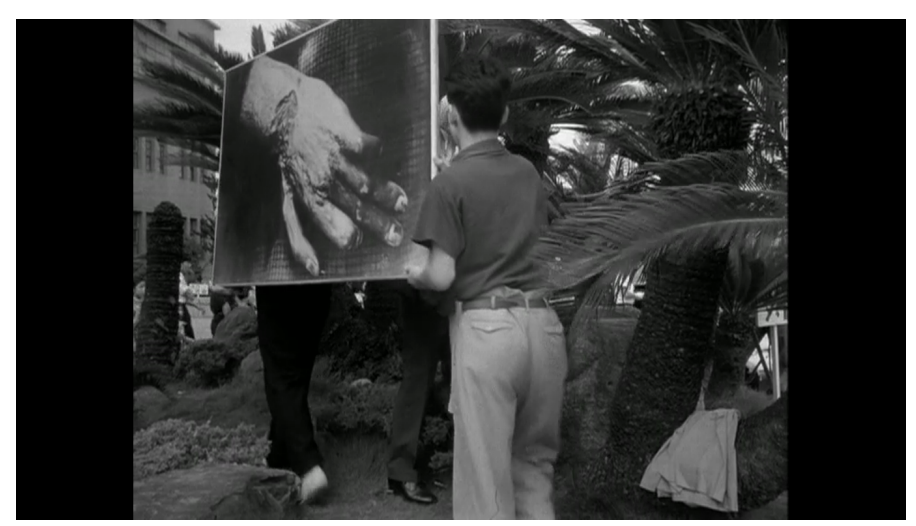

Fig. 1.2

Disfigured bodies take on an entirely more literal sense in the Nevers storyline. Here, where Elle and her soldier lover are almost exclusively filmed at a distance, bodies appear whole but without faces, disturbingly indistinct figures that represent a different kind of mutilation. Like the torsos that open the film, this alternate set of lovers is nebulous and difficult to establish, though instead of bodies filling the frame we see bodies shrunken into minute elements within them. Elle occasionally appears in a middle-distance shot, but constantly in motion and often from the back, her face barely identifiable as that of Riva. The soldier appears from the front, but only in extreme long-distance shots; later he appears closer, but in profile, more than half his face still invisible (Figure 1.3). In fact, the only real close-up of the German soldier appears in Elle's first flashback, ${ }^{24}$ when we see his face covered in blood, eyes open and staring in death, an image which lasts only an instant. In one sequence, we see the Nevers lovers together in a shot which, filmed from the top of their heads, obscures the rest of their bodies; we then see them covered in a blanket with only feet and hands visible. Immediately following this, Elle and Lui reappear, nude, both facing the camera; as Resnais tends to film Elle and Lui from one side or the other, this shot clearly sets them in contrast to the faceless lovers of Nevers (Figures 1.4, 1.5).

\footnotetext{
${ }^{24}$ See Chapter 4 of Hirsch for a thorough survey of the history of the flashback in psychology and film. Joshua Francis Hirsch, Afterimage: Film, Trauma, and the Holocaust (Philadelphia: Temple University Press, 2004).
} 


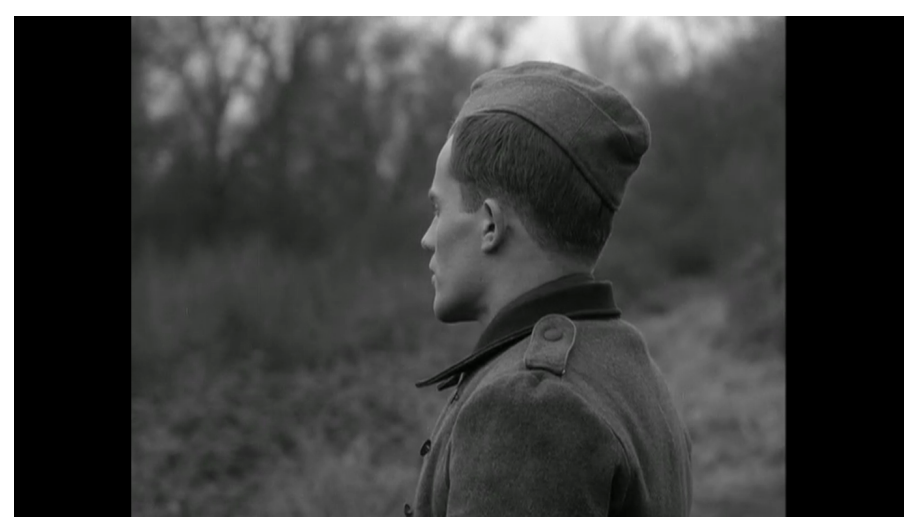

Fig. 1.3

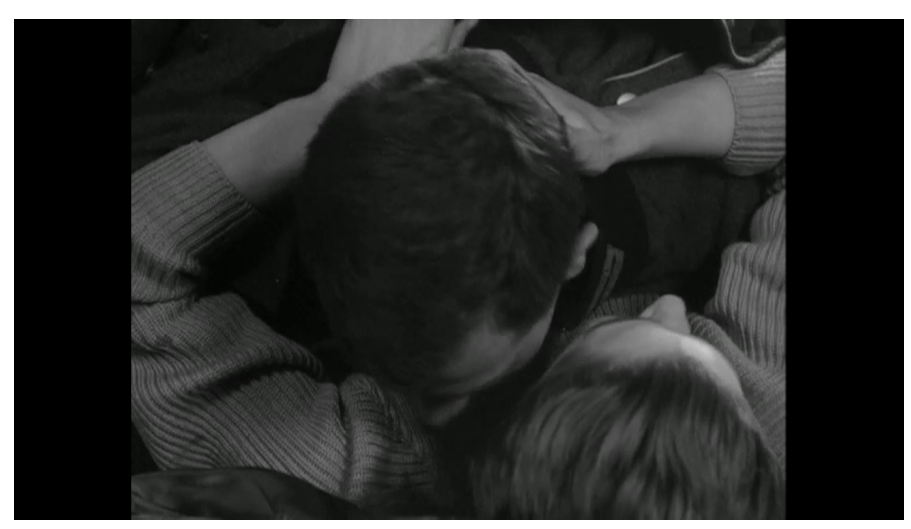

Fig. 1.4

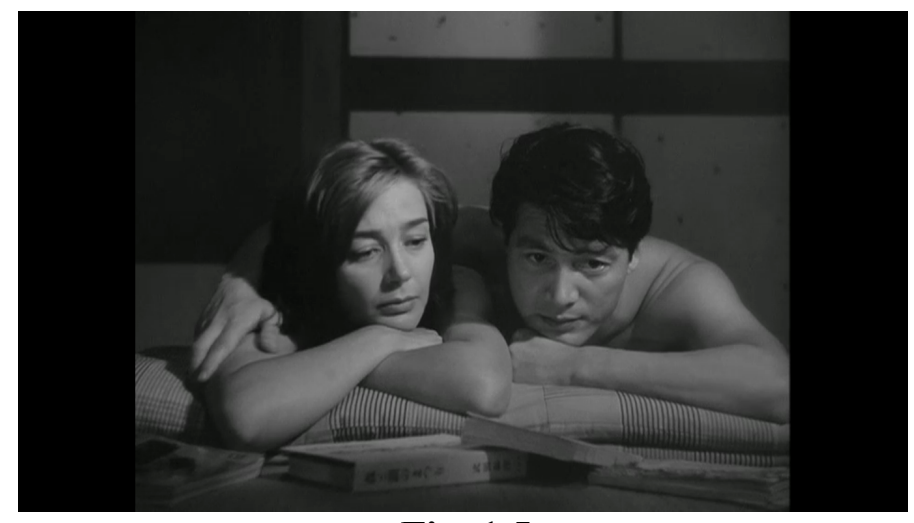

Fig. 1.5 
Resnais also creates a visual association between Elle's first love, the German solider, and her most recent, the Japanese Lui, by reinforcing the otherworldly aspects of the latter. Aside from Elle's love for both men, the connection between the two lovers is heightened by the fact that both were enemies of France during the war; while Elle was falling in love with the German soldier in Nevers, Lui was himself fighting with the Axis forces against France and the Allies. Lui is not so much a double of the German soldier but rather a ghost of him, an ethereal duplicate whose literal presence in Hiroshima is problematized by his strange and occasionally inexplicable movements. Although Elle repeatedly escapes from him, he seems to know exactly where she is at all times, often showing up where and when she thinks of him. Early in the film he tracks her down at the set of the film where, as he comments, "tu étais facile à retrouver,",25 probably a true statement considering she had already told him she was working for the film. Yet she, sleeping under a tree, suddenly wakes up as he arrives, as if his presence piques her in some way (Duras notes in the screenplay that "son regard à lui la réveille.”) ${ }^{26}$ Later, although they separate multiple times, Lui consistently shadows her, reappearing at the café where they have previously parted, then again as she waits under an awning for the rain to stop; he enters "comme une ombre" into the train station where she takes refuge, ${ }^{27}$ then tracks her down in a late-night bar. Each time he appears successively less human; at the café he looms over a sitting Elle, filmed at an extreme angle so that she appears miniscule at his feet (Figure 1.6). Approaching her as she waits under the awning, Lui strides down the street with his face expressionless and his hands at his sides, his dark shadow mirroring him against a non-descript wall (Figure 1.7). Although rain pours down, he remains completely dry. ${ }^{28}$

\footnotetext{
${ }^{25}$ Duras, Hiroshima mon amour, 65.

${ }^{26}$ Ibid., 14.

${ }^{27}$ Ibid., 117.

${ }^{28}$ But he is "trempé de pluie" in the screenplay - thus this reflects Resnais' choice, not a Durasian one.
} 


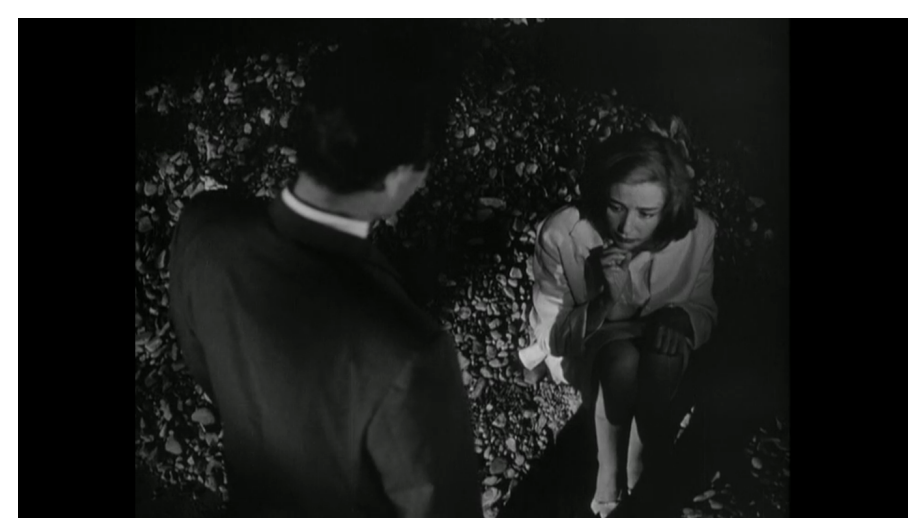

Fig. 1.6

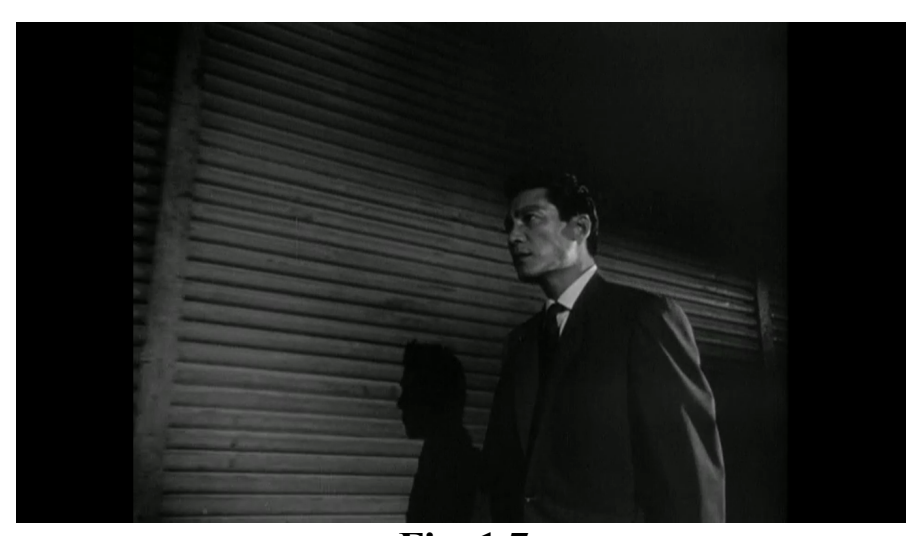

Fig. 1.7

He also knows exactly what to say in order to elicit her story; even Elle questions him as to why and how he knows to ask about Nevers, which, as she notes, is not at all "comme autre chose" for her. ${ }^{29}$ Although she says nothing about the incident, he asks her during her recitation if she spits in the face of her mother during her madness, which Duras specifies in the screenplay is one of Elle's only lasting memories. And immediately after Elle resolves, within herself and via voiceover, to stay in Hiroshima, he appears from nowhere and repeats the sentiment, in almost the exact phrase (Elle: "Je vais rester à Hiroshima. . . Je vais rester là. Là."/ Lui: "Reste à Hiroshima"). Elle herself recognizes the German within him, and as she walks away from him down the street she acknowledges as much, in voiceover: "Je me doutais bien qu'un jour tu me

\footnotetext{
${ }^{29}$ Ibid., 80 .
} 
tomberais dessus./ Je t'attendais ... "30 This is also the moment when Elle turns to an incantatory monologue that calls up the spectre of the past: "Je te rencontre/Je me souviens de toi/ Cette ville était faite à la taille de l'amour/ Tu étais fait à la taille de mon corps même / Qui es-tu ?/ Tu me tues. ${ }^{31}$ Echoing words from the opening of the film, Elle accepts that the "tu" to whom she speaks may be both men at once, or rather that the second may finally replace the first. She fears this ghost of her past who has appeared in her present, but also desires him, and craves the release he offers her.

But what kind of life does Elle find, with Lui? Together in her hotel room, the lovers evoke the places that have become the keys to their story, as Elle names Lui "Hiroshima" and he, in turn, names her as "Nevers." Through the act of naming, Elle tries to encapsulate the city of Hiroshima and more, its past, in the body of Lui. She has in a sense established ownership over his body, and perhaps even his emotions; after all, he is the one following her. However, the identification itself is flawed, for Lui's body cannot contain the traumas of Hiroshima, nor its many stories, except in a vague and imperfect way. He represents the city (politically as well as racially) and, as politician and architect, may play a role in its rebuilding, but he remains a victim at a remove. His knowledge of Hiroshima is such that he can remind Elle that her experience at the museum does not automatically make her all-knowing, but he does not become Hiroshima any more than Elle becomes Nevers once he so names her. The mutual naming does not conclude the process of remembering so much as bring it, as well as the film, to a somewhat unsettled close. By relinquishing the past and giving no indication of the lovers' future, the film leaves the lovers in a tenuous present which gives way to black. The imageless moment before the word "Fin" appears may well represent not a future life, but rather another, mutual, death.

\footnotetext{
${ }^{30}$ Ibid., 115.

${ }^{31}$ Ibid.
} 
Yet beyond the obvious associations with death, the bodies of the film also represent the sustenance through which Elle both accesses the past (ultimately a cathartic experience) and then finds her way back into the present. As she loses herself in her memories, she depends on the constant presence of the body of her lover, whether German or Japanese, to maintain her bearings. She has chosen, consciously or otherwise, to locate her past within the dead body of the soldier, and as the two bodies become conflated, she uses the amalgam as a prism through which to focus her past and present stories. As such these bodies, even in death, also hint at the possibility for life and a future. Therefore Elle, in the early morning hotel room, settles on the bed and puts her mouth in the crux of Lui's elbow, sucking at it, in a gesture that will be mimicked later when she mouths the walls of the cellar, tasting the saltpeter (Figures 1.8, 1.9). She may well be responding to an unconscious urge to suck some kind of sustenance out of his body as she had sucked at the walls and at her own bloody fingers. Making her fingers bleed in the cellar, she tells Lui, was all that she could do to help herself, "pour se rappeler. . . J'aimais le sang depuis que j'avais gouté au tien." 32 Craving a taste of the life pulsing through Lui, she fixates on his living body as a corrective to the dead one she cannot quite seem to shake. After all, the first episode of Elle's journey occurs when the sight of Lui's twitching hand sends her into the momentary flashback in which we see the soldier's dead hand and face, glassy eyes barely glimpsed before the camera cuts back to the Japanese man's body on the bed. ${ }^{33}$ This second body, though initially appearing as lifeless as that of the German, soon moves and stretches, and Elle can take a momentary comfort in life where she previously saw death.

\footnotetext{
32 Ibid., 89.

${ }^{33}$ Wilson notes the psychological underpinnings of this moment: "The film here merges two senses of the term flashback. Flashback is used in film criticism to denote a sequence in a previous time or era; flashbacks are often understood to have an explanatory function in narrative cinema, offering us some key prehistory. In psychoanalytic discourse, by contrast, a flashback is an unwilled returning hallucination or memory which takes possession of the victim of trauma." Wilson, Alain Resnais, 52.
} 


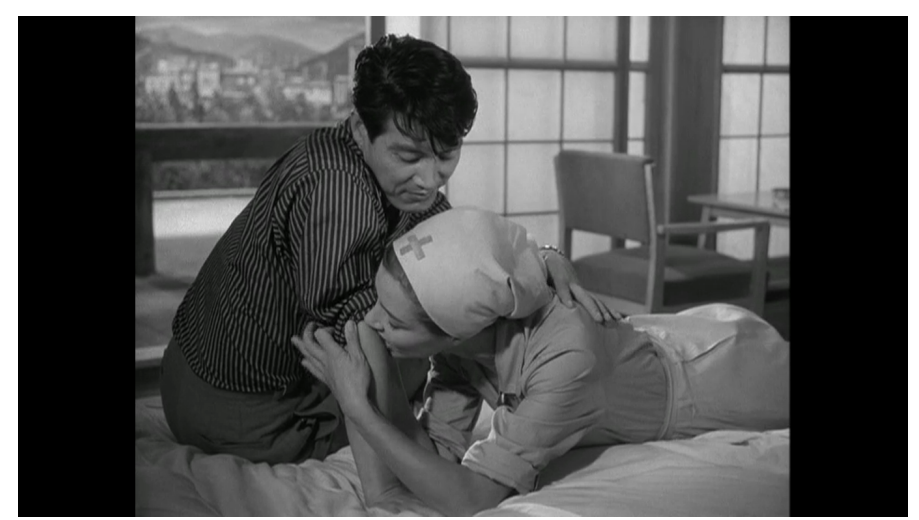

Fig. 1.8

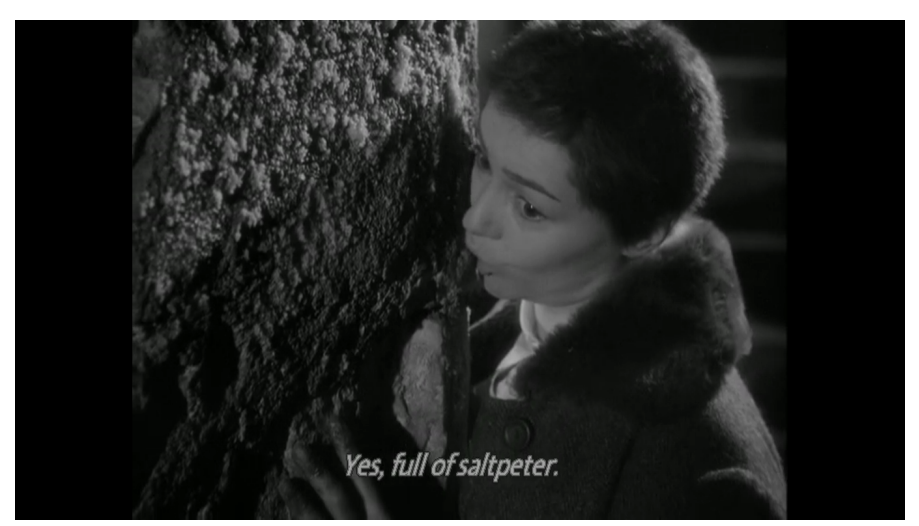

Fig. 1.9

Further, Lui's extraction of Elle's story is very physical in nature, not only when it comes to their sexual interludes but also in less evident ways, centering (unsurprisingly) on his hands. Although his naked body lies alongside hers for the first two mentions of Nevers, in the hotel room and in his home, it is Lui's hands that finally root out Elle's complete story as he places them on her face in the café, essentially helping her "feel" her way to the memory. As he touches her, she describes the Loire river near which she grew up: "En France, la Loire passe pour un fleuve très beau, à cause surtout de la lumière. . . tellement douce, si tu savais." ${ }^{34}$ In describing the douceur of the light on the Loire, she may just as well be describing his mains douces against her face; she momentarily fluctuates between the past and her present, seeing the softness of the

\footnotetext{
${ }^{34}$ Duras, Hiroshima mon amour, 87 (ellipsis original).
} 
light on the river as she feels it against her skin. At this moment Lui begins speaking of himself as the German (“Quand tu es dans la cave, je suis mort?”) as if he has drawn out the essence of the soldier into himself. In turn Elle places her own hands on her face, immediately and momentarily flashing back to the image of her past lover dying on the pavement below her before starting to tell her story. To mark the beginning of Elle's extended recitation of the past, Resnais films her from a low angle, the only non-level shot of the sequence. Later in the sequence, as Elle spirals out of control, Lui slaps her hard across the face, twice. The action, completely out of character for him, shocks not only the other characters in the café but also the viewer; his physical intervention, however, has become his only remaining option for dragging her back into the present. She cannot find her way back without his guidance. For Elle also locates her past trauma in the body of Lui as a means to better understand it, in the same way that she tries to understand Hiroshima by associating it with her own past. Bodies thus also become means to grasp a reality that exists both within and around memory, or tools essential to the process of remembering. Hence the appeal of Elle herself, a body through which we can identify - or in which we can situate - a larger, otherwise incomprehensible trauma.

All of the above - the mangled, ghostly bodies - are strange, unsettling elements that ultimately reflect Resnais' concern with the victims of the event around which the film, after all, circulates: the bombing of Hiroshima. From the early segment in the museum to the final closeups of Elle and Lui's faces, Resnais traces the materiality of the human face and body and the ways in which it may be manipulated and damaged. Hiroshima shocks in part because of the sheer magnitude of the bodily harm inflicted; the trauma itself is highly corporeal, and Resnais' treatment of the physical bodies within his film echoes this awareness. Each survivor, however, also reminds us of those who perished, and Resnais equally uses the motif of bodies to hone in 
on the idea of death. The specter of death permeates the film, not only in the literal deaths of the Hiroshima victims and that of the German soldier but also the multiple metaphorical deaths of Elle. For Elle could be said to die each time she is sent to the cellar, and in fact the people of her town believe she has, her parents doing nothing to discourage them and even sending their daughter away in secret once she emerges (with exile itself a different kind of passing on.) Beyond this she experiences a kind of death upon having her head shaved, and again when she falls into madness, both of which dissociate her from 'normal' life. Finally, in repressing her memories Elle kills off her past, leaving behind the young and foolish Nevers girl in order to start a new (albeit inhibited) life in Paris. The death she does not die at the side of the soldier only resolves itself via the petites morts she finds with her Japanese lover, sexual deaths that finally propel her into life.

These faceless and anonymous bodies also offer troubling visual associations with Resnais' prior film Nuit et brouillard (1955), a documentary on the Holocaust that brings together film and photographs from Nazi concentration camps with footage from the abandoned camps a decade after their relinquishment. In countless disturbing images from the camps we see crowds of victims, blurry and indistinct, often filmed at a distance and in motion. As the film moves further into recounting the horrors mutilated bodies fill the screen, with close-ups on bare feet, shaved heads, tattooed arms, and eyes staring, often in death. As in Hiroshima's museum, these images are all that remains of many of these victims - but Resnais also shows us the piles of hair, shoes, combs, and glasses that were stolen and repurposed, as if to emphasize the different role that objects play in this situation. Nuit et brouillard also marks Resnais' earlier experimentation with camera movement, as the camera recording the 1955 remnants of the concentration camps is constantly in motion. As if driven by pain or sadness not to linger too 
long in any one place, the camera pans and travels and zooms in order both to expose (zooming out to show the electrified barbed wire that blocks the peaceful landscape) and to reinforce (panning to the right along the multiple openings in the crematorium.) In many ways, Nuit et brouillard resembles a Hiroshima that has been stripped of the alternate storylines, an agonizing precursor through which Resnais begins to contemplate - and force the contemplation of unknowable horrors. In fact, if compared with Nuit et brouillard, the alternate storylines of Hiroshima come as an emotional and visual relief, allowing temporary reprieves from shock and creating instead a space of reflection in which to process the images and their meaning while still cultivating an emotional reaction.

\section{Strange movements}

Having established the strangeness of the bodies in Hiroshima, Resnais also questions the way these bodies move, both through the motions of the characters within the film and the motions of the film itself. In part, these elements reflect the cinematic tendencies of the period in which the film was made, the beginnings of New Wave experimentation in French cinema that would continue for another decade. In addition, however, the erratic pathways of Elle establish her as not just a foreigner in Hiroshima but also a woman who must journey through her own consciousness. Her journey is like that of a flâneur, but in addition to walking through the city she moves through memory, the doubled iteration of Hiroshima (1945 and 1959) combining with 1945 Nevers to create a less coherent space in which to travel. When she does move through the city, in 1959, she moves without consciousness of those around her, lost in her own head and indifferent to what surrounds her. Often the camera reflects her mentality by presenting altered angles and speeds, refusing a direct path for Elle as she herself struggles to remain on course. 
Elle's path is primarily a personal one; she is less concerned with mapping the steps than with following the vagaries of her desire.

Where in Nuit et brouillard the movement of the camera primarily works to disturb the viewer, in Hiroshima the physical movements of the camera as well as that of both sets of lovers establish a consciousness of the surrounding space by offering contrasting rhythms of movement in the two primary locations. In Nevers the landscape appears almost exclusively in panning and/or tracking shots, often at an accelerated pace that emulates Elle's bicycle travel. Young Elle herself is constantly in motion, running or biking or climbing, repeatedly jumping over physical barriers which themselves have obvious metaphorical significance as obstacles to her path. The frames, filled with trees and fields and walls, highlight the morass through which Elle and the soldier move at an incredible and inexhaustible pace, punctuated only by their moments of lovemaking (which themselves appear in a relatively quick montage, with hardly the space to take a breath in between one and the next.) Even one notably still shot, in which Elle and her soldier embrace against an enormous, ruined wall, is nonetheless full of energy as the wind visibly blows across their hair and clothes (Figure 1.10). In contrast, the Hiroshima lovers move at a much slower pace, an ebb and flow of motion across a cityscape that contrasts sharply with the fields and grottos of Nevers. Rarely moving faster than a stroll, Elle and Lui are most often lying down or sitting and essentially immobilized in the frame. The only images of Hiroshima that appear at an increased pace occur during Elle's opening monologue, as she invokes a city "faite à la taille de l'amour" and the camera speedily traverses the streets. ${ }^{35}$ Of course, the subject of Elle's speech in this moment remains elusive; she could just as well be referring to her past love as to her newest. The two locations, Hiroshima and Nevers, thus shape themselves

\footnotetext{
${ }^{35}$ Ibid., 35 .
} 
around the physical movements of Elle and her lover, whose perambulations in essence dictate the form and figure of the cities themselves. ${ }^{36}$

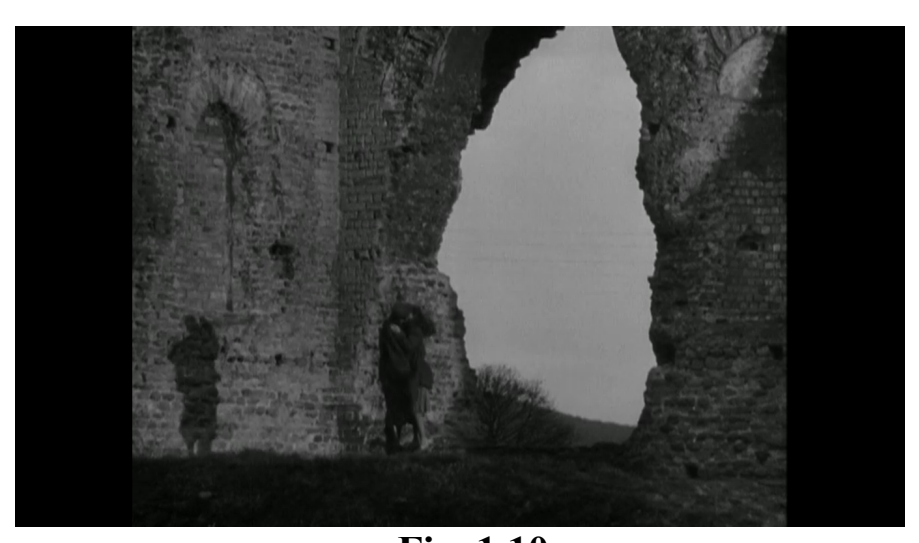

Fig. 1.10

The opening section of the film, the discursive dialogue between the two then-

anonymous lovers, also relies in part on camera movement to explore and define the space of the city. Resnais' own footage, shot within the museum, tends to focus on the quietly evocative images, the camera slowly circling around a model of the bomb, or the twisted metal of bicycles, as if the viewer were physically attracted to these proofs of destruction. The camera zooms in on particularly poignant elements of the museum display, such as a photograph of a man with a burned back, followed by an extreme close-up of the scar on another man's head whose map-like appearance will later be echoed by a scraggly plant and then the map of Hiroshima, its river branches stretching out across the screen. Objects dominate the footage, but visitors to the museum are also seen, likewise pacing through the exhibits, often with their faces obscured. Later, when Resnais films images of present-day Hiroshima outside of the museum walls, he uses similar pacing, allowing his camera to slowly observe the city and a variety of anonymous faces filmed in medium or long shots. Scenes of agonized recovery (doctors tending gaping wounds) melt into those of remembrance and life as contemporary Hiroshima dwellers visit

\footnotetext{
36 "As well as functioning as one of the most resonant films about traumatic experience. . Hiroshima mon amour is also, as the critics have begun to acknowledge, an extraordinary urban film." Wilson, Alain Resnais, 58.
} 
memorials and the river tides rise and fall, forcing a new contemplation of the concept of the 'everyday.' Resnais' visual pairing of film and museum - both institutional means of gathering up the past - highlights the affective nature of both, but also the limitations: if visiting the museum (and other memorials) has become an everyday experience, how much are visitors really understanding the trauma exposed within the display?

So too do Elle's wanderings throughout the city break down the map of the city (briefly glimpsed in the opening sequence) into a series of images condensed and organized by her equally meandering thoughts. Most of her exploration of the city occurs off-screen, including the visits to the museum and hospital of which she speaks in the opening monologue and her travels to and from the film set where she works. However, one extended sequence does show Elle in the streets of Hiroshima, walking numbly along deserted storefronts late at night, having left Lui behind but still contemplating him and/or her German lover. She has already descended into the past and returned, already been confronted with her memories and fears, but she has not yet quite decided whether to stay in Hiroshima or return home, whether to accept the finality of the past or to return to it yet again. She muses on the city, repeating her amazement at its shape and size having been fit to her body and her needs. The streets, oddly empty considering Hiroshima's reputation as a city “où toujours il y a des gens qui sont réveillés, la nuit, la jour" (at least according to Lui) mean little to her; ${ }^{37}$ she barely notes the two men who walk past her, strumming their guitars, nor the flashing fluorescent lights of the displays. Her voiceover, eerily present in the darkness, hovers over the scene as Resnais films her at increasingly severe angles (Figures 1.11, 1.12), emphasizing her tenuous grasp on her surroundings. Speaking to her lost lover, Elle wanders not just the streets of contemporary Hiroshima but also the streets of 1945 Nevers, glimpsed in several intercut images that alternate with Elle's present-day path. Elle's

\footnotetext{
${ }^{37}$ Duras, Hiroshima mon amour, 106.
} 
journey wavers between these two cities, both so important to her own personal narrative; she walks not just the streets, but also her memories, one final time. ${ }^{38}$

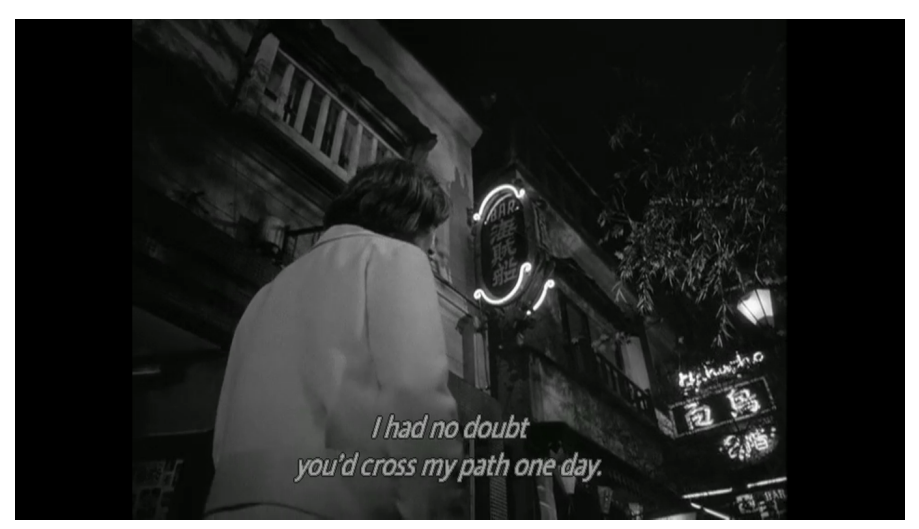

Fig. 1.11

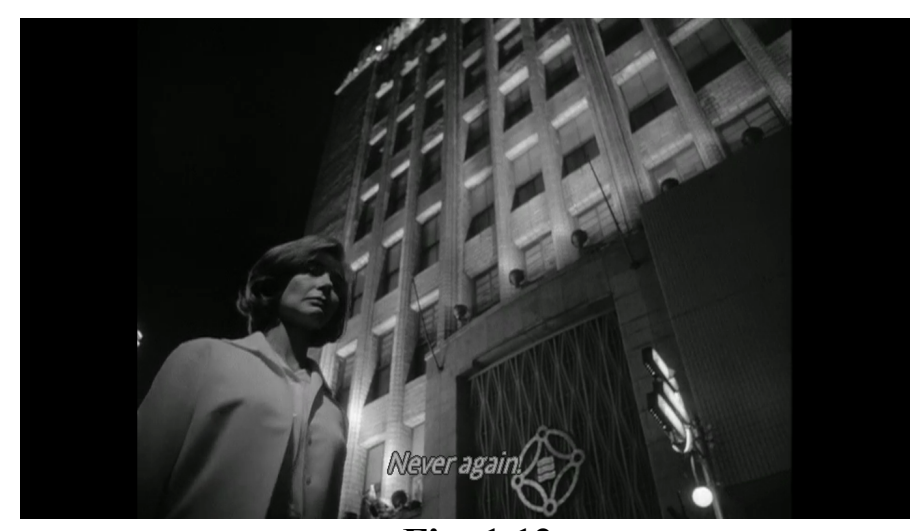

Fig. 1.12

Elle's perambulations towards the end of the film act as a bookend to the exploration of the city that occurs in the opening sequence of the film, in which Elle's voiceover accompanies the camera as it moves through the hospital, museum, and streets of Hiroshima. Although Elle's words in both sequences are similar, the earlier sequence fails to show Elle, instead representing her only through her point-of-view, if at all. As Elle speaks of her impressions of the hospital and museum the camera floats slowly down the aisles and corridors; other people in the frame notice

\footnotetext{
${ }^{38}$ Elle's journey through nighttime Hiroshima, especially when accompanied by Lui, also brings up intriguing connections to other "all-nighter" films (Eric Rohmer's 1969 Ma Nuit Chez Maud, Richard Linklater's 1995 Before Sunrise) that use night-long, conversation-heavy meanderings to probe similarly weighty issues of identity, place, love, etc. My thanks to John Lyons for suggesting this connection.
} 
a presence, but turn away or ignore it. In this earlier sequence she visits Hiroshima but remains absent, replaced by a roving camera eye that approximates her movements but has no connection to her physical body. As her meditation becomes less and less connected to the objects surrounding her, the camera picks up speed, eventually tearing down the streets at a non-human pace. These streets, the same ones that will appear in Elle's late-night walk, are a part of Hiroshima but also disappear beneath the weight of Elle's meditations, non-essential to her understanding and only a backdrop to her real, emotional journey. Elle's flâneur experience, in the sequences that open and close the film, is that of a lost walker, whose steps are directed not by the ebb and flow of the city but by the impulses of her thoughts and the emotions contained within them. ${ }^{39}$

\section{Irrational intimacy}

Elle's haunted movements are accompanied by a series of monologues that reflect and express her tortured thoughts. Elle's words contribute to a sense of the uncanny, for her voiceover in the opening section of the film immediately indicates that her presence may be slightly unnatural or non-worldly, not entirely at home in this world. In the midst of the opening dialogue between her and Lui, which if not entirely everyday conversation at least follows some conventions of a question-and-answer exchange, Elle suddenly begins to speak in rhythm, setting off a monologue in which repetition and rhyme create an incantatory interlude that serves to further distance the monologue and its speaker from any identifiable place and time. In fact, the rhythmic nature of Elle's monologue begins at the same time she switches from speaking in the

\footnotetext{
${ }^{39}$ Wilson on the connection Pierre-Louis Spadone makes between Michel de Certeau and Resnais: "For Certeau, the walker has a knowledge of the city that is as blind as in an erotic encounter. The words are resonant for Resnais: his night walker through the city is a woman, her adoption of the role of flâneur (stroller) is transgressive, her encounter with the city glancingly erotic as she recalls the image of the streetwalker. Yet more insistently her encounter is, like that of Certeau's walker, bodily, sensory, blindly corporeal." Wilson, Alain Resnais, 61.
} 
past tense into the present: “J'ai eu chaud place de la Paix. Dix mille degrés, sur la place de la Paix. Je le sais. La température du soleil sur la place de la Paix. Comment l'ignorer?"40 Later, describing the breakdown of cities following the atomic fallout, Elle gradually falls deeper and deeper into the chant, an invocation of the past, told in the present:

La pluie fait peur./ Des pluies de cendres sur les eaux du Pacifique./ Les eaux du Pacifique tuent./Des pêcheurs du Pacifique sont morts./La nourriture fait peur./On jette la nourriture d'une ville entière./On enterre la nourriture de villes entières/Une ville entière se met en colère./Des villes entières se mettent en colère. ${ }^{41}$

Starting with the repetition of words such as "Paix", "pluie", and "Pacifique" and the introduction of simple rhymes (paix/degré/sais/soleil/ignorer, or entière/enterre/colère), the rhythm of the chant gathers momentum, until Elle's recitation is broken off by images of crowds gathering in protest. When she begins again, it is to speak alternately of "l'oubli" and "la memoire" and then to reaffirm the inevitable repetition of the event itself, moving into the future: "ça recommencera." The changing tenses and references to both remembering and forgetting intimate that the topics touched upon are intended to reach from the present both forward and backward, unanchored in any given present but rather due to be remembered (or forgotten) in all times, past and future. Later, when Elle returns to the hotel, exhausted and unstable following her extended recollection of Nevers, she speaks one final time in rhythm, this time speaking both to herself and to her dead lover: "Elle a eu à Nevers un amour de jeunesse allemand./Nous irons en Bavière, mon amour, et nous nous marierons." ${ }^{42}$ The beautifully delivered anapestic first line stuns, no less because Elle speaks of herself in the third person for the first (and only) time, while the second, spoken to the German soldier, rhymes just enough (allemand/marierons) to close off the couplet. Spoken in the future tense, the second line allows Elle to briefly relocate herself in

\footnotetext{
${ }^{40}$ Duras, Hiroshima mon amour, 25.

${ }^{41}$ Ibid., 30-31. These sentences, not coincidentally, are each given their own line in Duras' scenario. I have indicated where these line breaks occur with slashes throughout the chapter.

${ }^{42}$ Ibid., 110.
} 
1945, before the death of her lover. As she has already acknowledged, however, that childhood love was in a place, and a time, long past.

The imbrication of desire and fear also appears in the final section of Elle's opening monologue, which brings together Hiroshima, her past and present lovers, and pleasure and pain. Having just prophesied another Hiroshima, she begins to speak to an unidentified "tu," someone she has just met and yet remembers ("Je te rencontre/Je me souviens de toi"). ${ }^{43}$ Already, Elle associates her new lover with her past affair, although in this early part of the film the parallels have not yet been made explicit. She falls into her slow chant, reciting an ode to pleasure and pain (quoted here in its entirety):

Tu me tues./Tu me fais du bien./ Comment me serais-je doutée que cette ville était faite à la taille de l'amour ? / Comment me serais-je doutée que tu étais fait à la taille de mon corps même ?/ Tu me plais. Quel événement. Tu me plais./ Quelle lenteur tout à coup. / Quelle douceur. / Tu ne peux pas savoir. / Tu me tues./ Tu me fais du bien. / Tu me tues. / Tu me fais du bien. / J'ai le temps. / Je t'en prie. / Dévore-moi. / Déforme-moi jusqu'à la laideur. / Pourquoi pas toi ? / Pourquoi pas toi dans cette ville et dans cette nuit pareille aux autres au point de s'y méprendre ?/ Je t'en prie .... ${ }^{44}$

Elle draws parallels between the city and love, between "tu" and her body, all of the same size and all encompassing the same sudden event - a coup-de-foudre, perhaps, or an atomic detonation. She wonders at her lack of comprehension, accepting and marveling at the sweetness, the pleasure to be found in love. Yet her acceptance of this pleasure is expressed in terms of death, an event, shocking, delivered "tout à coup." Elle cannot separate these contradictory elements; for her, love and death are the same, and always have been - her first love was also her first death. She therefore wants, even needs, to experience pain alongside her pleasure, pleading with her lover -the Japanese man, but also her lost German soldier - to devour and deform her, so that she too can be consumed in the event, passing through the pain into a sweetness, a

\footnotetext{
${ }^{43}$ Ibid., 35 .

${ }^{44}$ Ibid. Although Duras' scenario says explicitly here that "le ton récitatif cesse," the voiceover in the film maintains the recitation quality of earlier sections of the monologue.
} 
slowness much like death. Her plea, like her chant, exists in all times and places; not only does she have time ("J'ai le temps") but in fact extricates herself from the Hiroshima streets we see passing at an impossible speed, elevating herself into the strange time of memory. In these moments, Elle is no longer just a flâneur taking in the city at a walking pace, but rather an altered, uncanny one, traversing a city both sped up and slowed down. ${ }^{45}$

Yet with Elle's final plea (“Je t'en prie"), without warning, we suddenly see Elle and Lui in the hotel bed as she casually jokes about the softness of his skin. The incantation has broken. It will take the unspooling of the rest of the film before Elle returns to her chant, once the parallels among lovers and places and events have been made explicit, and the two lovers, having negotiated the streets and memories of Hiroshima, return to each other and to the hotel room in which the film opens. In the last seconds of the film, Elle turns to the Japanese man and declares: "Hi-ro-shi-ma. C'est ton nom.” Reciprocating, Lui responds: “Ton nom à toi, est Nevers. Ne-vers-en-France." ${ }^{46}$ By calling her lover "Hiroshima” Elle tries to claim him, her desire (both the physical desire for him in the present, and the emotional desires of the past) driving her to possess him. Her fascination with the city and its trauma, rooted in her own suffering, finally relocates itself in the body of her Japanese lover, who has also been the means through which she revisits her past, the linchpin of the emotional reconstruction of her history. Her desire for his body becomes inextricable from the desire for understanding, knowledge, experience - of trauma, of Hiroshima past and present, and even of herself. Although she cannot,

\footnotetext{
45 "Her sick wish to find annihilation in love, to find herself deformed, contorted in love, vulnerable, frangible like the victims of the bombing, is bound up with her wish to embrace the city, to find in it a fleshed image of her own fantasies of suffering and oblivion." Wilson, Alain Resnais, 62.

${ }^{46}$ Duras, Hiroshima mon amour, 124.
} 
at the beginning of the film, truly access her memories of Nevers, Lui will in the end guide her on a path of desire, through which she can finally speak her own history. ${ }^{47}$

Speaking to Lui in the first minutes of the film, Elle argues for her own understanding of a traumatic past: “Comme toi, moi aussi, j'ai essayé de lutter de toutes mes forces contre l'oubli. Comme toi, j'ai oublié. Comme toi, j’ai désiré avoir une inconsolable mémoire, une mémoire d'ombres et de pierre." 48 Though still technically speaking in terms of Hiroshima, Elle has already begun to evoke her experience in Nevers, although neither her lover nor we quite know it yet. Her experiences with remembering, and forgetting, are linked to the time she spends in the cellar in Nevers, insane with the loss of her lover and, day by day, despite herself, forgetting. For the young Elle, forgetting equals healing; the longer she waits, the less broken she becomes, the closer she gets to the night when she will leave the cellar and ride to Paris, alone. Yet this process of forgetting is exactly what Elle claims to regret the most, against which she has struggled "de toutes [ses] forces." As if forgetting, and returning to a more normal life, would be compounding the initial tragedy, would end in the "horreur de ne plus comprendre du tout le pourquoi de se souvenir." 49 Instead, young Elle is driven by an unquenchable desire to remember, preferring painful memories to the pain of forgetting. Despite this, she has spent fourteen years without remembering Nevers, which she initially claims is "la chose du monde à laquelle [elle] pense le moins;" ${ }^{50}$ her desire (or ability) to access this past has, until she meets Lui, been cut off. It is Lui - and in particular his body, which reminds her of death but also brings her sustenance - who releases her from her self-imposed prison of forgetfulness; only

\footnotetext{
${ }^{47}$ For more on Orphic elements in the film and the importance of seeing/being seen, see Joëlle Cauville and Josette Déléas, "Fragments orphiques dans Hiroshima mon amour de Marguerite Duras et d'Alain Resnais," Cinémas : revue d'études cinématographiques 9 no. 2-3 (1999): 159-173.

${ }^{48}$ Duras, Hiroshima mon amour, 32.

${ }^{49} \mathrm{Ibid}$.

${ }^{50}$ Ibid., 58.
} 
when she physically experiences his body and his city, only when she travels along the tumultuous paths of her past can she properly face the future.

\section{Exploding place and time}

Uncanny elements of body, movement and speech are thus established as essential elements of the process of remembering and commemorating a painful past. The remainder of this chapter will consider how the film also establishes narrative as a construction, first by destabilizing traditional narrative expectations within the film itself and then by establishing parallels among three different kinds of narrative construction, those of film, museum, and memory. While memory is widely acknowledged to be constructed, imperfect and subject to faults and emotional twists and turns, the discussion is enhanced in Hiroshima because of the other forms of commemoration that are offered up for our consideration. The film's masterful deconstruction of traditional expectations of narrative space and time forces a revisiting of how stories of all sorts - and particularly those about the past - are pieced together in a variety of settings, both personal and institutional.

The first fifteen minutes of the film - a lengthy dialogue in which is couched most of the film's discussion of Hiroshima's traumatic past - immediately establish the destabilized narrative space of the film. ${ }^{51}$ Although the present-day storyline, in which Elle and Lui travel through Hiroshima, will soon bring a sense of normalcy to the film, the first section infuses even the events that follow it with a degree of uncertainty. As the film opens, two unidentified torsos

\footnotetext{
51 "Amongst the various disjunctions that this film activates, the most extraordinary one surely has to do with the unclassifiable nature of the opening sequence or prologue whose discontinuous montage, horizontal and vertical, cancels out the narrativity that the credit titles seemed to announce. The irregular alternation between embracing bodies and burning bodies, the recitative of two unlocatable voices off-screen, the uninterrupted tension of image and voice - such is the opening sequence. This disruption appears even more provoking since this inaugural passage, which lasts 15 minutes, represents the sole reconstruction that the film provides of the atomic explosion." RoparsWuilleumier, "How History Begets Meaning," 179.
} 
appear on the screen, framed in extreme close-up and engaged in a slow, sinuous struggle.

Intercut with these images, which last several seconds each, are sequences showing scenes from contemporary Hiroshima, either the hospital, the museum of remembrance, or the streets of the city. Over both sets of images, an uninterrupted and non-attributed dialogue offers up a report on Hiroshima, specifically referring to the atomic bomb dropped in 1945 and the ways in which the museum commemorates the event a decade and a half later. Elle, whose voice provides most of the dialogue but who has at that point not yet been introduced, proposes her own assessment of Hiroshima and its sufferings, while Lui (similarly unidentified) rejects her assertions, telling her repeatedly that she knows nothing of Hiroshima. The voices, disembodied and without affect, float above the images like an extradiegetic accompaniment, more music than narrative.

The opening dialogue could easily be considered a part of the general Hiroshima storyline, and the two lovers do continue to speak about their experiences of the bomb once the film settles into the present. However, the dialogue is only tenuously located in the present, and only by proximity; in fact, the entire opening sequence cannot be definitively placed and rather seems to exist outside of an identifiable place and time. Clues to its non-location occur both within the dialogue and in the way it is filmed, beginning with Elle's portion of the opening dialogue in which she speaks in both past and present tenses. Speaking of her knowledge of Hiroshima, Elle switches from the past ("J'ai vu les actualités. . . Je les ai vus") to the present (“Les femmes risquent d'accoucher d'enfants mal venus. . La nourriture fait peur”), and even temporarily places herself in the time of the bomb ("J'ai eu chaud place de la Paix.") 52 She takes the specific instance of the bomb at Hiroshima and extends it into the present, changing her phrase "ça a continué" to "ça continue," but also performs the same switch in reverse, taking her present impressions and effectively re-situating them in 1945. Logically her visits to hospital and

\footnotetext{
${ }^{52}$ Duras, Hiroshima mon amour, 25-30.
} 
museum have happened in the recent past, far from the immediate aftermath, but she speaks of the patients as victims of the bomb, as if she views them in both past and present iterations. Similarly, when she speaks about her memory of the newsreels covering the bombing, she could just as easily be speaking of her memories from 1945, in Paris, as describing the newsreels now endlessly playing on repeat in the galleries of the museum. The hospital, with its long corridors staffed by waiting nurses, appears more like a dream sequence, as the camera floats down the hallway and all of the patients turn away from the gaze of the camera, refusing to make contact. Further, Elle does not appear in either the hospital or the museum, the camera instead representing her point of view as she recalls her impressions of both locations. As Elle's voice and the images fluctuate between past and present, the viewer's sense of time remains fluid and changeable, with no real certainty as to whether the words belong to the past (the time of the bomb) or the present (the time of the museum.)

Nor can the images of the lovers' bodies be clearly placed, especially in the minimal context provided in the early minutes of the film. All of the images from the museum seem to be "past" within the context of the film, illustrating what Elle has already seen and subservient to the film's ostensible present, in which two as-yet unidentified bodies lie together, covered in what Duras describes in the screenplay as "de cendres, de pluie, de rosée ou de sueur." $"$ But are these corporeal images truly in the present? For the early minutes of the film, the primary time and place of the story cannot be identified any more than the shape or meaning of the body parts that cover the screen. Shown in close-up, the torsos twist and morph under their filmy coating, lacking any physical or even conceptual context. Barely lit, the bodies could be anywhere, at any time of day, shut in from the world or excluded from it. Although Elle and Lui will later appear together in similar proximity, never again in the film do the twisted torsos of the opening

\footnotetext{
${ }^{53}$ Ibid., 21 (italics original).
} 
sequence reappear, and while they must, lacking any other options, be Elle and Lui, they are never fully identified as such. None of the early images - of the museum, the hospital, or the torsos - exists in a comfortably defined time; instead, the opening sequence revels in the malleable time/space context that will permeate the rest of the film.

Thus the film sets up not just two but three storylines and time periods, with 1945 Nevers and 1959 Hiroshima accompanied by an indistinct, nebulous time in which Elle and Lui contemplate and rework definitions of memory and truth. In presenting a third setting, neither past nor present, Resnais problematizes the concept of time and along the way establishes parallels among three different concepts or ways of telling: museum, film, and memory. ${ }^{54}$ As the film eventually demonstrates, each of these methods of remembrance succeeds in some ways and fails in others, with institutional methodologies butting up against personal histories. Two of these ways of telling - the film and the museum - are generally recognized as constructed entities, but Resnais is also interested in memory, and the ways in which memory too may be constructed, or not, to form a more stabilized version, a story. Alongside the discussions of films and museums as institutions of remembrance, Resnais investigates how memory becomes story and how, in return, story may betray memory.

Before addressing memory in its most personal iteration, Resnais introduces the two alternate forms of remembrance - film and museum - by setting up parallel explorations of their respective means of commemoration. As Elle explains to Lui, in the opening dialogue, that she "knows" Hiroshima, she recounts the elements of the museum's collection as proof of the knowledge she has gained:

J'ai regardé moi-même pensivement, le fer. Le fer brulé. Le fer brisé, le fer devenu vulnérable comme la chair. J'ai vu des capsules en bouquet : qui y aurait pensé? Des

\footnotetext{
${ }^{54}$ Other Resnais films in which time and memory are particularly relevant include Providence (1977), L'année dernière à Marienbad (1961), Nuit et brouillard (1955); Muriel (1963); Toute la mémoire du monde (1956).
} 
peaux humaines flottantes, survivantes, encore dans la fraicheur de leurs souffrances. Des pierres. Des pierres brûlées. Des pierres éclatées. Des chevelures anonymes que les femmes de Hiroshima retrouvaient tout entières tombées le matin, au réveil. ${ }^{55}$

The physical remnants of the event are supplemented with informative films, recreated "le plus sérieusement possible" to show the death and destruction of the city and its people. The sum of these pieces, she argues, is that she has seen everything of Hiroshima, that she has captured a true sense of the reality of the event (and the city itself, whose name remains synonymous with the dropping of the atomic bomb) through viewing the accumulation of its remnants. Despite her distance from the event at the time it happened, and the changes undergone in the city in the intervening years, she insists: "J'ai tout vu. Tout." ${ }^{, 56}$ In essence, Elle's conception of the museum as a place of truth and knowledge echoes the goals of the museum itself, which was created in 1955 to "convey what specifically happened to Hiroshima on August 6, 1945,"57 including explanations of the atomic bomb that was dropped, testimonials from the survivors, and the types of physical remnants described by Elle. The museum, in the film as in reality, exists as a place of remembrance, with monuments and memorials to lost lives, but also as a place to encourage (or re-create) remembering. The museum, if effective, does not just fix the event in the past, but also brings it into the present, encouraging visitors to become new witnesses to the event through their experience of its artifacts.

Resnais' film, too, acts on this impulse; initially commissioned as a documentary on the bomb, the film acts in part as a collection of images and ideas about the event, set within and around a fictional story but no less evocative of the specific historical event known as Hiroshima. The accumulation and display of filmed moments, particularly in the opening discussion of

\footnotetext{
${ }^{55}$ Duras, Hiroshima mon amour, 24.

${ }^{56}$ Ibid., 22 (italics original).

57 “Hiroshima Peace Memorial Museum,” Hiroshima Peace Site, 2011, http://www.pcf.city.hiroshima.jp/top_e.html
} 
Hiroshima's museum, certainly works to open what Andreas Huyssen would call "spaces for reflection and counter-hegemonic memory." ${ }^{, 58}$ The piecing together of the footage in this early section works to create certain associations for the viewer, like any film, but Resnais makes a point of stitching together not just his own shots, but also the historical remnants of the bombing, mimicking the accumulative role of the museum as documentary footage and filmed reenactments are carefully elided into the footage shot by Resnais himself. The three types of footage share certain qualities, most notably all being shot in black and white, and they blend together almost seamlessly, though the re-enactments are usually betrayed by their low-quality acting and the newsreels by their grainy quality. However, Resnais obscures the transition from his own camera work into the first example of the reenactments by panning extremely quickly to the right and directly into the reenactment, as if the man in the footage were there in the museum, silently screaming and gesturing frantically in our faces. The grainy quality of the series of reenactments then switches (again with little visual indication) into newsreel footage, a change noted only, and belatedly, in the voiceover. Further, Resnais' quick montage keeps the distinctions minimal, and to further smooth the transitions the camera in all three types of footage tends to keep moving, panning over the destruction and occasionally resting on important elements - a pile of hair in the museum, or a woman clambering out of a destroyed building in a reenactment. ${ }^{59}$ Throughout the montage, Elle's voice (interrupted occasionally by

\footnotetext{
${ }^{58}$ Andreas Huyssen, Twilight Memories: Marking Time in a Culture of Amnesia (New York: Routledge, 1995), 15.; Ropars-Wuilleumier adds that "In making the spectators take on, within the filmic perception, the burden of the transference and the modulation of remembrance-oblivion, Hiroshima mon amour demands that we realize, in every meaning of the word, the ambiguity of a historicization which the textual mediation renders necessarily indirect and thus uncertain. Unless it is inscribed in bodies, History leads to the museum; the trace is at once an aid to readability and a sign of the unfamiliar; and if the reading still remains to be done, the writing-reading reminds us, by its surplus and its overflowing, of the loss of substance that the acquisition of meaning costs." Ropars-Wuilleumier, "How history begets meaning," 182.

${ }^{59}$ Ropars-Wuilleumier ties these images from the museum directly to the alternate storyline: "A deformed hand, a destroyed eye, hair torn out, a distraught woman breaking out of a cavernous dwelling, a twisted bicycle, legs of passers-by, river, anger, stone - long is the list of materials which the narrative of Nevers drags out of Hiroshima's museum and reconstructs into appeased, if not acceptable, forms." Ibid., 180.
} 
Lui) acts as an explanatory index to the images, identifying more difficult images such as a mass of bottlecaps and providing basic context to add emphasis. As if reciting a set of informational placards, she speaks entirely without affect; the result is a film that in that excerpt feels very much like a museum itself, complete with a rudimentary display guide.

Yet neither film nor museum can entirely capture the truth of the past, represented in Hiroshima by the atomic bomb and its aftermath. Instead, both are mere representations, often with troublesome aspects that alter and shape an audience's understanding of the event portrayed. ${ }^{60}$ The museum in particular has long been heralded as an effective but problematic locus of cultural and historical identification, often relying on the conceit that what is displayed can adequately represent the larger context of its origin, as Susan Stewart notes in her study $O n$ Longing in which "she shows how collections, most notably museums, create the illusion of adequate representation of a world by first cutting objects out of specific contexts (whether cultural, historical, or intersubjective) and making them 'stand for' abstract wholes." ${ }^{\text {,61 }}$ The museum at Hiroshima in particular exists as a too-rigid institution of fact, at least in Resnais' treatment of it. Both museum and film leave little space for personal meditation, as Resnais' camera follows a set and unchangeable path down museum aisles, at varying but non-negotiable heights depending on the intended focus of the gaze. In general, the camera maintains a steady forward movement, allowing only a cursory glance at most artifacts. When it does pause, as for example on the pile of hair or a close-up of a man's impossibly scarred head, those objects immediately gain importance, and must be visually if not intellectually contemplated for as long

\footnotetext{
60 "Against the ideological critique of the museum, [Huyssen] asserts that the museum 'enables the moderns to negotiate and articulate a relationship to the past that is always a relationship to the transitory and to death' (Huyssen 1995:16). Yet, as [Cathy] Caruth and others have suggested, massive trauma unsettles that articulation of a relationship to the past, to past catastrophe. The museum of mass trauma will never be secure or aptly commemorative." Wilson, Alain Resnais, 59.

${ }^{61}$ James Clifford, "On collecting art and culture," The Cultural Studies Reader, ed. Simon During (London: Routledge, 1993), 53.
} 
as the camera lingers. In this, Hiroshima echoes an earlier work that Resnais co-created with Chris Marker, Les statues meurent aussi (1953), a short visual exploration of a French museum housing a collection of African culture. Accompanied by a highly political commentary, Les statues posits that the static objects (and images) of culture, as collected in the museum, can never truly convey the culture in question and in fact represent just another form of colonization, as the French attempt to define the 'other' in potentially condescending terms. In the museum shown in Les statues no one acknowledges that time has been frozen, that the collection represents only one of many possible snapshots. Instead, Les statues meurent aussi intentionally displays the negative effects of collection, the fossilization of a culture when all intimacy has been removed. By fixing the viewer's perspective in place, the museum in Les statues denies any opportunity for the culture to come alive and thus for any true act of communication to take place.

Unlike either of the museums he films, however, Resnais refuses to let Hiroshima "create the illusion of adequate representation." Instead, by pairing the images of the museum with the voiceover of Elle and Lui's dialogue about the meaning of memory and comprehension, Resnais questions not just the construct of the museum in which he films, but also the purpose of the film itself. None of what Elle describes, or the film shows, really represents an artifact of the bombing so much as what was left, "faute d'autre chose." ${ }^{\prime 2}$ Elle tries to name and catalogue what she sees, but Hiroshima (the event) can only be absent. It is the "rien" and the "tout inventé" of Lui, whose skepticism serves as a reminder that the sum of this collection may be more than what appears in the displays. Although physically located in the center of the bomb's blast, the museum of remembrance in Hiroshima lies at an even greater remove, for the objects found there are mere remnants, a kind of negative image of the blast; they are that which was not destroyed. The

\footnotetext{
${ }^{62}$ Duras, Hiroshima mon amour, 24.
} 
objects, and even more so the images and recreations, depend on an evocation of a loss, asking the viewers to notice the empty spaces, the missing flesh, the disappeared. ${ }^{63}$ Overall, the film reveals itself to be (like any other) not only a collection, but also a fabrication, a consciously created set of elements which, when seen together, intentionally present a certain whole. ${ }^{64}$

The film in turn repeatedly exhibits the place now inhabited by the museum, a structure which would not exist (materially or conceptually) had the bomb never fallen. Resnais opens his exploration of the museum with a quickly-paced montage of the building's architecture, filmed from outside as well as from within, emphasizing the presence of the building itself and calling attention to the way it has been put together (the museum itself notes that "the Main Building was designed in the pilotis-style so that the space between the land surface and the elevated floor can symbolize the human power to rise from the ashes.") ${ }^{65}$ Accompanying the shots of the museum are several images of other pieces of architecture around Hiroshima, including the recurring view of a building now known as the Genbakú (A-Bomb) Dome, one of the few buildings to survive (in part) the bomb (Figure 1.13). ${ }^{66}$ Flipping through these images of 'new' Hiroshima, Resnais questions the physical place of the museum; it is a structure that has been constructed in order to carry memories, but within the museum itself exist countless images of

\footnotetext{
63 "Consignation, that ordering of signs associated with an event into a system that 'makes sense', but never belonged to the event in the first place, 'assures the possibility of memorization, of repetition, of reproduction, or of reimpression' (Derrida 1996: 11), but at the same time requires the repression of the event's aporias, of its interminable effects, and its unnameable, or even unimaginable, particulars. In the case of the atomic bombings, the singularity of each death is funnelled into a grand figure; the singularity of each deformity is collapsed into a photograph." Nina Varsava, "Processions of trauma in Hiroshima mon amour: Towards an ethics of representation," Studies in French Cinema 11 no. 2 (2011): 115.

${ }^{64}$ This may also be why, in part, Resnais repeatedly shows the mechanisms - director, camera equipment, assistants - behind the production of the "film sur la paix" for which Elle is working. These glimpses, further, always show the participants in the act of "taking apart" the film - as Duras specifies, "On défait des tribunes. On décroche les banderoles." Duras, Hiroshima mon amour, 13.

65 "Hiroshima Peace Memorial Museum," n.p.

${ }^{66}$ The cuts among the various images of the dome (in increasingly close-up shots) correspond to the words spoken by Elle: "Pourquoi nier l'evidente necessité de la memoire" - with every word prompting a new image. The series feels very fast unless you understand the architectural images as punctuation to this phrase and an early hint as to what exactly Resnais considers important in the film.
} 
that same place, empty and destroyed. In the opening minutes of the film, the place explored by Resnais' camera is thus simultaneously both past and present, barren and thriving.

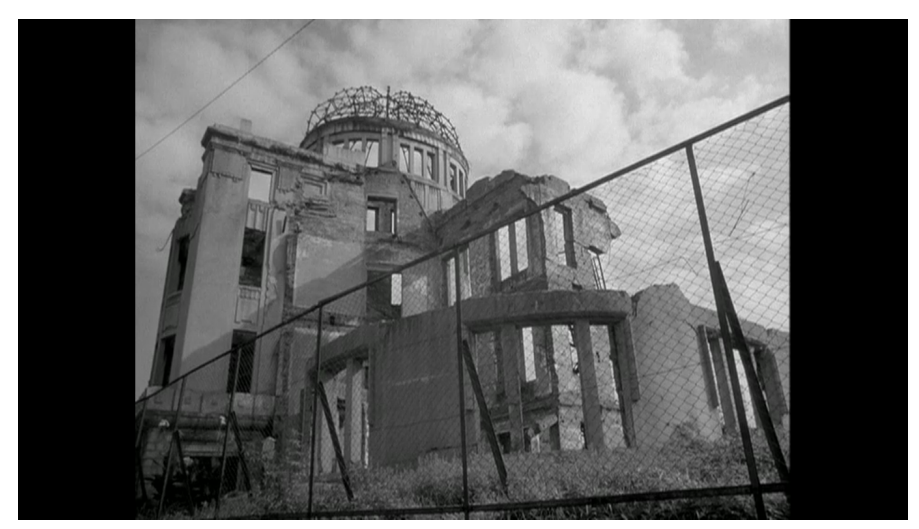

Fig. 1.13

In part, the parallels between museum and film in this early section of Hiroshima function to explode customary ideas of continuities of time and place, both of which break down early in the opening dialogue and continue to vacillate throughout the film. One of the most unsettling effects of a museum is its ability to displace objects from their original time and place, rooting them into the constructed place of remembrance and allowing them to continue to exist in whatever time the visitor inhabits. As Jean Baudrillard notes, "objects do not merely help us to master the world by virtue of their integration into instrumental series, they also help us, by virtue of their integration into mental series, to master time, rendering it discontinuous and classifying it, after the fashion of habits, and subjecting it to the same associational constraints as those which govern the arrangement of things in space." ${ }^{, 67}$ The sorting and classification of objects, in film as in museum, allows one to essentially construct a narrative by establishing chronologies and associations. Resnais' film, however, openly disturbs the rigidity of the institution by refusing to settle in any given time or place. Instead of mastering time as he puts in order various objects, images, and events, Resnais allows time a certain amount of freedom,

\footnotetext{
${ }^{67}$ Jean Baudrillard, The System of Objects, trans. James Benedict (London: Verso, 1996), 94 (italics original).
} 
accepting its fluidity and even insisting on it through his evocations of not just one but several chronologies. With the exception of the present-day Hiroshima storyline, none of the narratives of Hiroshima mon amour follow a logical progression, and even the Hiroshima storyline, caught up as it is in alternate events, seems to overflow with chronological uncertainties.

It soon becomes clear that the inarticulate distinctions between past and present drive the film itself, in which, as Resnais himself claimed, "time is shattered." ${ }^{68}$ Over the course of the film, Resnais steadily ignores past and present continuities in favor of a nebulous, alternate time and place, strangely located but easily accessible, a space in which the past can be reconstructed or curated as if in a gallery or editing room. Within this space he constructs the three storylines of the film, two of which ignore chronology altogether and all of which are subject to being subsumed by the others at any given moment. The 'present-day' storyline, in which Elle and Lui move together and apart through a revitalized Hiroshima, is the only story to respect any sort of logical order of events, but even here time slowly shakes itself free from 'normal' functioning, particularly for Elle, who increasingly tumbles back into her own past as she revisits the tragic love of fourteen years prior. Following the opening dialogue, which lasts fifteen minutes, moments of alternate time (i.e., jumps to the past) occur with increasing regularity, starting with Elle's momentary flashback to the site of her German lover's death, spurred by her association of his lifeless hand with that of the Japanese man, twitching on the bedspread as he sleeps. Following this, however, Elle stays in the present until she visits Lui's house, in the afternoon. Here, as Elle begins to speak about her past, Resnais cuts to another image of the German soldier, alive and walking through the square. This insertion, several seconds longer than the first, leads to several additional flashbacks, but for the most part Elle again centers herself in the

\footnotetext{
${ }^{68}$ Kent Jones, “Hiroshima mon amour: Time Indefinite” (New York: The Criterion Collection, 2003$), 8$.
} 
present, at least until she and Lui sit down in a café and he again asks her about her past. Here Elle loses herself completely, switching between past and present so rapidly that she begins speaking to Lui as if he were her German lover; he, too, takes up the conceit, asking her "Quand tu es dans la cave, je suis mort?” She responds: “Tu es mort. . . comment supporter une telle douleur? La cave est petite. . . très petite. La Marseillaise passe au-dessus de ma tête. . . C'est . . . assourdissant. .."69 Although she is clearly sitting in a café in 1959 Hiroshima, she hears again the sounds of La Marseillaise, and struggles to speak over its sound. ${ }^{70}$ And this final break, for Elle, proves too much; when she leaves the café she returns to her hotel room and speaks directly to her dead lover, having somehow bridged the gap of fourteen years. She is no longer anchored in time, and while her body appears in present-day Hiroshima, she herself feels equally present in newly liberated France. No wonder, then, that at this moment she has what is essentially a doubled experience, speaking to herself in the mirror and hearing herself respond in voiceover. Although the narrative of the moment follows a certain logic - Elle is upset, comes back to the hotel, washes her face, and faces a decision about her next move - the words themselves do not have the same cohesion: Elle speaks successively in third person (about herself), in second person (to her former lover), and in first person, and we hear both what she speaks and what she thinks. The brief incorporation of the musical lover's theme from Nevers at the beginning of the sequence further indicates what Elle thinks about, although for once we do not join her in her flashback. ${ }^{71}$ Overall, this strange two-voice monologue gathers together the unsettling chronological dissociations that Elle has undergone and reflects (literally) the accumulation of past memories in Elle's present.

\footnotetext{
${ }^{69}$ Duras, Hiroshima mon amour, $87-88$.

${ }^{70}$ In the screenplay, Duras writes specifically that "Elle revient à Nevers." Ibid., 94.

${ }^{71}$ For a discussion on how the soundtrack indicates different character perspectives, see Leah Anderst, "Cinematic Free Indirect Style: Represented Memory in Hiroshima mon amour," Narrative 19 no. 3 (2011): 358-382.
} 
For films and museums are not the only locations in which Resnais explores the fabrication of the past. Constructed pasts appear again in Elle's personal history, which Lui slowly draws out of her over the course of their mutual journey through Hiroshima. Very little of her story appears in her initial telling, however, and the narrative can only be pieced together once the chronology of her telling is discarded and her memories are rearranged into a more logical order of events. Certain clues in the visual flashbacks help to organize the timeline, including most notably Elle's hair, which is shown at various lengths depending on whether she is in love, in shame and mourning, or in recovery. For the most part, however, Elle herself accesses pieces of her past in non-chronological order; we see her hair being shaved off immediately after she comments on it growing back, for example. Certain key moments recur, so that it becomes unclear how many times she screams, or how many times she returns to the cellar. In terms of filmic structure, Resnais gives the Nevers story a treatment similar to that of the Hiroshima museum in the opening sequence, with episodes from an alternate time spliced into a conversation between Elle and Lui. He also uses the same slow right-to-left pan of the Loire river, which introduces Nevers, as he used to show Place de la Paix, in Hiroshima, and even includes the same obstruction: the column that intersects the view of the square is replaced by a tree in front of the river (Figures $1.14,1.15) .{ }^{72}$ By pairing the two non-present stories, Resnais infuses the second (Nevers) with the same problems of time and representation he openly questions in the first.

\footnotetext{
${ }^{72}$ Interestingly, according to Wilson (among others), the two shots were filmed by separate cameramen, who had no access to each others' work. Nonetheless Resnais effectively makes use of the two similar shots to pair the two locations. Wilson, Alain Resnais, 49.
} 


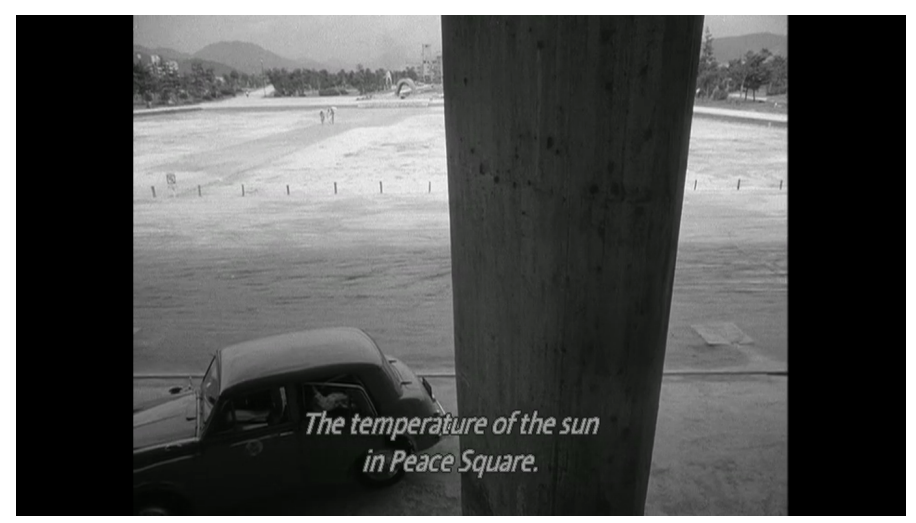

Fig. 1.14

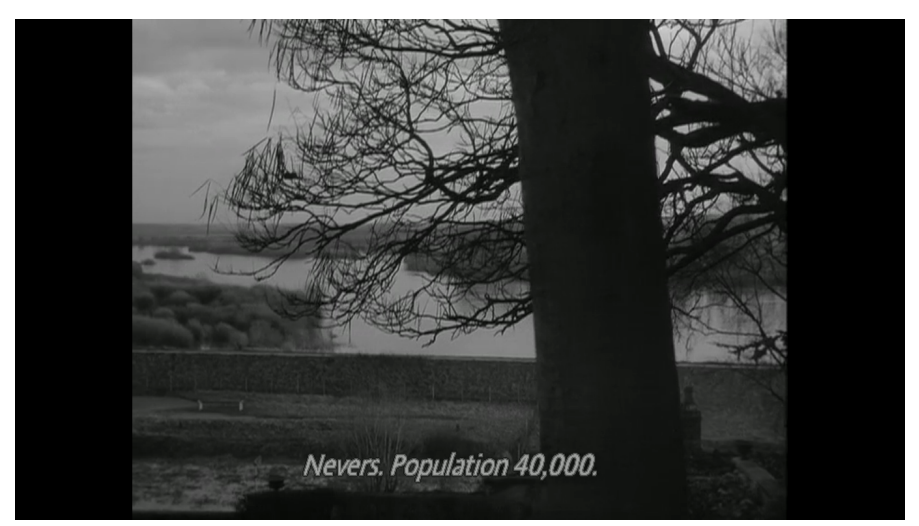

Fig. 1.15

Echoing her earlier report of the official figures of death in Hiroshima, Elle begins her Nevers story with concrete numbers. She offers up the population, geographic location, and a few key details of the city and the Loire River on which it sits, setting the foundation for what will become a jagged narrative of insanity and loss as both words and image break down into a staccato set of partial memories which only barely cohere into a comprehensible story. In addition to the odd repetitions of key moments, the images of Elle's love affair in Nevers have a fairy-tale quality to them, as a young, long-haired Elle repeatedly runs or bikes toward her distant lover, who turns toward her, or throws up his arms in greeting, as soon as he sees her (Figure 1.16). One extreme long shot shows the two lovers indistinctly embracing along a wall; later there is a quick image of the two lovers under a blanket, at a slightly closer distance but 
with only their feet visible. Frames containing the two lovers are filled with obstacles, including trees, bushes, and walls; in one four-shot montage Elle repeatedly climbs over physical barriers. Filmed at a much greater distance than any other sequence in the film, the meetings of Elle and the German soldier in Nevers are visually indistinct, especially when contrasted with the consistent and occasionally extreme close-ups of Elle and Lui in present-day Hiroshima. The Nevers lovers appear to be constantly trying to reach each other, and rarely succeeding, as if the anticipation exceeded the event, or as if Elle still cannot access the too-painful memories of their actual time together.

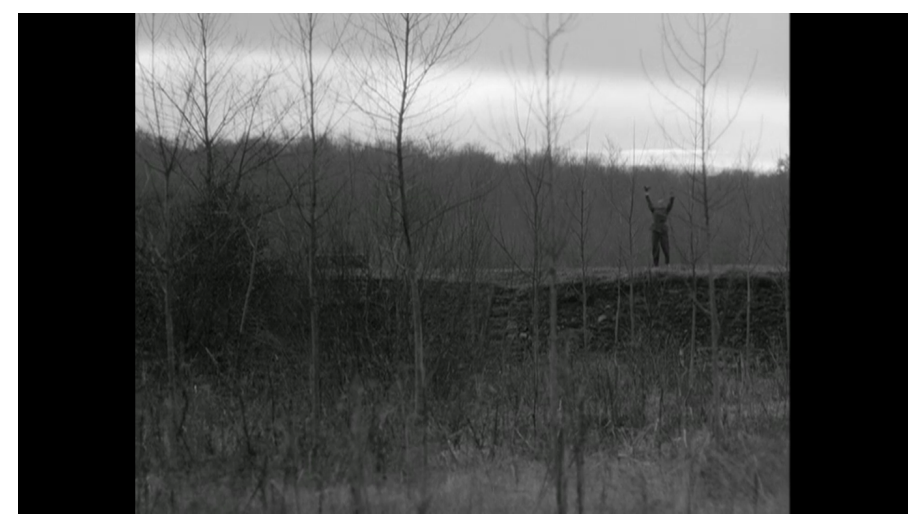

Fig. 1.16

In fact, Elle's memories are faulty, in part, precisely because they are drawn from particularly strong emotions and center around a traumatic experience. Elle's memories, as conveyed by the images on the screen, derive directly from her emotions: her excitement every time she sees her lover at a distance, for example, or her horror on seeing his body lying on the pavement. Only the key moments of their relationship are highlighted, with everything more mundane completely erased. In fact, the longest shot of the Nevers lovers together occurs when Elle clasps her dying lover's body and lies with him “toute la journée et puis toute la nuit suivante" - in other words, the moment of her most heightened emotion, a shot that reprises Elle's first flashback, back in the hotel room, in which we also see Elle alongside her dying 
lover. ${ }^{73}$ The initial flashback marks the first in a series of death memories, as Elle repeatedly relives the moment of trauma: following the occurrence in the hotel room, Elle sees her lover die again in Lui's house, in the afternoon, and then twice more during their dialogue in the café. Sometimes she openly refers to the death, telling Lui "Et puis, il est mort" or "Quand je suis arrivée à midi sur le quai de la Loire il n'était tout à fait mort," but sometimes she only pictures it (as in the hotel, or when she says merely "comment supporter une telle douleur?" while she, and we, watch the German writhe on the ground. $)^{74}$ The timeline of her story, already vague, gets further corrupted by the dominance of the traumatic memory, with Elle herself losing the thread and becoming disoriented even in present-day Hiroshima. As a result, any attempt to piece together Elle's past from the various parts must rely on memories irreversibly altered by pain and time to be both visually and contextually vague.

The need to piece together Elle's story from these corrupted memories again reinforces Resnais' interest in the nebulous functioning of time and place when any sort of history must be constructed. The reliance on a non-actualized space in which to curate the past becomes even more pronounced when reconstructing the past out of personal memories, which may well carry certain inaccuracies or represent only a sliver of actual events. In order to understand how Elle's story comes together (or rather, to compensate for how it initially does not) we thus need to call upon a sort of mental editing room, a 'memory-space' that has no definitive place or time but rather exists in multiple places and times, allowing access to both past and present without privileging one over the other. And in fact from the opening of the film, Elle is clearly established as a character who exists in various times, calling upon all times and tenses to establish her history. At times, as in the doubled-voice experience at the hotel, she vacillates

\footnotetext{
${ }^{73}$ Duras, Hiroshima mon amour, 99.

${ }^{74}$ Ibid., 79, 99, 87.
} 
precariously among past, present, and future, seemingly barely in control of her own location, and this tendency becomes more pronounced when she speaks of her own past, as well as that of Hiroshima.

Within the film, subtle clues build up early on that Nevers is important to Elle. As we watch the two Hiroshima lovers interact in the early morning hotel room, Elle casually mentions that she is from a town called "Nevers", and further highlights the name by pronouncing it carefully: "Avant d'être à Paris? . . J'étais à Nevers. Ne-vers.",75 Although the significance of the town, for Elle as well as for the film, has not been established, Lui's next action is to turn on the interior light, suddenly lighting Elle's face as if by an interrogation lamp and presaging the role he will play in drawing out the rest of the story over the course of the day. When, slightly later, Elle mentions Nevers again, the two actors (previously both in the frame) are suddenly framed on their own for the first time in the sequence, Elle forced back into solitude by the verbalization of what will soon prove to be a long-denied trauma. Unsurprisingly, this visual isolation of Elle is immediately followed by a shot of Elle in the mirror, momentarily reestablishing her sense of self but also foreshadowing how, over the course of the day, Lui will compel her to reflect back on her past. Seen both in the mirror and from the back of her head, Elle already appears slightly fragmented, a process further established in the shot immediately following, when Elle speaks from off-screen (Figure 1.17).

\footnotetext{
${ }^{75}$ Ibid., 40.
} 


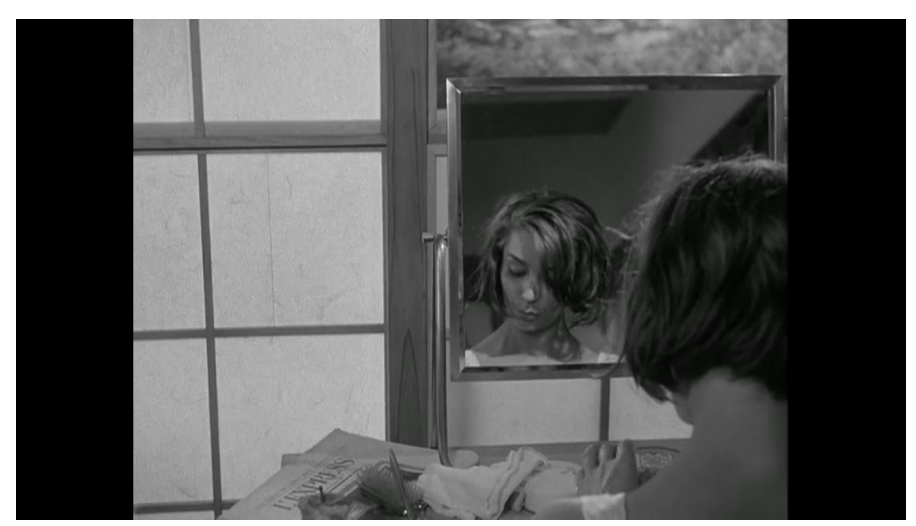

Fig. 1.17

Of course, the structuring of the images and dialogue, especially in the early part of the film, also mimics the inarticulate nature of memory, which exists in a perpetual now as past events are reconstituted in the present, not necessarily in their original chronological order. Similarly, the images on the screen appear in the present, regardless of whether they are from the 1957 filming of Hiroshima, newsreel footage from the immediate aftermath of the bomb in 1945, or a re-enactment filmed sometime in between. Together, the words and images establish and continually reinforce an understanding of memory, or rather the process of remembering, as inherently constructed. The focus lies on the process itself, whether filming, or curating a collection, or creating a story. If memory is to be made whole, Resnais argues, it needs the same kind of attention as any other human-made history. Further, Resnais suggests for this project a space of construction that is neither past nor present but rather somewhere outside of time. Elle is an ideal vehicle, for she exists in an uncanny space, present in Hiroshima and yet verbally and even visually detached. The film thus establishes a distinct, if non-identifiable, space of memory, somewhere outside of regularized time and place, in which Elle revisits Hiroshima and, later, Nevers. This memory-space, because it allows access to both past memories and present tools of reconstruction, results in a more complete history, one subject to bias and selection but nonetheless one that stands in for the past as completely as possible. For if the representations of 
museum and film are problematic, they are nonetheless acceptable substitutes for what may no longer be accessed any other way. Each of the processes is also, in a way, cathartic. Before she restructures her memories into a story, Elle lives in denial; once she completes the story, she finds herself able to move forward in the present, perhaps into a new love. As she says, speaking to her German lover, "J'ai raconté notre histoire./Elle était, vois-tu, racontable."76

\section{Conclusion}

In Twilight Memories Huyssen suggests that museums are "the only place where the flâneur still ha[s] a hide-out" in an era when every action seems to have been accelerated almost beyond belief. $^{77}$ Indeed the museum remains the most concrete of the three examples given here; it still (primarily) collects objects, rather than images or memories. ${ }^{78}$ Collecting may serve as a reason to slow down, to take the time to wander among the recesses of memory, history, and other narratives of the past. Reading into a poem by James Fenton, James Clifford unpacks the fascination of collecting, arguing that on a personal level collecting is often driven by an almost fetishistic obsession with a certain object or theme. ${ }^{79}$ Noting the strangeness of children's collections (crayon shavings, or shells, or what have you) Clifford suggests that by extension the museum can, or rather should, be considered "a place of fascination," is inescapably tied to obsession, to recollection." ${ }^{81}$ Such is the case, at least, for those visitors who are able to extract themselves from the institutional detritus and relate to the objects contained therein on a personal level, like Fenton's childhood self. Then, the museum collection

\footnotetext{
${ }^{76}$ Ibid., 110.

${ }^{77}$ Huyssen, Twilight Memories, 23.

${ }^{78}$ Although (effective) museums must traffic in these latter as well.

${ }^{79}$ James Fenton, “The Pitts-River Museum, Oxford," Newsletter (museum Ethnographers Group) 16 (1984): $37-40$.

${ }^{80}$ Clifford, "On Collecting Art and Culture," 50.

${ }^{81}$ Ibid., 51.
} 
becomes a place whose smallest details "increase the wonder . . and the fear" of the unknown, ${ }^{82}$ acting with opposing forces on the viewer by both drawing him in and pushing him away. In this view the process of collecting can, indeed must, be driven by emotions in order to truly encapsulate the small piece of the world it is supposed to represent.

Clifford suggests that allowing objects in a collection to retain their power as objects of our own desires, "our own fetishes. . . would accord to things in collections the power to fixate rather than simply the capacity to edify or inform. . Seen in their resistance to classification they could remind us of our lack of self-possession, of the artifices we employ to gather a world around us. ${ }^{93}$ Resnais' film plays on the ability of cinema to fascinate, his images and editing contributing as much to visual pleasures as to narrative edification. But the film is also the story of Elle's attempt to 'collect' Hiroshima by mapping her own past onto the past of a city. Forcing parallels between her Japanese lover and her German lover, Elle by extension tries to understand and explain the losses of Hiroshima in terms of her own loss. Initially it seems to be an inaccurate process, in fact almost ridiculous, to try to compare the death of one man with the annihilation of a city population. Elle is looking for a pattern in order to understand, but both experiences defy regularity, and there can be no ordering, no forcing these elements into place. Like most traumas (personal and historical), they can be accessed in many different ways and perhaps comprehended to a certain extent but much will be lost (or rather all cannot be gained) in the attempt. Resnais is not suggesting that perfect memories (or exhibits, or films) can be crafted, but rather urging an awareness of the artifice, and lacks, with which we have surrounded ourselves; our instinct may be to refer to our own experience in order to understand a distant event, but some things may in the end resist classification.

\footnotetext{
82 Ibid., 50.

${ }^{83}$ Ibid., 60 (italics original).
} 
For the process of commemoration - remembering and respecting a traumatic historical event, for example - benefits from allowing a certain degree of fascination - by welcoming the fixations, the possibly inarticulate or inarticulable connections between ourselves and the past. We benefit from letting something unexpected gain access, in accepting the perhaps strange desire to focus in on the tiniest of details - a lost button, a half-melted photograph, a still-tied shoe. These objects, so familiar and yet so strange, spur our emotions and thereby help us recollect, on a personal level, what can perhaps be understood no other way. It is this uncommon fixation that emancipates us finally from our attempts to put a label on the past, to wrap up in a tidy package what could never be so easily contained. It is this uncanny fascination that proves the release. Elle's fault, when trying to understand Hiroshima via the museum of remembrance, lies in following the rules of the museum too closely, treating the artifacts as evidence or art and remaining at an appropriate distance. Her interaction with the collection is not appropriately intimate, at least not initially; she does not relate to the model of the bomb, or the pile of hair, on a personal level but rather 'reads' the museum as a purely informational institution. Or at least Lui assumes so, arguing that her understanding is no more than that of another casual visitor. But is he wrong? Elle's desire for her German lover is still a very raw emotion, and her attempt to catalogue it in bits and pieces for Lui mostly fails to cohere. She cannot properly put these pieces together for herself, much less display them for others, hence the disjointed quality of her narrative. But whereas the museum itself is very sterile, Elle's memory is full of, even reliant upon, her emotion, both those felt at the time of the affair (which determine which memories resurface) and those felt in present-day Hiroshima. The latter become, via Lui, the stimuli that reverse the process of forgetting that has taken place over the intervening years despite all of Elle's struggles against it. Only by proving, through her highly personal association of the 
bomb's aftermath with her own deep-seated trauma, that Hiroshima does mean something more than just photographs and metal scraps - only by eradicating the distance between the event and herself - could Elle possibly "see everything." She may, by the end of the process, see more than most. When she comments that her only option, on viewing the collected remnants, is to “justement pleurer" she seems, unlike other tourists, truly to cry, in a highly intimate reaction driven by desires and fears past and present. Elle succeeds, then, when she allows the uncanny to accompany her, listening not to the museum in its capacity as institution of fact but rather to the less identifiable moments that exist in between the display cases and yet capture her attention. Elle cannot understand the past - neither hers, nor that of the city - until she allows herself to be accompanied by Lui, the vessel in which the familiar and the strange are finally joined.

Should we then not 'read' the film of Hiroshima mon amour, instead opting for a more affective relationship to its collection of images and sounds? Resnais does not duck analysis, instead meticulously crafting every moment of the film to reward careful observation (note, for example, the fade-out from the German soldier crossing the square, in which his body momentarily appears in between the bodies of Elle and Lui on the bed [Figure 1.18.]) Yet affect does play a major role in the film, from the shadowy lighting of the torsos opening the film to the musical themes composed by Georges Delerue and Giovanni Fusco. Elements that will later become touchstones of the New Wave proliferate, including repeated images, odd rhythms of camera and speech, chronological spirals, and the lack of a definitive ending. In fact, the film's success as both visual and technical pleasure depends on the combination of affect and formalism that situate it as a New Wave film in the first place; the film both structures a coherent display and leaves room for emotional response. 
Much of the power of Nuit et brouillard springs from the brutality of its images and the poetry of its contemplative voiceover, as delivered by poet and camp survivor Jean Cayrol. In Hiroshima many of the questions are the same - why has this happened, and what will prevent it from happening again - but where Nuit et brouillard informs at a distance, Hiroshima holds the viewer close. Hiroshima provides the personal link that Nuit et brouillard (perhaps intentionally) avoids; by allowing a certain amount of identification with Elle, the momentousness of Hiroshima becomes, if not less painful, at least more accessible. ${ }^{84}$ In the same way, Elle finds her way to and from the past via the intimacy of her desire for Lui, both in his present iteration and as the ghostly double of her past love. Setting aside a rational path, she follows her instincts through the streets and through her memories, seeking out the touchstone images and words that will allow her to finally craft a story from her recollections. Once completed, her narrative allows her the freedom to move forward, wherever the path may lead.

Having been asked to create a documentary on Hiroshima, Resnais presents the incredibly personalized story of a woman who loses herself in an alternate space of memory, jarred out of time and place because of the intensity of her pain. Although she has only a tangential relationship to the bombing itself, Elle becomes an effective means of documenting Hiroshima, for she both experiences and provides an emotional relationship to the event that is otherwise impossible to achieve for those who were not victims. She acts as a stand-in for the viewer, especially because she remains anonymous; we identify with her because of her pain and struggles, but she can be anyone (in addition to not giving her a name Duras specifically calls her

\footnotetext{
${ }^{84}$ In this I am in agreement with Anthony Reynolds, who writes that "...where both Night and Fog and Hiroshima mon amour explicitly acknowledge the limitations of representation, it is only the latter film that undertakes a considerably more ambitious dialectical negation of representation in order to recuperate a sovereign immediacy." Anthony Reynolds, "Toward a Sovereign Cinema: George Bataille's Hiroshima mon amour," Literature Film Quarterly 38 no. 4 (2010): 316.
} 
“cette femme anonyme.") ${ }^{85}$ The trauma of Hiroshima, while very real, also stands in for any painful trauma of the past, fearful events whose occurrence shocks and harms. The unpredictability of these traumas, which could occur again at any moment, creates an atmosphere of fear: we fear to remember, and we fear to forget. Elle recognizes the immensity of the dilemma, saying to Lui in reference to all the time that has passed and that still remains, "C'est énorme..." but he responds, "Non. Il ne faut pas que tu aies peur." ${ }^{86}$ At the end of the film, as in the beginning, Elle and Lui find themselves together in the same hotel room, but something has changed; Elle no longer fears facing the past. Through her exploration of Hiroshima, she has found a way to ease her future paths.

${ }^{85}$ Duras, Hiroshima mon amour, 9.

${ }^{86}$ Ibid., 83. 


\section{Chapter Two}

\section{Redirecting the gaze in Sans toit ni loi}

The first image of Mona Bergeron in Agnès Varda's 1985 Sans toit ni loi is not a pleasant one: filthy, filmy, she lies frozen in a ditch, so clearly dead that the man who discovers her does not even check her vital signs before running to report his find. Only a minute into the film, Mona already exemplifies the trait that will accompany her character throughout: she is first and foremost a body (Figure 2.1). As a body she invites the gaze, a source of fascination for the other characters in the film and for the viewer. Previous scholarship on the film has emphasized this aspect of Mona, Mona's body as the object of the gaze. Often the focus is on the male gaze and the female body, and how Varda's film responds to or illustrates Laura Mulvey's seminal views on the same. ${ }^{1}$ Scholars such as Sandy Flitterman-Lewis, Susan Hayward, and Alison Smith rightly suggest that Varda's approach problematizes social constructs beyond the role of the "woman seen," including those of poverty and homelessness. Nonetheless, most scholarship still primarily hypothesizes Mona as a woman, as the object of the gaze, and furthermore as an object of desire whose presence disturbs those around her mainly for those reasons. In this chapter I would like to acknowledge these approaches but push beyond them to consider the ways in which Mona's female body is not seen but rather hidden in the film, primarily through the use of mirrors, close-up shots, and clothing, and analyze in greater detail how the hidden body redirects the spectator's gaze from Mona to her surroundings.

In order to do so, it is essential to consider the movement that takes up a large part of the storyline of the film: Mona's walking across the winter landscape of the Languedoc. In

\footnotetext{
${ }^{1}$ Originally published 1975. Laura Mulvey,"Visual Pleasure and Narrative Cinema," Visual and Other Pleasures (Bloomington: Indiana University Press, 1989), 14-26.
} 
particular, this movement is emphasized by a series of 12 tracking shots that show the slow but steady progress of her path and act as punctuation to the episodes that make up the film. By focusing on Mona's wandering it becomes possible to identify her as a modern-day flâneur, a descendant of the young men who walked the streets of $19^{\text {th }}$ century Paris. The direction of her gaze then becomes as important as the gazes turned upon her, and what she sees takes on new significance. However, while Mona's movements are flâneur-like, she does not move through the streets of her native city but rather across a foreign landscape where she is consistently perceived as an outsider. As non-native to this space, she can also be productively analyzed as a stand-in for the non-French in France, the immigrant population. Immigration was (and remains) a divisive question for France; as the final section of this chapter will show, considering Mona as a representative of the immigrant population in France opens new avenues of analysis for Varda's film. The discussion around immigration as the film was being made was at the forefront of French politics, stemming in part from the Algerian War of Independence which, although ended in 1962, was not fully discussed for many years. Although not explicitly mentioned, the war and its aftermath are present in the background of the film, particularly in the lingering distrust directed at those perceived to be foreigners. The film contributes to this discussion by presenting a figure who, despite being French, exists very much outside of the French community. As the camera tracks Mona's progress across the frigid landscape, the conceptualization of Mona as immigrant again encourages the spectator's eye away from her body and towards her reception as one who is perceived as not belonging despite having a right to be there. 


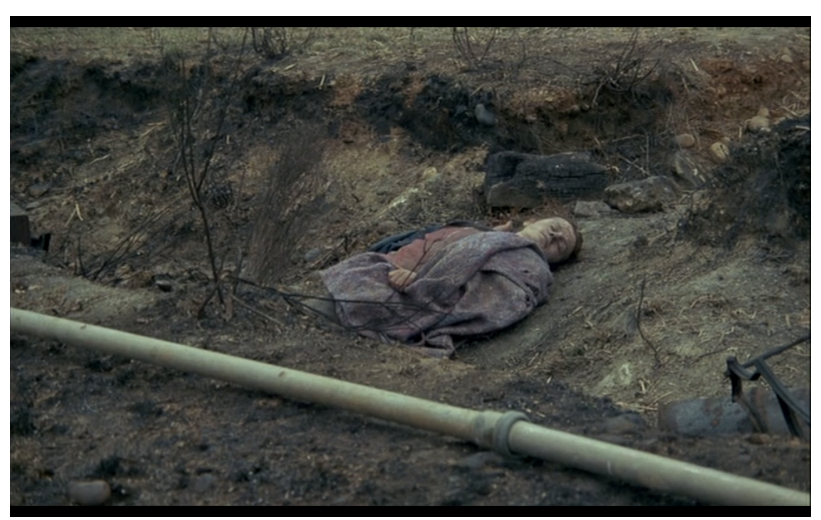

Fig. 2.1

Therefore the narrative conceit of the film - redirecting the spectator's attention from the dead body lying in the ditch to the various aspects of the young woman's life - is also the underlying thread of the analysis. Rather than look at the body, we must more closely scrutinize the surroundings and community within which the body moves. By doing so, the focus changes: Mona herself may remain unidentified, but France's reaction to her cannot be ignored. As Varda herself notes, Mona is "a catalyst, someone who forces others to react and adjust themselves in relation to her." 2 This chapter will examine not the gaze on Mona but rather Mona's gaze, and how she disturbs the environment around her as she moves across the landscape.

\section{A woman seen}

Sans toit ni loi tells the story of a young French woman, played by Sandrine Bonnaire, and in particular the last few weeks of her life as she travels through France with no plan, shelter, or money. The film opens with Mona's death, but the storyline soon backtracks to recount the days that lead up to the discovery of her frozen body in a ditch. The story is more or less linear and centered on Mona herself, but is complicated by occasional jumps in time and space and an unreliable camera that sometimes follows Mona and sometimes ignores her. The composition

\footnotetext{
${ }^{2}$ Sandy Flitterman-Lewis, To Desire Differently: Feminism and the French Cinema (Urbana: University of Illinois Press, 1990), 244.
} 
also includes twelve right-to-left tracking shots interspersed through the film that show Mona walking through the late fall or early winter landscape of southern France. Over the course of her travels she meets a wide range of people, spending minutes with some and days with others, sometimes doing an odd job here and there to earn money. She carries a big backpack, a cloth tent, and a smaller bag into which she stuffs a water bottle, any food she gleans from her surroundings, and her cigarettes. Beyond these basic plot points, the story of the film is structured by her interactions with other characters and is largely reliant on how they remember her. These encounters, which punctuate the twelve tracking shots, include several days spent with a goatherd and his wife, a Tunisian worker, a female professor, and a young fellow traveler, as well as hours and minutes spent with other people of the countryside. An early voiceover, provided by but not identified specifically with Varda herself, is often quoted: "Les gens qu'elle avait rencontrés récemment se souvenaient d'elle ... Elle les avaient impressionnés."As the voiceover immediately indicates, the question of the gaze is central to the work, and in particular the question of how - and if - an identity can be (re)constructed via the recollections of others.

Indeed many scholarly approaches to the film center on some aspect of the (often male) gaze and Mona's rejection of it. Since Laura Mulvey's 1975 essay on the subject, it is difficult not to consider the male gaze and the female object as an underlying element of any film featuring a strong female protagonist. Sandy Flitterman-Lewis writes that, following Mulvey’s essay:

The female figure, always and inevitably defined in terms of sexuality, is seen as the structural mainspring - the very site of desire - of conventional cinematic narrative. According to the lines traced out by Mulvey, the resolution of this crisis evoked by the woman's image is most often achieved in one of two ways - ways that outline the available representations for the woman in dominant cinema: The female figure is either fetishized in the luminous isolation of an objectifying image, or made subject to the abusive mastery of some form of sadistic domination through the narrative. ${ }^{3}$

\footnotetext{
${ }^{3}$ Ibid., 2.
} 
Both Flitterman-Lewis and Susan Hayward to a certain extent read Sans toit ni loi as a textbook example of Mulvey's ideal corrective approach, in which any imbalance of power in the relationship between the male viewer and the female on the screen is either resolved or subsumed within the workings of the film. According to Flitterman-Lewis, the initial means of identification with the female object, fetishization, does not exist in Sans toit ni loi, for "in denying traditional modes of looking at the female body in favor of a camera that is both analytic and direct, Varda redefines pleasurable looking as something independent of sex." ${ }^{, 4}$ arda achieves this, argues Flitterman-Lewis, by creating a film that invites the gaze of the spectator, male or female, onto a protagonist whose femininity or masculinity remains secondary to the overall question of personal identity; although Mona clearly identifies as female, and is treated as such, she reflects elements of characters who are both male and female and embodies characteristics of both. Certain of Mona's experiences are completely reliant on her femininity, but Flitterman-Lewis argues that ultimately "Mulvey's dual project - the creation of a selfreflexive, materialist cinema ('to free the look of the camera') and of a self-conscious, critical spectator ('and the look of the audience') - is powerfully achieved in Vagabond not through the destruction of cinematic pleasure, but through a gorgeously exultant, alternative view." Hayward also argues for Mona's freedom from the traditional roles posited by Mulvey, adding that "male discourse (whether uttered by men or women) cannot produce her identity. Mona's independence from a fixed identity is an assertion of her alterité (her otherness); her autonomy from male fetishization is an obligation to recognize her différence - woman as an authentic and not a second sex. As an authentic sex, Mona both attracts and repels - meanwhile she remains

\footnotetext{
${ }^{4}$ Ibid., 40.

${ }^{5}$ Ibid., 307.; Vagabond is the English title of Sans toit ni loi.
} 
indifferent, impassive to the violence of these responses. ${ }^{.6}$ Here, Hayward indicates how closely Mona's non-identity and her perception as other are linked to her reception by both characters and audience, who either respond to her traditionally and fail, or recognize her alterity and are nonetheless confused and rejected in their attempts to identify her.

Thus Varda's film has already been acknowledged as an effective corrective to traditional cinema in terms of how it presents its female protagonist. Yet scholarship on the film still relies primarily on hypothesizing a gaze directed toward Mona's body, even if that gaze is ultimately confused or denied. Therefore, for example, Hayward summarizes the film as follows: "The film is a series of gazes, of one-way exchanges from different specular positions. Each contributor fixes their gaze not on Mona but on their perception of Mona as a figure of their desire."” Hayward argues that it is only through these speculations that any sense of Mona may be established; her identity within the film depends upon the other characters and how they remember her. Inevitably such an identification will be flawed and at least somewhat artificial, and indeed the film suggests that a Mona exists beyond the stories told about her. Hayward notes: "Eighteen visions of Mona are presented by those who saw her. However, as the film makes transparently clear, Mona refuses to be coopted into any image. In her refusal of all social discourses - which her preponderant mutism serves to reinforce - she defies identification. ${ }^{\prime 8}$ As the characters are perpetually thwarted in their attempts to identify Mona, so too will the film's audience be. Hayward concludes that "we cannot fix the film any more than we can fix Mona,", that the preponderance of visions serves not to help pin Mona down but rather to emphasize the impossibility of fully knowing her.

\footnotetext{
${ }^{6}$ Susan Hayward, "Beyond the gaze and into femme-filmécriture: Agnès Varda's Sans toit ni loi (1985)," French Film: Texts and Contexts, ed. Susan Hayward and Ginette Vincendeau (London: Routledge, 1990), 286.

${ }^{7}$ Ibid.

${ }^{8}$ Ibid.

${ }^{9}$ Ibid., 294.
} 
Flitterman-Lewis likewise emphasizes the body-centered gaze in her 1990 essay “Agnès Varda and the Woman Seen.” According to Flitterman-Lewis, Sans toit ni loi "is a film about looking, but a kind of looking which is quite precise: in its massive project of reformulating both the cinematic gaze and its object - the body of the woman - it restructures relations of desire, both in the text (desire of its characters) and for the text (desire of its viewers)." ${ }^{10}$ Problematizing the construction of identity as a social process, the film reflects on the agents of the gaze as well as its object: "Because the film takes the form of an inquiry, the characters are all figured as witnesses who contribute their testimonies to the construction of Mona," interweaving of their testimonies constructs a social vision of French culture as well."12 But in the end, Flitterman-Lewis returns to focus on Mona as primarily an instantiation of what it means to be, and to be perceived as, female: according to her the film is about "Mona herself, this 'impossible portrait' - this wanderer, this homeless person, this . . . woman. In this film, Varda as filmmaker asks the questions - the social and psychic questions of femininity. And in posing a central character who remains an enigma, she offers us, and her characters, the possibility of engaging in the process of meaning construction." ${ }^{\prime 13}$ This approach, she suggests, is representative of Varda's approach as a whole and an important part of her intent as a filmmaker who relies on "a distinctly feminine authorial voice in exploring the social articulation of vision and (feminine) identity. . . it is here in Vagabond that we see most clearly what has arguably been Varda's central concern all along: constructions of 'the feminine' as they are visually and culturally inscribed." 14

\footnotetext{
${ }^{10}$ Flitterman-Lewis, To Desire Differently, 285 (italics original).

${ }^{11}$ Ibid., 245.

${ }^{12}$ Ibid., 243.

${ }^{13}$ Ibid., 245 (ellipsis original).

${ }^{14}$ Ibid., 243.
} 
In her study of Varda for the French Film Directors series, Alison Smith explores a number of themes across Varda's body of work including the use of objects, landscape, mythology, time, memory, and place. Yet Smith too spends a good deal of time on the concept of the female body with relation to Mona, devoting most of her chapter on "Woman's Images and Self Images" to a discussion of Sans toit ni loi. She points out that from the very beginning of the film Mona defies viewer expectations; she is described in voiceover as an Aphrodite rising from the sea but in fact is a sort of "anti-Aphrodite." 15 All we get of Mona, she continues, is a series of "fleeting voyeuristic glances." 16 Smith suggests that Mona exists in the memories of those who speak about her as more of a still image, a photograph, than as a living person, and that "a person captured in a still image becomes an object, significant only in the way that she or he 'chimes' with the preoccupations of the observer." ${ }^{17}$ Echoing Flitterman-Lewis, she questions:

Is Mona a woman seen? Yes, presumably, since the film is constructed around various witnesses' interpretations of her - and yet, who really sees Mona? There is no character in the film of whom it can safely be said that they understand Mona, or even that they construct a full and rounded image of her. . . Most people, and the spectator with them, are left with nothing more than a question mark. ${ }^{18}$

In fact, "readjustment of expectations is a continual requirement of Sans toit ni loi; the spectator has continually to change preconceived ideas which spring up in the face of incomplete evidence, and we also watch as a series of different people form their expectations of Mona and cope with their destruction." ${ }^{\prime 19}$ But Smith also considers a new element of the gaze: those who look at Mona and identify with her rather than wanting to possess her. In this case the desire has been shifted; rather than taking on a sexual or possessive aspect, the desire is one of becoming. Yet as Smith points out this second approach is also gendered, and turns out to be "equally

\footnotetext{
${ }^{15}$ Alison Smith, Agnès Varda (Manchester: Manchester University Press, 1998), 38.

16 Ibid.

${ }^{17}$ Ibid., 29.

${ }^{18}$ Ibid., 114 (italics original).

${ }^{19}$ Ibid., 116 (italics original).
} 
exploitative, equally distorting ... one is left to ask whether it is ever possible to escape from patterns of representation which project one's own desires on to the object represented." ${ }^{20}$ She concludes that "in the end, [Mona's] otherness makes her subjectivity irrelevant: she serves as a mirror for those who look at her to see their own desires, or indeed as a screen for the author(s) to project what they/we choose. ${ }^{21}$ Whether it is a question of possession or identification, the viewer relates to Mona as a woman seen and thereby identified, if falsely.

Even the most recent work on Varda gets caught up in questions of the body as a seen object, including recent investigations into the haptic eye. Ruth Hottell, in a 1999 article building off the work of the three scholars mentioned above, adds a discussion of landscape and movement to her analysis but for the most part continues to emphasize the importance of the gaze, specifically pointing out the influence of Mulvey's article on Varda's work:

Varda presents us with woman's image demystified and the effect is far from soothing for the other characters, particularly for the men. She upsets the trajectory of objectification and its bolstering of the system, and turns the look back toward the camera and the spectator. Varda answers Mulvey's critical call for she breaks down the cinematic codes and their relationship to external structures, hence challenging mainstream film and the pleasure it provides. . . With the alienated and alienating Mona, the film disrupts the classical structure of the look and narrative because she refuses that place culturally assigned to the woman. ${ }^{22}$

Hottell's Mona disrupts the system because she is a woman "demystified." Yet she is still primarily a woman seen, her alienation related to the viewer's expectations of femininity. In a 2013 article Kate Ince calls for a move beyond a feminist approach to Varda's films, suggesting that "[Varda's] feminism - if it may be so called - is of a very particular kind, a sort of politicized bodily sensibility that has only lately come into focus in critical writing about film,

\footnotetext{
${ }^{20}$ Ibid., 120.

${ }^{21}$ Ibid., 134.

${ }^{22}$ Ruth A. Hottell, "Flying Through Southern France: Sans toit ni loi by Agnès Varda," Women's Studies 28 (1999): 692.
} 
under the influence of phenomenology. ${ }^{, 23}$ Following Delphine Bénézet, she therefore brings a phenomenologist approach to her readings of several of Varda's later films as well as 1961 's Cléo de 5 à 7, contending that Varda's films consistently "focus on screen women as embodied subjects of their own experience and desire." ${ }^{24}$ Indeed, while neither Ince nor Bénézet spends much time on Sans toit ni loi, Mona easily slips into the fold of Varda's other strongly embodied 'screen women,' who include Cléo as well as Varda herself. Yet here too the focus remains on Mona as a woman and as a body inspiring desires, even if they are her own.

\section{A hidden figure}

Throughout the film, Varda plays upon and against audience expectation in several ways as she frames and presents Mona within her surroundings. Rather than revisit how the gaze fails to identify Mona, this section will explore how Varda frames her protagonist in ways that pointedly distract the gaze away from her body. Mona's body is often portrayed such that our perception of her as a whole remains either incomplete or clouded, particularly through the use of mirrors, close-up shots, and costuming that obscure the gaze. Indeed, as her body is obscured, so too is her femininity. Mona is not a woman seen so much as a hidden figure, a body that in many ways merges with its surroundings.

Mirrors are among the elements that often appear in the frame with Mona and that add to a sense of distortion around her figure. ${ }^{25}$ She first appears in a mirror after being dropped off by a truck driver who refuses to let her ride unless she offers him something in return. She makes an obscene gesture at him as he drives away and appears briefly in the side mirror of his truck, as

\footnotetext{
${ }^{23}$ Kate Ince, "Feminist Phenomenology and the Film World of Agnès Varda," Hypatia 28 no. 3 (2013): 603. ${ }^{24}$ Ibid., 613.

${ }^{25}$ As Flitterman-Lewis and Smith have both noted, a similar effect occurs in Cléo de 5 à 7, Varda's earlier film from 1962 which also features a strong female protagonist. Smith clarifies that while mirrors in Cléo reflect and double Cléo, mirrors in Sans toit ni loi obscure and negate Mona. Cléo is a particularly interesting comparison to make with Mona, as she is very much a woman seen.
} 
the window of the truck quickly closes over her reflected image (Figure 2.2). Later, when she walks into a café, she passes behind a mirrored column three times, each time disappearing behind the reflection of a young man playing a game of foosball in the background (Figure 2.3). When she crosses the café a fourth time she walks in front of the mirror and is reflected in it for a moment. In the chateau with David, a young man she has briefly fallen in with, she writes their names in the dust across a large mirror, dust so heavy that you can barely see her reflection even after David wipes his hand across it (Figure 2.4). Mirrors also often appear in the frame with Mona without reflecting her, including the side mirror of a car that picks her up in the snow. In addition, Mona occasionally appears in or through the glass of doors and windows, including the window of the trailer where she stays at the goatherd's, through which she appears amidst the reflections of trees. Later, in an apartment she briefly occupies with the Tunisian worker Assoun, Mona is reflected in the glass of the doorway, through which we can also see the dirty sink (Figure 2.5). Each time that Mona appears in, or is hidden behind, a mirror or piece of glass, the viewer's perception of her must be slightly readjusted to acknowledge either her fragmentation or her doubling. These visual distortions reinforce Mona's non-cohesiveness as a body: she is both more and less than the figure we see most often. As she is reflected she merges with her surroundings, and they absorb and overtake her. Varda's mirrors serve to visually reinforce the viewer's misperception of Mona, not only in terms of her body but in terms of her actuality in time and space. Mona is indistinguishable from her reflection, becoming a part of the landscape. The reflection in the café mirror is a particularly useful example of this concept; as Mona passes the mirror, her body merges with the body of a man reflected beside her (Figure 2.3). 


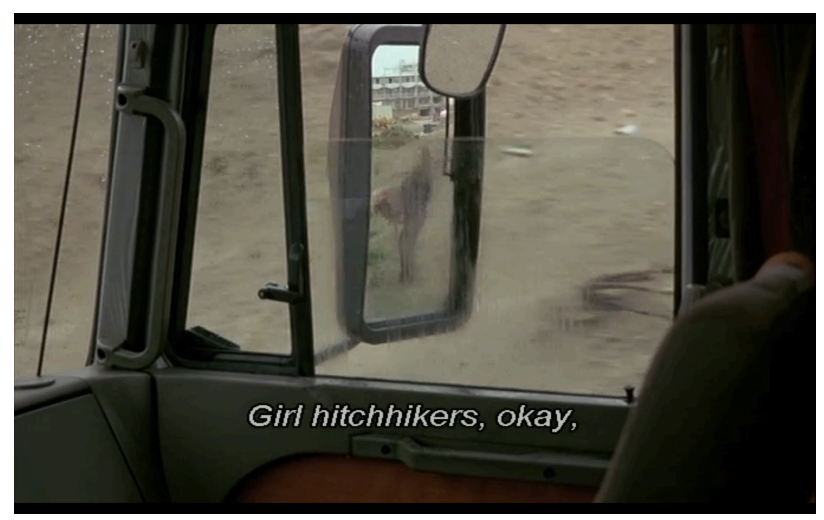

Fig. 2.2

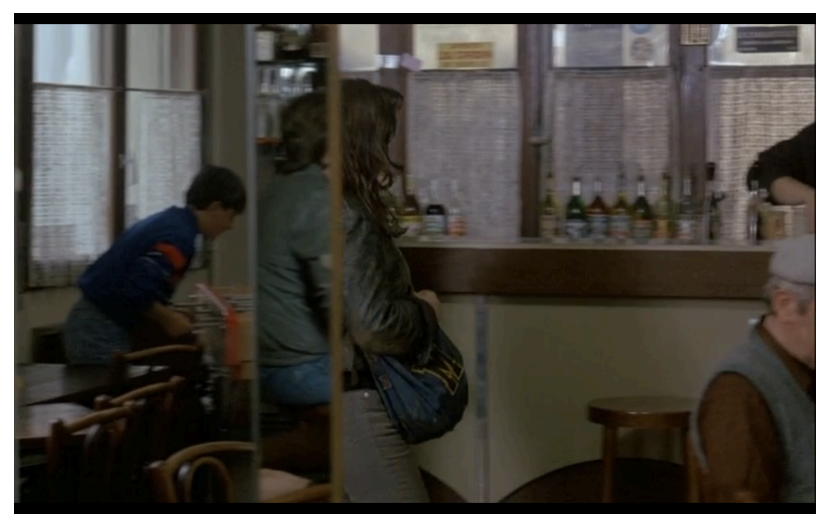

Fig. 2.3

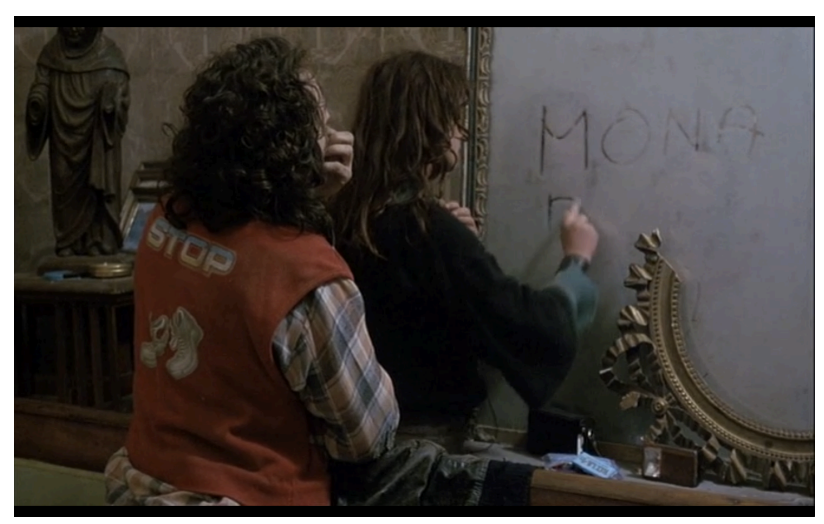

Fig. 2.4 


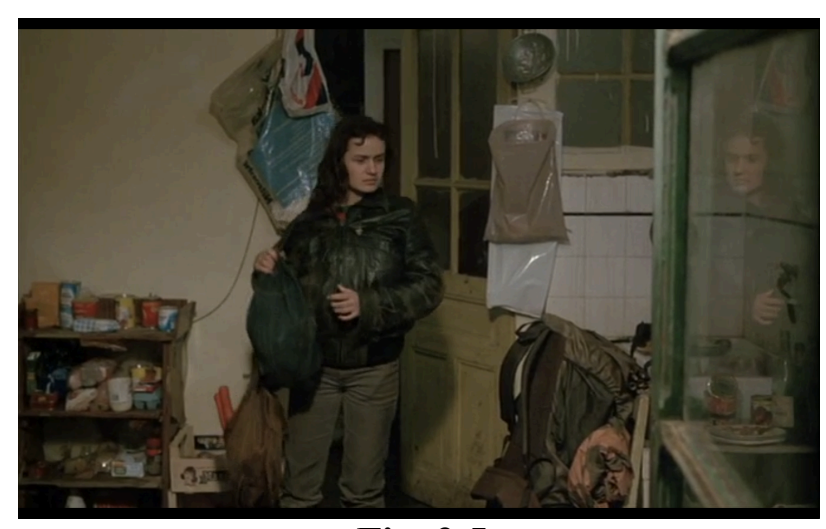

Fig. 2.5

Varda also frames numerous shots in close-up on Mona's hands or feet, in such a way that Mona as a complete body temporarily disappears. Many of the shots are striking, including the close-up of Mona's hands directly across from those of an older woman she meets, identically folded but ragged and dirty in contrast to the other woman's perfect manicure (Figure 2.6). There are repeated close-ups of Mona's hands rolling cigarettes, or her feet walking as her boots slowly deteriorate. We watch Mona's hands open a sardine tin as she sits alone in the woods (either immediately before or after her rape), and later see her caress the blisters on her hands following a day of work in the vineyard. Her hands zip up her jacket, or her boots, and the dirty boots themselves are framed on the pure white of a bed on which she temporarily rests. In another striking frame, which subverts the concept slightly, we see Mona's arm as she donates blood, framed by the hands of the technician and the image on Mona's shirt of a hand pointing directly at the needle (Figure 2.7). ${ }^{26}$ In each of these frames, Mona must be reconstructed from a very restricted view, if she is to be reconstructed at all. ${ }^{27}$ Deleuze again argues for the discontinuity of time as well as space that also accompanies the close-up, writing that: ...the close-up does not tear away its object from a set of which it would form part, of which it would be a part, but on the contrary it abstracts it from all spatio-temporal co-

\footnotetext{
${ }^{26}$ In the previous frame Eliane has just wondered to Jean-Pierre if Mona might have been "une droguée," making it all the more jarring to see Mona with a rubber band tied around her upper arm and a needle in her vein.

${ }^{27}$ The music that accompanies Mona's travels is also described by its composer, Joanna Bruzdowicz, as "fragmented" (Music and Dolly Shots, dir. Agnès Varda. 2003. New York: The Criterion Collection, 2007. DVD.).
} 
ordinates, that is to say it raises it to the state of Entity. The close-up is not an enlargement and, if it implies a change of dimension, this is an absolute change: a mutation of movement which ceases to be translation in order to become expression. ${ }^{28}$

If Mona's hand, or foot, or the crook of her elbow becomes the Entity of the shot, her entire identity is subsumed by the sudden importance - or expression - of the hand, foot, etc. Thus Varda changes the direction of the gaze on the character by refusing to allow an easy identification, even of where Mona is located in space, by negating all supporting evidence of location and instead narrowing the viewer's world to the immediate vicinity of the chosen, abstracted body part. The body is fragmented and misplaced.

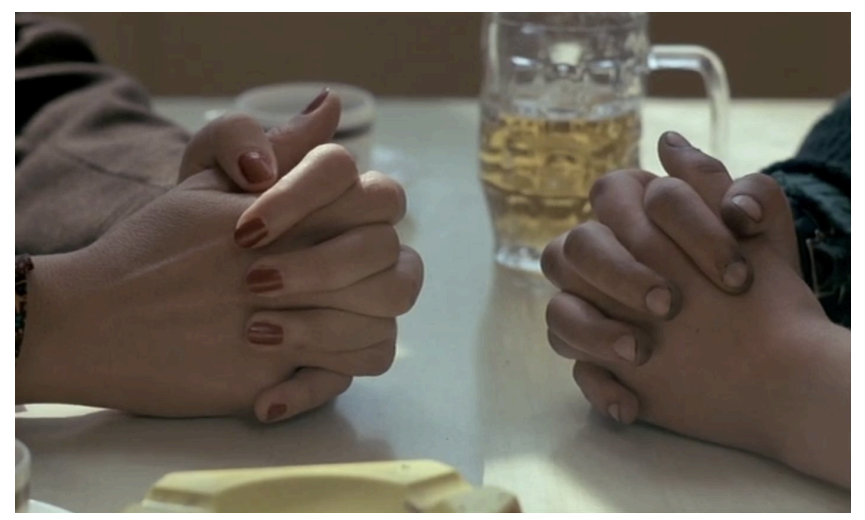

Fig. 2.6

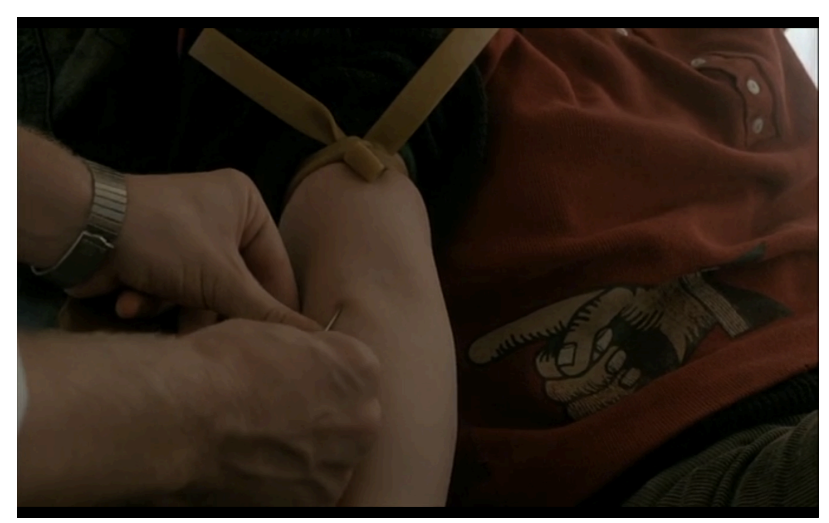

Fig. 2.7

${ }^{28}$ Deleuze, Cinema 2: The time-image, 95-96. 
Both the basic crystal-image of the mirror and the entity of the body shot in close-up are examples of what Deleuze terms “affection-images.” Calling upon C. S. Peirce's ideas of firstness and secondness, with firstness referring to something that is felt rather than understood as being in opposition to something else, Deleuze writes that "affection-images, in the strict sense, only refer to firstness. ${ }^{, 29}$ In other words, the affection-image of the close-up being the first point of entry into Mona, every time it occurs Varda (according to Deleuze's definition) is calling on a more primal reaction to her being than that which will follow once the image is intellectualized. We are not hypothesizing or even really seeing the body, just its abstract representation. Indeed, it is often nearly impossible to determine whether the body as partially seen is male or female.

Even when Mona's body appears more or less whole in the frame, it is almost always concealed - and thereby de-feminized - by a series of elements that include clothing, dirt, and accessories. The first image of a living Mona is an extreme long-distance shot of her on the beach, entirely naked. Here she is very clearly a woman seen, a point highlighted by the crude commentary of the two men who see her, who are also shown buying a postcard featuring similarly nude women. ${ }^{30}$ The second image, however, is a slightly closer shot of Mona mostly dressed, wearing a white shirt that will never again be seen beneath the other layers of clothing and pulling a second layer, a green sweater, over the top. Following these two shots the layers of clothing and dirt continually build up on Mona's body until a final coating of wine dregs is added in the hours before her death. The combination of jeans, boots, white shirt, green sweater, and black jacket that cover her body in the first tracking shot stays constant until she meets a young man, David, with whom she spends some time in an abandoned chateau. While there she

\footnotetext{
${ }^{29}$ Ibid., 99.

${ }^{30}$ Emphasizing the crudeness of the encounter, the two men joke about how one might have the naked woman (i.e., on the postcard), for the price of 2 francs.
} 
steals a black wide-sleeved sweater and a red vest with the word "STOP" on the back. She temporarily picks up a red scarf at one point but leaves it behind, and borrows a pair of slippers that likewise do not last. Other than these accessories, once clothes are added to her shape they never (visibly) leave her body. Instead, the clothes start to shift in form as they deteriorate, thus not only obscuring Mona's body but also changing her silhouette. Already by the third tracking shot Mona begins to fiddle with the zipper on her pants, adjusting it as she walks; by the time she reaches the train station around the tenth tracking shot the zipper has completely broken. By the fourth tracking shot her boot starts to fall apart; one fails completely in the seventh tracking shot, and by the eleventh both have fallen around her ankles and drag alongside her feet as she walks. In the tenth tracking shot, the zipper on her jacket sticks; by the twelfth she has lost the jacket completely running from a fire. ${ }^{31}$ The last layer she gains is a blanket, which adds some warmth but ultimately is open to the elements and not much protection. All that remains after this is the plastic body bag into which the policemen load her frozen body the next morning.

As she becomes progressively more covered in clothing, Mona also becomes progressively more covered in dirt. The characters she meets often point out, either to her face or in their testimony, that Mona is unclean. The goatherd she stays with for a few days comments, for example, that the trailer he gives her gets dirty, while the prostitute she meets on the road suggests to Mona that she really needs a bath. Mme Landier, who also spends a few days in Mona's company, describes Mona's dirt and smell multiple times. The foreman's wife remarks that Mona never washes her clothes. Mona's hands, when seen in close-up, have dirt under the fingernails, and her hair becomes more and more matted. On her last afternoon, she gets caught in the middle of a wine festival and has wine dregs thrown over her; as a result, her face,

\footnotetext{
31 A fire started, oddly enough, by David, the man from whom she has taken the black sweater and red vest that now become her uppermost protection against the cold.
} 
clothing, and hair are covered in a reddish substance. Hottell notes that "Varda has described Mona's demise in terms of her protectionary layer of grime - she sees Mona's death as the result of the ultimate filth imposed upon her." 32 As her silhouette changes, so too do her smell, her hair, and her skin. No part of her body can be seen beneath the clothing and the dirt. ${ }^{33}$

In addition to the concealment of Mona within the frame, the audience's perception of Mona's body is further problematized by the dissociations of time, place, and truth that Varda incorporates into the film. The audience primarily views Mona through the eyes of alternate characters, who because of the inherent subjectivity of memory present at best partial truths and at worst complete fabrications. The camera works among these iterations and often seems to come closer to some sort of "true" portrait of Mona. Yet ultimately the contradictions among the various versions of Mona serve to further establish her as a character who cannot be seen. Flitterman-Lewis writes that "finally, we become absorbed in the observational process ourselves, constructing our own fictions of Mona, as well as of the people she meets. In this way, the discursive threads of the text reach out and weave us in, embracing us as viewers while simultaneously keeping us away." ${ }^{34}$ Varda strengthens this double sense of attraction and repulsion by playing with these discursive threads and creating, through multiple techniques, an overall sense of narrative uncertainty that makes it virtually impossible to definitively pin Mona down.

Among the most noticeable elements of narrative confusion are the enigmatic jumps in time and space that occur throughout the film. The film itself is structured as a flashback, as Mona's corpse sets off the series of interactions through which she, still alive, will be re-

\footnotetext{
${ }^{32}$ Hottell, "Flying Through Southern France," 688.

33 "Mona assumes her filth just as she assumes her marginality, she answers to no one and thanks no one." Hayward, "Beyond the gaze," 287.

${ }^{34}$ Flitterman-Lewis, To Desire Differently, 306.
} 
constructed. The early sequence that introduces Mona is indicative of many of the jumps that will follow, as Varda's voiceover posits that "il me semble qu'elle venait de la mer" and the image shows the naked Mona emerging from the sea. Instantly the camera jumps several days forward to show another naked woman on a beach, this time on a postcard being examined by the same man who ostensibly watched Mona bathe. The next shot is again of Mona on the beach, clothed, but being discussed by the male observers. This early juxtaposition of different times and places, linked by the male observer and the carefully framed image of a nude woman emerging from the water, serves notice to the viewer that despite the documentary-like aspects of the film, the camera may not be playing a truly impartial role. The odd juxtapositions of character testimonials continue throughout the film; note, for example, the series of shots that occurs between the young woman priming the pump for Mona and her later assessment of Mona at the dinner table, in which we see 1) a close-up shot of Mona's hands rolling a cigarette; 2) a wide shot of Mona rolling the cigarette while sitting on a pier in the river, with an empty road behind her; 3) a wide shot of Mona walking up to a building and knocking on the door; 4) a close-up shot on Mona and an older man who goes to find her matches; 5) Mona staking her tent in the graveyard. By the time the sequence is finished, it is no longer possible to identify where Mona is, what time it might be, or even whether the various elements are running on the same timeline at all.

Varda also makes use of both diegetic and extra-diegetic sounds, often in extremely jarring ways. For example, Joanna Bruzdowicz's extra-diegetic soundtrack occurs only in very specific contexts, namely the long right-to-left tracking shots which define and punctuate Mona's journey. Aside from this recurring theme, the only other music in the film comes from a radio or jukebox, machines on which Mona tends to fixate whenever they are available to her. Often 
Mona herself turns on the music. Yet the music, supposedly part of Mona's surroundings, is instead often treated as another element to be questioned by the viewer. For example Mona and David turn on a radio while kissing inside the chateau, and the music continues to play as the shot switches to show another couple, Yolande and Paolo, in a bedroom also listening to a radio. The song ends, and a new song comes on the radio. So far the two couples could conceivably be listening to the same station, but immediately after the start of the new song the shot switches back to David and Mona, now outside and smoking and wrapped in blankets. For a few seconds the song continues to play, but then stops abruptly. Any sense of reality has been negated by the lack of continuity, and the difference between extra and intra-diegetic music has been oddly blurred. This jarring aural sequence occurs again as Mona rides in the car with Mme Landier. Mona again turns on the radio, and the song continues without pause as the shot changes from a profile of Mona to a wide shot of the car travelling down a road, to the car parked and Mona's hand rolling a cigarette, to Mme Landier returning to the car with treats. Again the music cuts off abruptly, this time when Mme Landier turns it off. The music seems to float without warning between intra- and extra-diegetic soundtracks, subtly affecting the viewer's perception even if the exact nature of the discord remains in the background. Occasionally the same effect occurs with dialogue: Mona's conversation with the goatherd and his wife about their young son's future education and her interest in farming, which seems continuous, is spread across three discontinuous scenes with abrupt changes of setting from outdoors to indoors and back again.

Another startling aspect of the film is the intersection of documentary and fiction, most notably as encapsulated within the interviews ostensibly given by the characters who meet Mona and who relate their memories of her either in direct or partially direct address to the camera. ${ }^{35}$

\footnotetext{
${ }^{35}$ A thorough discussion of the different modes of address seen in the film can be found in Flitterman-Lewis, To Desire Differently, 304-305.
} 
Although many of the 'witnesses' give their accounts of Mona, the camera often seems to be conducting its own investigation and its presence in certain parts of Mona's experience cannot be explained. In other words, the viewer cannot always determine the difference between what the camera sees (such as the accounts given by the witnesses) versus what the camera is purposefully reconstructing in order to give a visual impact to their testimony; the camera's perspective is omniscient, yet highly constricted by the memories of the witnesses and by its inability to stay with Mona. Often the characters appear as if speaking to another character within the diegesis; for example, the daughter who primes the pump speaks to her mother, the garage mechanic recounts his story to an unidentified man, and Yolande's uncle speaks to a policeman. When these other characters are the recipient of the testimony, however, they are only ever seen in partial view; the mother can only be seen from waist to neck, while the unidentified man and policeman only show the back of their heads. Strangely, the goatherd (who tells his story long after Mona has already appeared with and been dissected by other characters) speaks more or less to his wife, but refers to the experience in the plural first person, as if his wife were not there (and in fact she can barely be seen amidst the goats.) Other characters speak directly to the camera, or so one must assume, given the absence of any other figure within the frame; David, for example, squats in a train car and recounts his impressions of Mona before the train pulls away. Of these, however, only two ever directly look into the camera: Yolande and Assoun. Yolande's direct address to the camera, which occurs five times, completely disrupts the tone of the film, especially when she breaks the fourth wall while other characters are still in the scene with her. Later, Assoun's mute appeal as he caresses the scarf Mona has left behind acts as another unsettling moment (Figure 2.8). Clearly the documentary conceit remains intentionally 
imperfect, as does the idea that the film is pure fiction; the viewer can no more get a handle on what kind of film it is than on the identity and form of the protagonist.

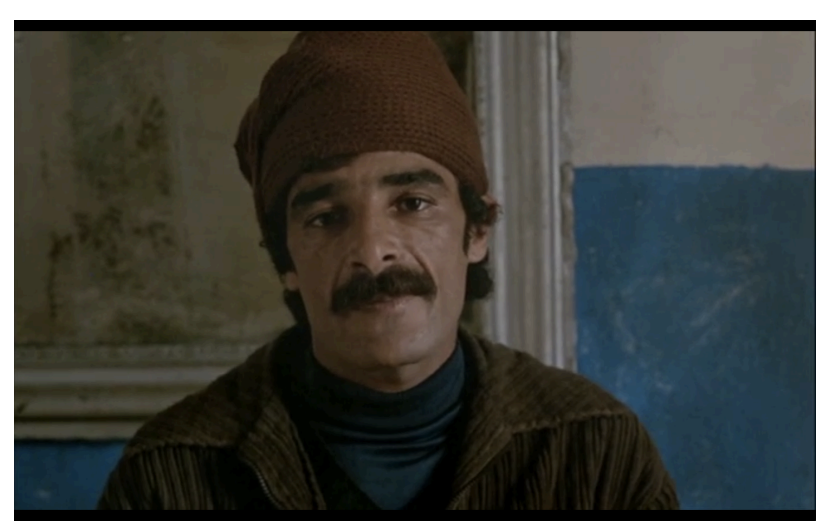

Fig. 2.8

Varda's cinematographic choices, along with the recollections of Mona that form the storyline, present the viewer with an unsettled and unsettling character, a young woman whose body remains hidden and hardly more identifiable at the end of the film than at the beginning, despite the time that has passed and the inquiries that have been made. The attempt to give some form, some character to the dead body without identification papers that gets thrown into a beggar's grave at the beginning of the film, fails. Despite the film being centered on Mona, Mona herself remains an unknown figure, fragmented and hidden and merging with her surroundings as they reflect or gradually engulf her.

\section{Champagne and the road, c'est mieux}

As Mona's body is hidden, the result is to turn the focus away from her body to her surroundings. Another way this change of gaze is emphasized is through Mona's movement, her wandering. While none of the scholars discussed above dismiss Mona's wandering entirely, rarely has it been the focus of analysis. In turning the approach to focus on Mona as wanderer it 
becomes possible to return to Varda's original conception of the film, which was "to make a film about road people/vagrants (male and female) in the winter, who perish from the cold." ${ }^{36}$ Mona embodies several characteristics of a vagrant or vagabond: she is a stranger, a blank slate onto which other characters project their expectations; she is an outsider, one who does not belong; she is a wanderer, one who is constantly on the move. This section will explore these different aspects of Mona's persona and how they establish her as a person stuck outside of the community: she walks among them but always at a remove, estranged. She inherits the tradition of the flâneur by walking through her native country and embracing her leisure, but to this tradition is added a darker element that stems from the inhospitableness of her surroundings.

As discussed above, despite the conceit of the film - the investigation into Mona's death and her life preceding it - Mona herself remains an indistinguishable form. All the viewer learns about Mona over the course of the film is that she likes marijuana and champagne, cares little for her appearance, is somewhat lazy, and gets along better with dogs than with people. She is an enigma: the witnesses who speak about their experiences with her are openly puzzled by their interactions with her. Hayward, as mentioned above, points out that "Mona refuses to be coopted into any image. In her refusal of all social discourses - which her preponderant mutism serves to reinforce - she defies identification.. ${ }^{37}$ Mona's ability to mutate is in part what makes her able to escape identification. It is not so much that she transforms - her only real transformation is to become progressively filthier as she travels - but more that she can sense the expectations of others and repeatedly, often intentionally, defeats them. Others react to her with a wide range of emotions - disgust, affection, desire, fear - but underlying each impression the basis for the connection is the same: each person that Mona meets identifies with her. They see within her

\footnotetext{
${ }^{36}$ Hayward, "Beyond the gaze," 285.

${ }^{37}$ Ibid., 286.
} 
elements of themselves, both positive and negative, and therefore their memories of her are both vivid and disturbing. What Mona most often represents to these characters is the embodiment of something - or someone - that they lack. To the people she meets, Mona is no one, a stranger, and as such she becomes a blank slate onto which they can (and do) easily project their own needs, desires, or fears.

As she travels, Mona encounters a relatively wide variety of people, from the well-off female professor Madame Landier to an unidentified male rapist. At times, as with the rapist, Mona represents lack in its most Freudian terms. Yet more often the depiction is more nuanced, or rather less overtly sexual, if no less Freudian at its base. For example, early in the film Mona interacts with a young woman who helps her prime a water pump in order to fill her bottle. On returning to her house, the young woman complains that she would prefer Mona's life to her own ("J'aimerais mieux m'en aller"). Her mother, setting food on the table, argues that Mona, among other things, clearly does not have access to food such as the daughter is currently eating, but the daughter responds: "Des fois ce serait mieux de ne pas manger. Moi, j'aimerais être libre." The young woman sees in Mona something that she desires: freedom. Here, Mona truly does embody what the young woman wants, at least to the extent that her wandering lifestyle could be considered free. This sort of immediate identification of and with Mona soon becomes a pattern, even in many of her most insignificant interactions. Yet Mona does not ever fulfill the expectations of those who met her; they project a certain image onto her, but the transference remains unrealized. She remains a stranger.

The unnamed goatherd, on the surface, could be considered the closest to Mona in terms of lifestyle. Educated and with a similar feel for living off the land, he too has spent time on the road and he openly sympathizes with Mona's rejection of the norms of society. And Mona does 
relate to him for a short time, confessing her perhaps nascent desire to own a piece of land and grow potatoes and even spending time trying to connect with his young son. The goatherd sees, in Mona, a younger version of himself, giving her advice and aid based on that identification. He offers Mona land, a trailer, and work, and cautions her about the dangers of continuing on her path of vagrancy. In return, she temporarily adopts his lifestyle, which he calls a "un milieu, un moyen terme entre la solitude et la liberté." In Mona, the goatherd also sees the life he could have chosen, with more freedom (he describes Mona as "plus libre que moi") and no family. Notably, he also projects his fears onto her, for Mona's comfort with solitude is more than he can stomach. Yet the sequence with the goatherd also provides a clear example of mistaken identification; Mona claims to want land and potatoes but ultimately rejects them, preferring to eat, read, and sleep instead of work. The goatherd tries to show her a different road - his - but fails. He sees in her both his younger self and the alternate path he could have taken, but Mona is neither. In the end, he is completely unable to affect Mona in any way; she is not the person he thinks she is.

In contrast to the goatherd, who sees in Mona the life and choices that were his in the past, David and Yolande are both attracted to Mona because she embodies something that they do not or cannot have. David, who is acknowledged in the credits and in his own words as "le juif errant," considers Mona "une casanière. . une qui s'accroche" or, in other words, the complete opposite of himself. He believes that she can provide the stability that he himself cannot embody, but he too is wrong: Mona proves to be as much of a wanderer as he. In turn, Yolande believes Mona to be one half of a loving relationship, both a lover and, more importantly, one who is loved (i.e. by David.) Yet over time she finds Mona to be not only not particularly attached to David, who has disappeared by the time Yolande brings Mona home, but 
also disrespectful of love in general, or at least the love that Yolande imagines between herself and her boyfriend Paolo. Both David and Yolande believe initially, and with little justification, that Mona embodies traits opposite to their own and that as such she would make a good companion. However, as with the goatherd, Mona proves them wrong; she does not provide balance for them any more than she provides the goatherd with a justification of his life choices.

These mistaken identifications and the ensuing disappointments gain in complexity as the film progresses. When Madame Landier encounters Mona, she first sees her as the opposite of herself in the very basic terms of dirt and smell (as do we, as we hear Mme Landier gossip about Mona's filth while sitting in a bathtub). ${ }^{38}$ Once she gets used to Mona's smell, however, Mme Landier treats her as an excuse to cut loose, to buy cigarettes although she does not smoke, to steal food and champagne from a conference, to sit in the car and eat chichis. She even makes awkward and repeated attempts at jokes that are at odds with her otherwise uptight persona (punning, as Mona often does, that one needs “du blé pour du pain.”) In fact, Mme Landier's interaction with Mona resembles nothing so much as a mother trying to connect with her daughter, and indeed for Mme Landier Mona represents the daughter that she does not have. She therefore offers her work advice, food, and money, and keeps insisting that Mona is comfortable "chez elle" (meaning in the car); she clearly wants to be liked by this dirty ragamuffin and takes on quite a bit of responsibility for her, letting her spend the night in the vehicle and ride with her for the better part of two days. Yet the mother-daughter relationship is only maintained in the abstract; in all that time, Mme Landier does not ask Mona her name. Instead, she treats her like an object or something to be studied, keeping her in the car and showing her off behind glass. Mona may thus also represent not just a surrogate daughter, but also a mammalian version of

\footnotetext{
${ }^{38}$ Another naked woman emerging from water, though this time without any of the mythological, Aphroditic implications.
} 
Mme Landier's beloved plane trees: an infected specimen to be saved, if possible. She even refers to her in plant-based terms, telling her assistant Jean-Pierre that Mona has "taken root" in her car. Mona, of course, does not stay either in the car or behind glass, instead getting out to talk to Jean-Pierre face-to-face when he comes to peer in at her. Further, the relationship does not work the other way; Mme Landier certainly does not represent a mother to Mona, who accepts her help but does not seem particularly perturbed or abandoned once Mme Landier drops her off. Mme Landier's connection to Mona is so strong that when she electrocutes herself a certain time later (the exact timeline remains unclear) she claims that visions of Mona haunt her "comme une reproche" and orders Jean-Pierre to track her down. The eventual disconnect between Mona and her would-be mother is only further heightened by Varda's staging, which has Mona riding in the backseat of the car in the last scene between the two women. Previously she has been in the front passenger seat, side-by-side with Mme Landier and therefore equal in terms of cinematic plane. Once she moves to the back, a change which Mona herself comments upon, any equality between them is broken, and any hope for a lasting identification disappears. ${ }^{39}$

When Mona meets Jean-Pierre, he is immediately both attracted to and repulsed by her wildness; he carefully approaches the car in which she is encased and she pointedly asks him whether or not he is afraid of her (as her hair, not incidentally, blows wildly in his face). Later, when he sees a drug-addled Mona acting out in the train station, Jean-Pierre will be even more overtly scared and disgusted by her, telling his friend on the phone that "elle me fait peur parce qu'elle me dégoûte.” In this case, Mona is placed in clear opposition to something - or rather someone - that Jean-Pierre does have: his wife, Eliane. The hair of the two women marks the first point of comparison, as Jean-Pierre tells Eliane how Mona's wild hair made him think

\footnotetext{
${ }^{39}$ Smith suggests that the Mme Landier/Mona relationship represents the interaction between Varda and the homeless woman, Settina, who in part inspired the film. Smith, Agnès Varda, 128.
} 
(fondly, we hope) of Eliane's smooth tresses (as Hayward notes, "Eliane rightly reads the subtext and refuses to make love.") ${ }^{40}$ Eliane also first appears in the shower, her cleanliness like that of Mme Landier in direct opposition to Mona's dirtiness. In addition, however, Mona's wildness stands in contrast to Jean-Pierre's own lack thereof; he exudes cleanliness, dresses neatly in collared shirts and sweaters, uses a handkerchief (whereas Mona uses her hand to blow her nose), and even appears to be cleaning the tree he is taking a sample from. Thus for Jean-Pierre, Mona represents two lacks: the wildness or sense of abandon that both entices and frightens him, and the embodiment of such in a wife-figure. Varda's staging again highlights the imbalanced interaction between the two, as Hayward notes: while Mona is behind glass when they first meet, Jean-Pierre ends up enclosed in the glass phone-booth in their last interaction. Mona's presence not only reveals to Jean-Pierre the perhaps latent desires he would rather not acknowledge, but in fact forces him, literally, into a constrictive box from which he cannot escape.

The pairing of Mona and Eliane continues into their respective relationships with JeanPierre's aunt Lydie, whose home Yolande looks after and into which she brings Mona after seeing her hitchhiking in town. Eliane sees the old lady only as an impediment to her gaining a larger home and is never seen interacting with her directly, instead just staring at her from a distance. Mona, on the other hand, invades Lydie's space but also becomes her (temporary) friend, perhaps a surrogate granddaughter, sharing jokes over brandy and laughing as if they had always known one another. She is the only person for whom Lydie leaves her armchair; again, as with Mme Landier, the two women are placed on the same cinematic plane as they sit closely together on the couch. In fact, Mona takes on several roles with regard to Lydie, first borrowing the room of Lydie's deceased sister Marcelle (whose photographs also spur their conversation) and also first appearing to the half-blind old lady as Yolande by wearing the latter's robe and

\footnotetext{
${ }^{40}$ Hayward, "Beyond the gaze," 287.
} 
carrying her duster. In this case too, however, Mona fails to meaningfully embody relative, housemaid, or friend; in fact her presence actually ends up being destructive, providing Eliane with the reason that she needs to fire Yolande and throw Lydie into a retirement home. As with her earlier interactions, once again Mona briefly embodies expectations and then moves on.

Finally, we must consider Mona's time with Yahiaoui Assoun, the Tunisian vineyard worker for whom Mona represents the wife or child he lacks. We learn from Assoun himself that all of his fellow workers have gone to visit their families back home, which is why he gets permission to integrate Mona - again temporarily - into his home. His interactions with her are entirely (to our knowledge) non-sexual, but very caring: he carries her bag, cooks for her, gives her permission to go outside while warning her to bundle up, and instructs her in her work. When Mona approaches him in a potentially sexual manner, touching his face, he instead takes her hand and comments that she has hurt herself working. Whether Mona represents wife or child, Assoun's relationship to her is clearly, and somewhat surprisingly, one of love. Again, the two characters are often shown on the same plane, sitting side by side at the dinner table and standing together on the back of the tractor on their way to work. Assoun asks Mona to stay level with him in the field, even if it means more work for him, presumably so that he can watch her and speak with her as they work. Further, Mona herself chooses to momentarily identify with Assoun, mimicking him by wrapping a red scarf around her head as they head out to work. However, despite this brief equivalence, the cohesion between the characters does not last; Mona almost immediately pulls the scarf down around her neck, and later she purposefully moves her seat at the table so as to face her benefactor rather than sit by his side. ${ }^{41}$

\footnotetext{
${ }^{41}$ Varda: "I work on behavior ... gestures, details. I told Sandrine just how she should touch the strap of her backpack, how she should put it down, how she should fix her boot on a tree-stump, or hold the ruined painting. . . I would often make her repeat the same gesture over and over again. I demanded a very precise kind of action. ... But finally the character of Mona emerged." Flitterman-Lewis, To Desire Differently, 223.
} 
Nonetheless Assoun's experience of Mona varies slightly from the others, for Mona does not leave of her own accord; instead, she is forced out by the return of Assoun's roommates and for the first time she is truly unhappy about it. For some reason, Assoun's apartment represents a place where Mona could perhaps be happy, and although she does not explicitly enunciate her desire to stay she does explain to the overseer's wife that Assoun "est gentil - il a de bons yeux." He is also the only other character to whom she offers her full name (Simone Bergeron). Her anger at Assoun is one of the few emotions Mona displays in the film; for once she appears to care about her own status with regard to someone else. In fact, Mona's relationship with Assoun reverses the direction of the transference - whereas the rest of her interactions involve characters projecting their desires and needs onto Mona, in this case Mona seems to project her desire for protection and maybe even love onto Assoun. Her anger stems from his failure to live up to his promise to take care of her, and her disappointment is highlighted by a close-up of Mona, standing still, with tears in her eyes (a shot later echoed in a brief, wordless "interview" with Assoun in which he caresses the scarf Mona had worn and, sadly, stares directly into the camera.) The impact of this particular interaction on Mona is not accidental, and will be explored later in the chapter.

In addition to being a stranger, an unknown quantity onto which other characters in the film project their expectations and hopes, Mona is also marked as an outsider in a literal sense. She is often forced to wait outside while other characters enter buildings or homes; when she does find shelter, it is almost always exposed to the elements. As Hayward notes, "walls, doors and shutters almost invariably shut Mona out, only at best do they conceal her from the police."42 She regularly appears as the only human framed in wide shots amidst a vast, neutral-toned landscape. The first shot of Mona exemplifies these wide frames, as we see her in the distance

\footnotetext{
${ }^{42}$ Hayward, "Beyond the gaze," 293.
} 
amidst sand dunes, the sea behind her (Figure 2.9). Sometimes she is so far away she can only be identified by her large backpack. Other characters, meanwhile, are never seen alone in the frame; even those who live by themselves (such as the old man who gets matches for Mona) share the frame with Mona when she arrives.

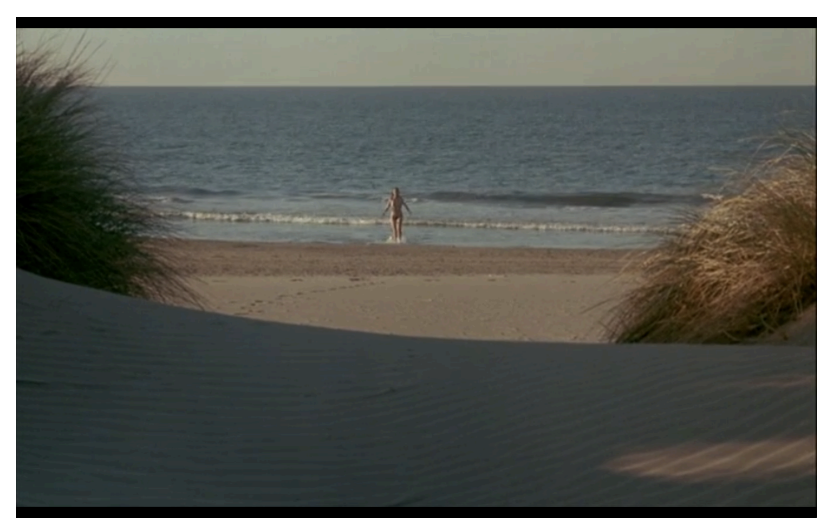

Fig 2.9

The motif of doors and windows being closed against Mona is prevalent in the film. Even Assoun, her protector, shuts the door on Mona when he asks his foreman whether or not she may stay with him for a night; later, he leaves her sitting on a pile of sacks while he goes to fetch her belongings from his room (Figure 2.10). Mme Landier, another temporary protector, leaves Mona outside in her car when she stops at the store, at a worksite, and at a conference, once leaving her there to sleep. The goatherd and his wife let Mona stay in their house for a night, but soon relegate her to a trailer outside; the wife shuts the door against her twice (Figure 2.11). Indeed, when Mona does find shelter it is often only partially "inside"; the trailer offered by the goatherd is enclosed, but barely, and the chateau she stays in with David has broken windows and no heat. She finds temporary refuge in a bungalow, but it too is unheated and she is 
awakened by the roof being torn off. The radish house where she spends her last night has a door that barely closes, and is made of plastic, little protection against the cold.

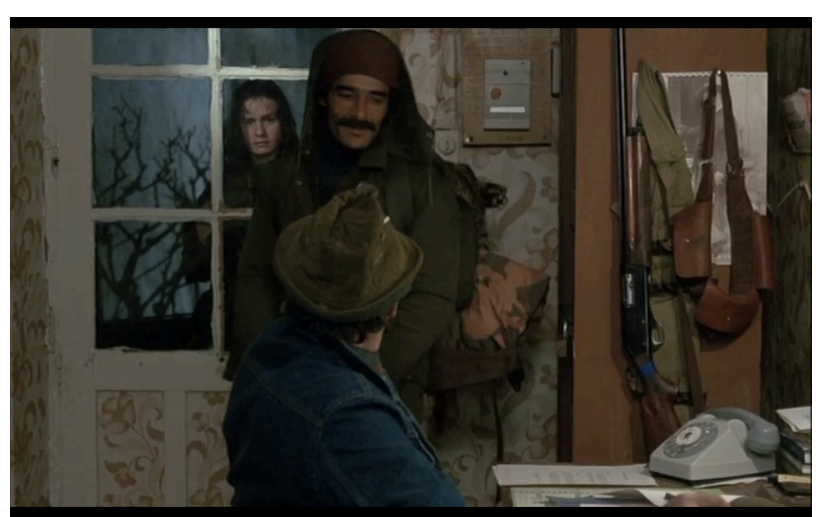

Fig. 2.10

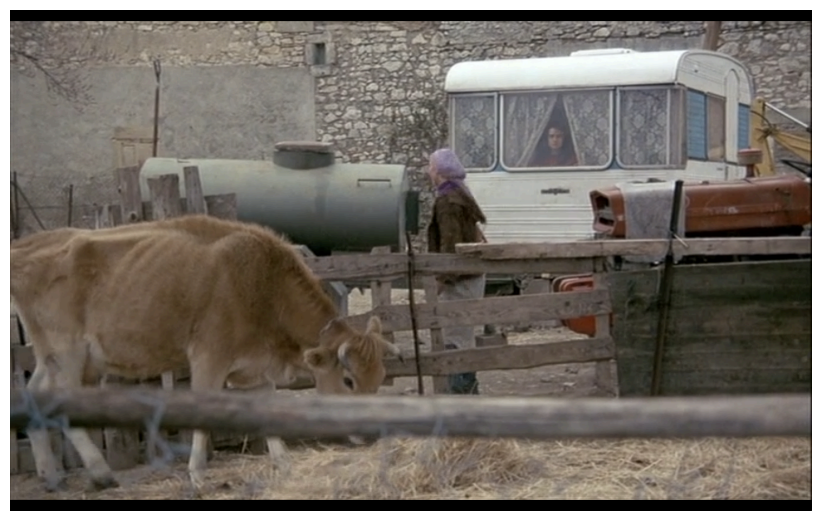

Fig. 2.11

In the most deliberate example of Mona's status as outsider, she is attacked by villagers celebrating a festival known as "La fête des paillasses" that Ruth Hottell describes as "the custom in Cournonterral-sec of drenching outsiders in wine-dregs. ${ }^{, 43}$ Much has been made of the fact that the ritual is misogynistic, with only men permitted to participate (Hayward refers to it as a "patriarchal pagan rite.") ${ }^{44}$ However, the ritual also emphasizes the inside/outside nature of the community, as the insiders - the inhabitants of the village - are tasked with demonizing the

\footnotetext{
${ }^{43}$ Hottell, "Flying Through Southern France," 688.

${ }^{44}$ Hayward, "Beyond the gaze," 291.
} 
outsiders. Interestingly, here Mona's only refuge is within a glass telephone booth, nominally "inside" though very much outside the understanding of the proceedings and certainly not very comfortable (Figure 2.12). Hottell recounts an anecdote from the filming of the scene in which Varda's crew was itself doused in wine dregs, suggesting that "the actual villagers' contempt for outsiders becomes a metaphor for the contempt the Order holds for foreign agents like Mona."45 In this, the last episode of the film, Mona is forced to recognize her own outsider status; she becomes overwhelmed by the festival, is drenched in liquid, loses most of her remaining belongings, and stumbles away very close to death.

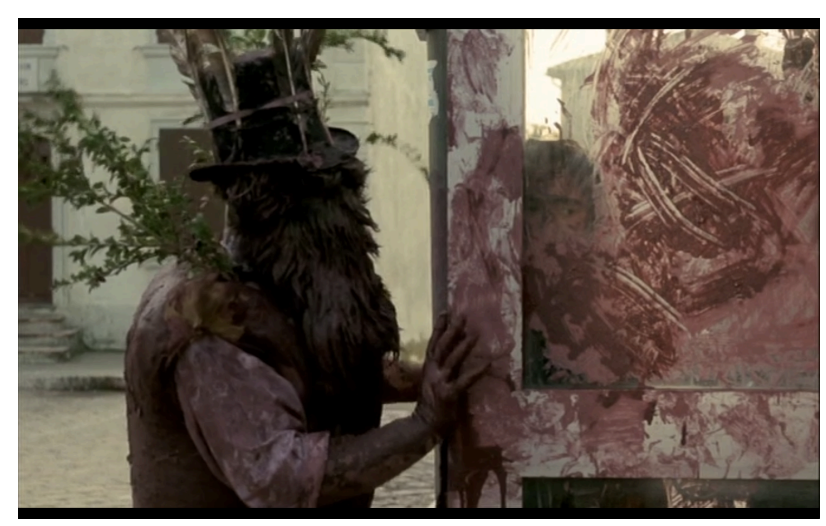

Fig. 2.12

Mona is also an outsider in that she does not seem to fit in with the people surrounding her. Often, as at the mechanic, in the café, or at Assoun's workplace she is the only woman present. She does not identify with other women in the film, who take on the various roles of wives, daughters, prostitutes, professors, maids, even nuns; the only close approximation to Mona's role is the other female drifter who appears at the end of the film. ${ }^{46}$ Hottell also points out the usefulness of Varda's title in emphasizing Mona's outsider status: "she has chosen a title which carries significance in common French expressions - 'sans foi, ni loi,' (literally, without faith or law') refers to someone who obeys no laws, who fears neither divine nor human justice.

\footnotetext{
${ }^{45}$ Hottell, "Flying Through Southern France," 694.

46 This actress is credited as "Setina" and is in fact the homeless young vagabond who inspired Varda to write and film Mona's story.
} 
In using a title so close linguistically to the well-known expression, Varda announces in advance the defiant nature of Mona, the outsider."47

Finally, the third aspect of Mona's persona is her status as a wanderer. The most evident cinematic indicator of Mona's movement comes in the series (referred to by Varda as the "Grande Série") of 12 tracking shots that structure the film, accompanied by music by the composer Joanna Bruzdowicz. Almost all writings on the film refer to Varda's use of this tracking technique, all the more so after Varda herself revealed her intentions in the short film Music and Dolly Shots (2003) included as a supplement to the 2007 Criterion release of the Sans toit ni loi DVD. ${ }^{48}$ Varda explains in this short that she intended the 12 travelling shots to be linked by the objects on which the camera begins and ends its journey, that she hoped viewers would notice "un rapport entre les travellings" that would put the focus more on the journey than on the encounters that interrupt them. The music, then, becomes a reminder of the journey, as there is "music when Mona walks and only when she walks." In fact, Varda sums up the film as follows, referring to the title of Bruzdowicz' piece: “au fond il y a une seule chose qu' on peut

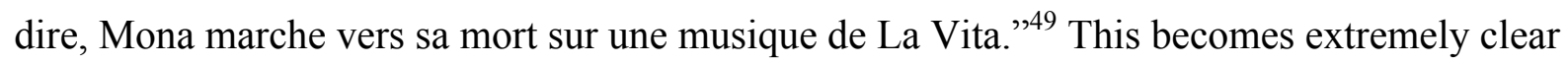
when the 12 tracking shots are watched back to back, as Varda presents them in Music and Dolly Shots. This despite the fact that at least two of the 12 shots do not show Mona walking, but rather stationary. The eighth musical fragment accompanies images of Mona being crept up on and thrown to the ground by the unnamed rapist, giving some credence to the idea that the rape occurs in Mme Landier's thoughts rather than in Mona's actual experience (in other words, we

\footnotetext{
${ }^{47}$ Ibid., 691.

${ }^{48}$ See also Frances Morgan, "In the Discomfort Zone," Sight and Sound 25 no. 4 (2015): 56-57.

${ }^{49}$ Mona, of course, is unaware that death awaits her at the end of this particular journey.
} 
see what Mme Landier imagines, while Mona herself continues her journey undisturbed.) ${ }^{50}$ The following tracking shot merely crosses Mona as she sits still looking at postcards, thus dreaming of traveling but not actually doing so. Although Mona does not make any progress on a physical path during these two segments, her story does move forward; seeing her dream of other places adds poignancy to the path she has chosen.

Indeed the twelve tracking shots quite clearly establish Mona as one who repeatedly turns to movement as a means to ease the discontent she continues to experience as each subsequent person she meets makes assumptions about her, uses her presence for their own needs, and eventually turns away from her. Hayward argues that "the tracking shot is Mona's sign, as is the music that accompanies it." ${ }^{, 51}$ She usefully describes the type of tracking shots employed:

[I]n the first instance, either the camera and frame 'abandon' Mona and go on to focus on an object, or she exits the frame; in the second, through her positioning the frame she splits the horizontal tracking shot either by crossing it (moving from the back to the foreground and exiting front-frame), or by remaining stationary as the camera continues its tracking movement and stops on an object; in the third instance, both camera and Mona stay in tandem and come to a halt together. ${ }^{52}$

Smith adds that "each begins and ends on some wayside object: the object where each shot starts begin the same or of similar nature to that which ended the previous one. Thus the tracking shots become a continuous walk - the incidents punctuate Mona's journey, rather than glimpses of the journey being used to link the incidents. ${ }^{, 53}$ Like most, Smith notes that the tracking shots move right to left, that therefore "Mona is moving in the wrong direction, against the culture, against the tide." ${ }^{54}$ But she is moving. Smith posits that other characters, in attempting to fix Mona in place, in essence create still images of her. Accompanied by Bruzdowicz's music, however, the

\footnotetext{
${ }^{50}$ If not, then the rape takes on a great deal more significance, being the only "action" besides walking that really takes place in this much-shortened version of the film.

${ }_{52}^{51}$ Hayward, "Beyond the gaze," 288.

${ }^{52}$ Ibid.

${ }^{53}$ Smith, Agnès Varda, 15.

${ }^{54}$ Ibid.
} 
tracking shots are the centerpiece of the film and rightfully emphasize Mona's movement, rather than her encounters.

The tracking shots are not, however, the only indication of Mona's wandering. Nor are the Grande Série the only tracking shots in the film. The camera moves in almost any scene that is not explicitly witness testimony, often without seeming to add any additional information to the scene beyond a greater view of the surrounding landscape. In the château, for example, the camera often moves away from Mona. As Mona and David eat dinner the camera leaves them to focus on a dark corner of the room; when they walk around the grounds, the camera moves past them to focus on some greenery; during another dinner, the camera follows David as he goes to investigate noises, leaving Mona behind entirely. Beyond the series of left-to-right tracking shots, these camera movements emphasize the mobility of the film and its main character.

And Mona is also fond of walking away from other people, often mid-activity. When she spends time with other vagrants at the train station near the end of the film, she is the one constantly getting up and moving around, even when no one wants to join her. She wanders away from two of her companions on the street without noticing when they fall behind. She leaves another fellow hitchhiker abruptly when a potential ride says he only has room for one passenger. Despite Mme Landier's suggestion, Mona refuses to stay in the car at the worksite. She walks around the café to turn on the jukebox, and around the train station trying to do the same. When she stops moving, she is often encouraged to start again: she asks a man for cigarettes but he tells her, "allez plus loin," the prostitute she meets on the side of the road tells her to keep moving so as not to scare potential customers, and Yolande kicks her out of the house when she suspects her motives. The streets become her natural habitat; she has no real goal in being there, except merely to live: as she says to Mme Landier, "la route et le 
champagne, c'est mieux." She is always in motion, or about to be; only when she falls in the ditch at the end of the film is she finally forced to stop.

In discussing Varda's earlier film, Cléo de 5 à 7 (1962), Janice Mouton points out that "Cleo embarks on a journey - by foot, in the city streets - during the course of which she takes on an identity so rare for women in Western culture that its feminine form, 'flaneuse,' is rarely mentioned. ${ }^{, 55}$ Varda has been known, like other cinematic auteurs, to turn artistic traditions on their heads; Hayward notes that "Varda's cinematic writing - cinécriture as she terms it - goes counter to the established canons of western filmmaking practices. ${ }^{, 56}$ Thus it is not surprising that she would reconsider the tradition of the flâneur by creating a female version. Cléo is the first, but Mona is in many ways the continuation of Cléo, a revisiting. Where Cléo's journey can be traced "on a trajectory from fear to curiosity," $" 57$ Mona displays none of the fear and a great deal of curiosity. Granted Mona's walking occurs in the country, not the city, but otherwise her wandering fulfills all the expectations of flanerie as set out by Mouton: it is on foot, at a leisurely pace, aimless, privileges looking over listening (despite the occasional radio interlude), and is accomplished alone. ${ }^{58}$

Yet there is an added element to Mona's wandering, an element that stems in part from the sociopolitical environment in which the film was made. Mona's experience is like that of the flâneur but does not take place in a hospitable environment such as a city she calls home. Rather, Mona's environment is literally and figuratively cold. She is tolerated but not welcomed. Even those who initially welcome her presence - Yolande, in particular - soon start to look upon her with suspicion, and many others openly express their reservations about her. Her longest

\footnotetext{
${ }^{55}$ Janice Mouton, "From Feminine Masquerade to Flâneuse: Agnès Varda's Cléo in the City," Cinema Journal 40 no. 2 (2001): 7.

${ }^{56}$ Hayward, "Beyond the gaze," 286.

${ }_{58}^{57}$ Mouton, "From Feminine Masquerade to Flâneuse," 8.

${ }^{58}$ Ibid.
} 
relationships, with Mme Landier, the goatherd, and Assoun, are nonetheless chilly; Mme Landier never asks her for her name, the goatherd chastises her for her laziness, and Assoun, the most accepting of Mona and all her various attributes, still throws her out. Each of them also removes the shelter that they have offered her, so that Mona must return to her status as outsider. She is a wanderer, with all the implied agency of that role, but never quite at home. The final section of this chapter will examine the sociopolitical environment of the film's genesis and suggest that the implications of Mona's experience go well beyond those of a woman seen.

\section{Mona as immigrant}

In her article on Cléo de 5 à 7 Mouton suggests that in enacting the flâneuse Cleo destroys the traditional subject/object dichotomy, and that "as flaneuse, she joins and becomes a part of the world in which she rambles and observes." ${ }^{59}$ Such is not the case with Mona. Although she briefly joins in the social constructs of her surroundings, Mona is much more likely to ignore and/or defy them. She openly admits to a man in the café that she would prefer his sandwich to him, then unapologetically goes to change the music on the jukebox. She makes eyes at the mechanic's son, flirting with him as she washes a car and listens to his music, but then invites or allows the mechanic himself to join her in her tent. She falls asleep while listening to Mme Landier explain her work, sells cheese to a prostitute, steals everything she can get her hands on, and sets up her tent in a graveyard. She is an outsider both literally and socially. Might she also be an outsider in a political sense?

Sans toit ni loi was originally intended in part as an inquiry into France's homeless population, and indeed much of what follows can equally well be applied as a discussion of the social repercussions of being homeless in France. However, certain elements of Mona's

${ }^{59}$ Ibid., 9. 
experience suggest that her status is not merely as one who lives outside in a literal sense, but also as one who lives outside in a national sense, in other words a foreigner, a non-national. In particular, Mona's emotional reaction to her treatment by Assoun, the Tunisian worker, indicates that this particular episode stands out among the rest. This section will consider how Mona might represent, within the world of the film, an immigrant in France.

Mona, if her wandering is ignored, could be considered stereotypically French: she is young, healthy, attractive, educated, and white. Yet her actions and decisions place her in situations common to the immigrant population. She is for one thing literally homeless, uprooted from her place of origin (so much so that we never learn where she comes from); her temporary abodes are an extreme example of the need for the immigrant to reestablish a new home in a new country. She has also left her family behind, perhaps adopting temporary replacements at times but never establishing anything resembling a true familial relationship. More importantly, Mona has essentially the same legal status as an undocumented immigrant, as highlighted several times throughout the film. For one, she has lost her identification papers, notably a birth certificate that would establish her Frenchness, along with her right to health care and legal work. Yet the film goes even further to establish Mona's inability to work; she points out to Mme Landier that she is unqualified for most jobs because she "doesn't have the look." This includes, of course, her ragged clothing and unwashed hair, ${ }^{60}$ but also hints at the importance of having the right "look" in order to work and move freely in a post-Algeria France. As Alec Hargreaves notes in his 1995 study on Immigration, 'Race' and Ethnicity in Contemporary France, the traditionally European characteristics of settlers returning from Algeria after that nation's independence meant that they were quickly assimilated: "Because they are French by both nationality and culture and generally indistinguishable in their somatic (i.e. bodily) appearance from the majority of the French

\footnotetext{
${ }^{60}$ The foreman's wife, when Mona stands up for Assoun, says of him: “oui, gentil, travailleur -- mais sale.”
} 
population, they are never referred to as immigrants in official or popular discourse, but are instead known as rapatriés ('repatriated citizens') or, more popularly, as pieds-noirs." ${ }^{61}$ In contrast, since members of French departments such as Martinique or Reunion who have more traditionally African or Asian characteristics are 'easily recognizable by virtue of their somatic features as originating outside France, at a popular level they are often treated as 'immigrants' in a way that the rapatriés are not." ${ }^{, 62}$ This emphasis on Mona's improper 'look' stresses her similarities with an immigrant, especially if one considers that certain types of jobs in France were and are closed off to immigrants, including civil service jobs of the sort Mona might expect to have with her vocational degree. ${ }^{63}$

Although she is a French national, Mona's actions also reflect her status as a political outsider. Her actions as a hitchhiker are illegal, as expressly indicated by her jumping back behind a wall to avoid the police early in the film and then turning away from them at the very end of the film, even though at this final juncture they may well represent a safe haven from the cold and sickness that are already starting to consume her. Mona also embodies the outsider when she demonstrates her complete lack of understanding of the cultural ritual of the wine festival, screaming and running in true fear rather than participating. Finally, Mona faces discrimination from many of the people she meets, even when they react positively to her: people stare at her when she enters cafes and often turn down her request for rides; Mme Landier and Jean-Pierre speak about her as an almost non-human entity when she is out of earshot.

Finally, it is notable that in the one sequence in which the North African presence in France is explicitly mentioned, Assoun identifies himself as Tunisian and his roommates as

\footnotetext{
${ }^{61}$ Alec G. Hargreaves, Immigration, 'Race' and Ethnicity in Contemporary France (London and New York: Routledge, 1995), 13.

${ }^{62}$ Ibid.

${ }^{63}$ Jane Freedman, Immigration and Insecurity in France (Burlington: Ashgate, 2004).
} 
Moroccan. In a country still overcoming the trauma of the Algerian war, the lack of an Algerian presence in the film is significant (in fact, even the worker who finds Mona's body is expressly identified in the credits as a "marocain"). The role of the Algerian may well be played by Mona herself, who by doing so would compensate for yet another lack. For all of her inability to be defined (or her rejection of definition) Mona nonetheless does embody the role of the immigrant, and in particular the illegal immigrant. She chooses homelessness, discrimination, illegality, and joblessness. She claims that these choices are because "la route et le champagne c'est mieux"but neither are they accidental. In an interview, Varda commented that "there are people who are 'inside' in the warmth, comfortably installed and others outside, in the cold, with not much idea of where they will sleep." ${ }^{\circ 4}$ The contrast between inside and outside might be productively applied to the status of those who are "at home" in France - French d'origine - and those who are not. Thus the question of immigration becomes implicit in the film, a film whose main character has experiences that closely mimic those of the immigrant worker in France and, in particular, those of the Algerian whose treatment during and following the Algerian War of Independence remained an essential question for the nation.

At the time the film was made, in 1984, the question of immigration and the status of immigrants with regard to French nationality could not be ignored. Benjamin Stora, in his history of Algerian immigration into France, suggests that until this time the presence of Algerians was not at the forefront of French national consciousness, but Hargreaves stresses that by the early 1980s the question of immigration "became a major preoccupation in French public life." North African immigrants in France in the 1980s, both legal and illegal, maintained a notable presence, both as a body of workers and as a political question. Stora notes that population

\footnotetext{
${ }^{64}$ Hayward, "Beyond the gaze," 287.

${ }^{65}$ Hargreaves, Immigration, 'Race' and Ethnicity, xiv.
} 
figures continued to increase even following the 1974 restriction on all immigration into France (later revised to allow familial migration.) Summarizing the immigration patterns of Algerians into France, he writes that “après la vague de l'entre-deux-guerres, celle de la reconstruction de l'après-1945, et le mouvement qui s'opère à la faveur de la guerre d'Algérie, voici donc une nouvelle évolution migratoire... Le nombre d'Algériens passe de 400000 à près de 900000 [in 1975]." ${ }^{.66}$ Alongside the various waves of Algerians entering the country, Stora notes that between 1960 and 1982 the number of Moroccans in France grew from around 30,000 to 431,000 and that by 1978 there were more than 300,000 Tunisians as well. ${ }^{67}$ Hargreaves adds that these Maghrebi populations, by virtue of their numbers and their presence in the work force, are essential to consider in discussions of immigration following the Second World War: "Minorities originating in the Maghreb (i.e. former French North Africa) have been both quantitatively dominant and qualitatively hardest hit in these difficult decades. It would be impossible to understand public perceptions and political responses to immigration in France... without giving due weight to the role of Maghrebis as objects of debate." ${ }^{\prime 68}$

Further, the question of immigration infused French national politics at the time, as indeed it had since the 1970s, when among other things the far-right Front National government was formed, under the aegis of Jean-Marie Le Pen, with anti-immigration policy at its core. Although certainly an ongoing question following Algerian independence in 1962, interest in the status of immigrants surged again in the late 1970s; Jane Freedman writes that "this period was marked by the growing public nature of the debates over immigration and over the place of foreign residents within France, provoked partly by increasing evidence of the sedenterisation of

\footnotetext{
${ }^{66}$ Benjamin Stora, Ils Venaient d'Algérie: L'immigration algérienne en France (1912-1992) (Paris: Fayard, 1992), 402-03.

${ }^{67}$ Ibid., 414-16.

${ }^{68}$ Hargreaves, Immigration, 'Race' and Ethnicity, xvi.; see Hargreaves 1-37 for a complete set of statistics and tables on immigration flows in France in the $20^{\text {th }}$ century.
} 
the migrant population," ${ }^{, 69}$ including familial migration and the relatively high birth rate among the immigrant population. Following the aforementioned restrictions on immigration of 1974, and repeated attempts to revise policy in that year and the year following, a new government was instituted in 1977 that began to consider repatriation of North Africans as a major goal. Further, although the Front National saw little progress initially, a municipal election in 1982 marked the first major victory for the party and ensured that the question of immigration would become essential to the political process at both local and national levels.

Alongside national debates over immigration policy, the French public also took up the issue. Freedman notes that public opinion seemed particularly hostile with regard to voting rights: "An announcement made by the Minister for Foreign Affairs, Claude Cheysson, in August 1981, stating that the government had resolved to grant voting rights to foreigners met with a storm of opposition despite quick rebuttals by other foreign ministers." ${ }^{, 70}$ Nor was the presence of immigrants in France just a matter of voting rights but also one of civil and social liberties. Although a 1972 law against discrimination had been put in place, it was considered ineffective and largely symbolic, with the burden of proof lying with the victim and no major organization in place to help victims of discrimination pursue justice. Racism and discrimination were widespread. It was not until 1981 that immigrants could form associations without the express authorization and control of the French Ministry of the Interior.

In turn, widespread discrimination and racism motivated a response from the immigrant population, and particularly the mobilization of large groups of young people of North African descent. The 1980s marked the beginning of the common use of the term Beur, a slang term for "Arabe" initially pejorative (though now claimed by these groups as an identity) (Freedman).

\footnotetext{
${ }^{69}$ Freedman, Immigration and Insecurity in France, 35.

${ }^{70}$ Ibid., 90.
} 
Examples of political action include a December 1983 'March for Equality and Racism' in which young Maghrebis marched to Paris from Marseille, joined by others along the way; the marchers were met by a 100,000 person demonstration and received by President Mitterand. In addition, a movement known as Convergences "involved five marches of young people of different ethnic origins converging on Paris ... to stress the multi-ethnic and multicultural nature of the protest." ${ }^{, 71}$ On both sides, the ongoing debate over the immigrant presence in France was passionate. Nonetheless, Stora writes, “malgré l'existence du chômage en France, la diffusion d'un climat hostile né de la montée du racisme et les différentes politiques d'aide au départ, les Algériens immigrés, dans leur grande majorité, se fixent en France..”72 Their presence could not be ignored, nor imagined away.

Thus the question of immigration formed a part of the environment in which Varda was making her film in 1984. Films, of course, are not required or expected to react specifically to prevalent political conditions, but Varda in particular seems to incorporate elements of the prevailing national debate into her film. In addition to Mona's often-emphasized outsider status and her undocumented, itinerant, odd-job lifestyle, an interesting exchange between Mme Landier and Mona might well serve as an analogy to highlight the underpinnings of the debate: in explaining her work to Mona, Mme Landier describes the fungus that has invaded the plane trees of France as "comme un cancer. . [qui] colonise l'arbre." Her job, as a researcher, is to find a way to create a population that is resistant to the invading species. She notes that the disease arrived in Marseilles, also a common entry point for North African immigrants to France, and that if a solution is not found, the native population of trees will have died "d'ici 30 ans." In a film that shies away from long conversations Mme Landier's monologue stands out, for

\footnotetext{
${ }^{71}$ Ibid., 158.

${ }^{72}$ Stora, Ils Venaient d'Algérie, 424.
} 
Mona's verbal exchanges are almost always on the subject of food, water, shelter, or temporary work. ${ }^{73}$ Mona wonders, here, if Mme Landier intends to "soigner" the trees, but Mme Landier suggests that remediation is not her concern; rather than taking care of the current situation, she hopes to drastically change it. In Mona's view, that is idiotic ("c'est con"). Might there be an implied critique of Mme Landier's view, her hopes to eradicate the foreign substance entirely from France, her view of the foreign presence as a cancer? Mme Landier treats Mona in a humane manner, but not a humanistic one; Mona is more of a pet than a fellow human. Mme Landier's views, then, might stand in for those of the French who feel entitled to keep their country free from contamination, who reject what is not native to their soil, who look on those unlike them as inconveniences - fascinating, perhaps, but to be dumped by the side of the road as soon as the intrigue fades. If this is the case, then the film might be suggesting that the French public needs - or will soon get - a shock to the system, electrocuted like Mme Landier as a reproach for their abandonment of those in need and their unwelcoming worldview.

\section{Conclusion}

In her analysis of the film Flitterman-Lewis quotes Varda: "I want spectators to define themselves vis-à-vis Mona. For example, would you give Mona a ride? Would you let her sleep in your car? Would you give her money? It's not the question, but the questioning that matters. ${ }^{, 74}$ None of these questions presupposes the spectator seeing Mona as a woman or an object of desire in some way. Rather, the questions imagine the reaction of one facing a stranger, a wanderer, an outsider. In this chapter it is this aspect of Mona that takes the focus. By acknowledging Mona's altérité - not as a woman but as an outsider - we allow her to act as a

\footnotetext{
${ }^{73}$ She does have a more extended, if still shallow, philosophical discussion with the goatherd about freedom and work.

${ }^{74}$ Flitterman-Lewis, To Desire Differently, 221.
} 
stand-in for the other outsiders in France, the immigrants. In addition, Mouton suggests that "one of the privileges of flanerie is being able to entertain the possibility of being many selves, in [Virginia] Woolf's words, 'to give oneself the illusion that one is not tethered to a single mind, but can put on briefly for a few minutes the bodies and minds of others." ${ }^{175}$ Mona's flânerie allows her to try on - and then to reject - a variety of roles; in doing so, she also turns the gaze back upon those who gaze at her. She makes them uncomfortable, in part, because they see themselves through her eyes, through the eyes of the outsider. Considering Mona as flâneur refocuses the gaze from her to her surroundings, both the landscape through which she moves and the people she encounters.

Herein lies the larger social role of the film, as it shifts from an artistic product into a deeper investigation of the place of the outsider in the French community. Like other New Wave filmmakers Varda creates a film which responds to prevailing social and political conditions, including the ongoing question of French reaction to the trauma of the Algerian War of Independence. Mona, the protagonist, is essential to this project, as she allows Varda to turn the question of perception back onto the viewer. Despite representing a wide swath of French society, none of Mona's interlocutors gains the privilege of identifying Mona. She cannot be properly seen, because she is not intended to be the object of the gaze. Instead, those who are attempting to place her, to give her meaning and context, are those who must be more fully considered. This includes, of course, the viewer, who also tries to properly see and understand Mona. Flitterman-Lewis acknowledges this effect, writing that "[ $[$ ] he film gives us, its spectators, the same status as its fictive characters; it thereby produces a profound object lesson in the

\footnotetext{
${ }^{75}$ Mouton, "From Feminine Masquerade to Flâneuse," 12.
} 
interconnection - the interdependence - of both cinematic and social reality, and an intriguing illustration of the continuity of psychic life.,"76

The film thus insists that we reexamine our prejudices towards those who do not share or conform to our expectations. ${ }^{77}$ In the end, the gaze is most productive when turned back upon ourselves. Varda notes: "We are not with Mona because she is dirty, selfish, unappealing. [On the other hand] we are with her because she walks freely; she carries something of ourselves with her, some of our dreams, our struggles." ${ }^{, 78}$ This push/pull dichotomy is exactly what the other characters who meet Mona experience. They see themselves, or something they lack, in her. The view, however, is only partial, and often disturbing, not because of Mona herself but because of how her presence causes them to reflect upon themselves. Julia Kristeva writes that "[s]trangely, the foreigner lives within us: he is the hidden face of our identity, the space that wrecks our abode, the time in which understanding and affinity founder. . The foreigner comes in when the consciousness of my difference arises, and he disappears when we all acknowledge ourselves as foreigners, unamenable to bonds and communities." ${ }^{, 79}$ Mona is a stranger, an outsider, and their and our - inability to welcome her is frightening because of what it implies about the world in which she moves. By turning the gaze away from Mona, it becomes possible to read Sans toit ni loi as a political and social critique of a France that cannot get past its preconceptions and seems unable to fully recognize the essential humanity of the strange figure(s) wandering in its midst.

\footnotetext{
${ }^{76}$ Flitterman-Lewis, To Desire Differently, 306.

77 "A key reason for the general rejection of these terms ['race' or 'ethnicity'] in France lies in the fear of giving even verbal recognition to the settlement of people seen as enduringly different from the indigenous majority." Hargreaves, Immigration, 'Race' and Ethnicity, 2.

${ }^{78}$ Ibid., 244.

${ }^{79}$ Julia Kristeva, Strangers to Ourselves, trans. Leon S. Roudiez (New York: Columbia University Press, 1991), 1.
} 


\section{Chapter Three}

\section{Chasing the cats of Chats perchés}

Once, as Jacques Derrida dressed (or undressed) in the privacy of his residence, he was startled to find his cat staring back at him. He documents his resultant self-questioning in the 1997 seminar "L'animal que donc je suis," in which he explores what it means to come face to face with an animal and thereby to become ashamed. ${ }^{1}$ Derrida finds this mutual gaze - himself, looking at the animal, while the animal looks back at his nakedness - profoundly disturbing, and hopes through his lecture to answer, in part, the question: "Whence this malaise?"2 The cat becomes, because of its gaze, an utterly fascinating source of contemplation for the philosopher. As it turns out, Derrida shares this fascination with Chris Marker, whose interest in cats, particularly their odd behaviors and steady gaze, sneaks into almost all his work. ${ }^{3}$ In his 2004 film-essay Chats perchés Marker, like Derrida, channels his feline fascination into a philosophical inquiry into human behavior, touching on the usefulness of collective movements, the intersection of anonymity and the mutual gaze, and how art becomes an increasingly important element of political discourse in contemporary times. Mixing documentary with narrative in Marker's characteristic style, Chats perchés covers an assortment of protests and other popular gatherings that occurred in Paris between 2001 and 2003 while also tracing the evolution and repeated appearances and disappearances of a popular cat-shaped graffito known

\footnotetext{
${ }^{1}$ Published in French as Jacques Derrida, L'animal que donc je suis (Paris: Editions Galilée, 2006); in English as Jacques Derrida, The Animal That Therefore I Am, ed. Marie-Louise Mallet, trans. David Wills (New York: Fordham University Press, 2008).

${ }^{2}$ Derrida, The Animal That Therefore I Am, 4.

${ }^{3}$ Le joli mai (1962), Sans soleil (1983), Le fond de l'air est rouge (1977), and Chat écoutant la musique (1990) are good places to start; despite otherwise serious subject matter, they are full of (actual) cats. Derrida assures us, lest we try to make his cat into an analogy: "I must make it clear from the start, the cat I am talking about is a real cat, truly, believe me, a little cat. It isn't the figure of a cat. It doesn't silently enter the room as an allegory for all the cats on the earth, the felines that traverse myths and religions, literature and fables." Derrida, The Animal That Therefore I Am, 6.
} 
as M. Chat in that same city (Figure 3.1). ${ }^{4}$ In the case of Chats perchés, the itinerant protagonist is not an individual but rather a non-corporeal figure made up of a highly mobile camera-eye that films what it encounters, an editorial presence that chooses and pieces together these images behind the scenes, and a disembodied voice that communicates largely via intertitle. Like Elle and Mona, this protagonist is a descendant of the nineteenth-century flâneur; he moves through the streets without any destination in mind, keenly observing and reporting back, with commentary, on his surroundings. In this case, he is aided by the use of a camera that records what he sees, transmitting through image what was once put down on paper. Like Benjamin's concept of the flâneur, the Speaker is astonished by what the world around him has become, focused on consumerism and full of people rushing from place to place. And like the nineteenthcentury figure he remains completely anonymous, to such an extent that we never see his face or hear his voice. This flâneur, however, is a composite figure representing a set of individuals who have a deep and powerful urge to react in some way, a desire for change, and an inability to remain quiet in the face of atrocities large and small. As a composite figure, he can be in many places and times, observing and reporting back his or her experiences and reflections. What he finds, in the film, is that hope, humor, and happiness can be found in the smallest of places: in the presence of a cat in the subway, or the smile of a woman who happens to catch his eye as she passes. ${ }^{5}$ While Marker is not (despite his claims) a cat, nor an exact stand-in for the camera, through them he creates an elusive but identifiable alter ego (a "Speaker") who searches for a source, and a balm, for the malaise felt by Parisians living under the threat of terror, war, and extremist political parties. In Chats perchés both the camera and the cat thus become

\footnotetext{
${ }^{4}$ The graffito began appearing in France in 1997 and eventually was used, as documented in the film itself, as a symbol of peace in the protests. Toma Vuille, M.Chat (Paris: Éditions Alternatives, 2010).

${ }^{5}$ Echoes of Baudelaire's "À une passante": Charles Baudelaire The Flowers of Evil, trans. James McGowan (New York : Oxford University Press, 1998), 189.
} 
contemporary iterations of the flâneur, roaming the streets of Paris and staring unapologetically at whatever crosses their path.

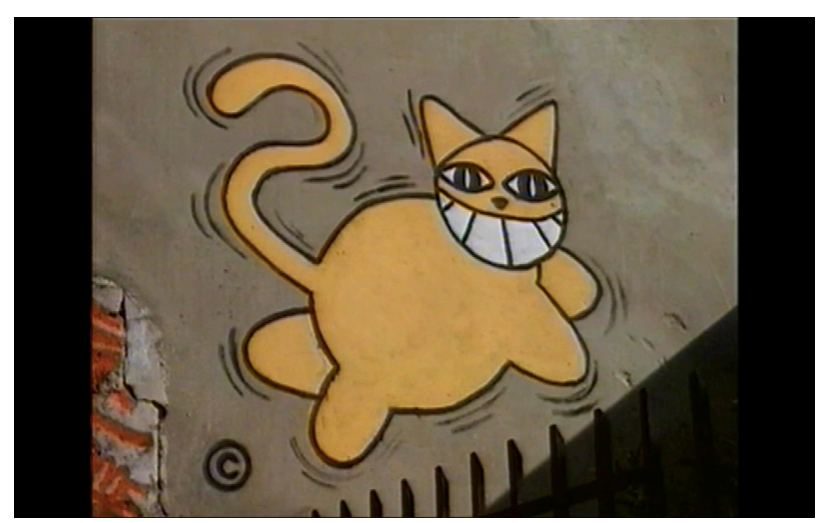

Fig. 3.1

\section{Marker and the film-essay}

A prolific filmmaker, Chris Marker reveled in anonymity. Famously unwilling to be photographed or interviewed in person, his oeuvre consists of a wide variety of documentary and mixed media projects focusing on subjects ranging from the 1952 Olympic Games to the photographs of Denise Bellon. His films are often intriguing in subject and fascinating in form, but can be difficult for audiences due to long running times and unusual techniques. Marker is probably best known for the short science-fiction film La jetée (1962), a compilation of still images sequenced together to tell the story of a dystopian future. Many of his films treat interesting, highly specific individuals or concepts, such as his documentaries on Alexander Medvekin (Le tombeau d'Alexandre, 1993), Leftist political movements of the 1960s (Le fond de l'air est rouge, 1977), and photography (Si j'avais quatre dromedaires, 1966). Chats perchés marks the epitome of his unique filmmaking style, featuring a series of short narrative episodes and a proliferation of characters, none of which ever take center stage. However, unlike many of 
his other films, it also features a strong, though unseen, narrator, an unnamed figure whose presence is revealed through a series of intertitles that regularly appear, directing the attention of the audience by indicating possible connections between episodes, expressing more universal themes, and often making witty observations about the images on the screen. The presence of this Speaker is part of what makes Chats perchés one of Marker's strongest works, becoming a means to tie together various otherwise disparate episodes in a recognizable narrative.

The construction of Marker's films and the musings of the protagonists within these constructed filmic worlds have long fascinated scholars, though he remains widely unknown to the general populace even within France. Studies of Marker such as Nora Alter's 2006 Chris Marker or Catherine Lupton's 2004 Chris Marker: Memories of the Future tend to focus on the artist's work, often tracing his chronological development from photographer to engaged communist filmmaker to what is often termed film-essayist without reference to the biographical details that Marker kept private. ${ }^{6}$ As of this writing previous scholarship is largely focused either on genre and form or on themes that recur throughout the films such as time and memory, travel, and political engagement. Building from these analyses of form and especially the idea of engagement, this chapter will explore among other things the underlying affect of Marker films and of Chats perchés in particular. For in addition to the visual investigations of Paris and M. Chat, there is an intensity hidden amidst the plenitude of images, a sense that the subjects of the film - the anonymous Parisians who gather together to protest, to celebrate, to mourn, even to participate in flash mob art in the tradition of Allan Kaprow's Happenings - have a real, albeit limited, power. Unlike the dreamlike movements of Resnais' Elle or the measured movements of

\footnotetext{
${ }^{6}$ Undoubtedly more detailed biographies will be forthcoming once the Marker archives currently being catalogued at the Cinemathèque Française in Paris become available in or around 2018. Joël Daire, "Estate Chris Marker: Where are we at with the inventory?" Chris Marker: Notes from the Era of Imperfect Memory, 2015, http://chrismarker.org/2015/06/state-of-the-estate/.
} 
Varda's Mona, the subjects captured by Marker's camera are moving with a purpose, driven by an urge to do something, to react, to express emotion, to scream obscenities at a world that could permit such atrocious acts of war and terrorism as those that spur the demonstrations in which they participate.

Marker is often considered to be a maker of serious films. And indeed Marker films are not the most accessible works of French cinema, even given an audience accustomed to the formal and narrative experiments of other filmmakers who came to prominence during the French New Wave movement of the early 1960s. Marker's films tend to feature odd or hidden narrative logic, a theory of montage that privileges quantity as well as quality, and themes, motifs, and recurring images that can be difficult to interpret. These elements contribute to his reputation as a film-essayist, rather than a narrative filmmaker. Phillip Lopate uses Marker's 1983 Sans soleil as an archetypal example of the essay-film in his prescriptive 1992 article "In Search of the Centaur," noting that "Marker has an inveterate essayistic tendency that peeps out even in his more interview-oriented documentaries." ${ }^{, 7}$ Nora Alter points out that Marker tends to work in the sub-genre of audiovisual essay, with an emphasis on pushing the boundaries of genre and "innovative formal techniques." "Indeed Marker took an early interest in film formats as one of the "groupe des trente" aiming to invigorate the short, 30-minute film in the 1950s. His work has been praised by Andre Bazin for being "unlike any other documentary" and "a truly innovative form of filmed intelligence."9 Marker's films, like many of his New Wave contemporaries, also adhere to Alexandre Astruc's definition of the caméra-stylo, although often without the devotion to narrative found in the majority of that era's productions. Rather, Roy

\footnotetext{
${ }^{7}$ Phillip Lopate, "In Search of the Centaur: The Essay-Film,” The Threepenny Review 48 (1992): 19.

${ }^{8}$ Nora Alter, Chris Marker (Urbana: University of Illinois Press, 2006), 15-16.

${ }^{9}$ Ibid., 15.
} 
Armes posits that Marker chooses to "replace narrative with documentary discovery,"10 often as a means "to report on [his] travels." "11 Hamid Naficy, who considers Marker in his study of exilic, border-crossing filmmakers, prefers the term "letter-film" and the genre "epistolary filmmaking" to describe Marker's productions, ${ }^{12}$ which he terms more "performances of the documentary form, not documentaries themselves."13 Marker himself disliked the term documentary; as Sarah Cooper notes that "Marker's idiosyncratic documentaries reassess what the term 'documentary' means. This is fitting with regard to his critical comments in interview when he says that the term leaves behind it a trail of 'sanctimonious boredom' . . and that he only uses it because nobody has come up with anything better." ${ }^{\prime 14}$ In addition, several of Marker's works call to mind ethnographic film, particularly the tradition established by Jean Rouch during his years of film production in Africa. Rouch, who conducted fieldwork primarily in Niger, "blend[ed] observation and participation, science and art, constructing a provocative ethnographic oeuvre that challenge[d]" viewers' assumptions; ${ }^{15}$ likewise Marker's work, while not intentionally ethnographic in the anthropological sense, nonetheless asks viewers to reconsider previous notions of the foreign. The most common descriptor for Marker's works, however, is the term film-essay (or alternately, essay film), as adopted by Alter and many other Marker scholars. Indeed Hans Richter had already invoked the idea of a film-essay in a 1940 text in terms that presage Marker's oeuvre, identifying it as a film that "produces complex thoughts

\footnotetext{
${ }^{10}$ Roy Armes, The Ambiguous Image: Narrative Style in Modern European Cinema (Bloomington: Indiana University Press, 1976), 57.

${ }^{11}$ Ibid., 109.

${ }^{12}$ Hamid Naficy, An Accented Cinema: Exilic and Diasporic Filmmaking (Princeton: Princeton University Press, 2001), 104.

${ }^{13}$ Ibid., 278.

${ }_{15}^{14}$ Sarah Cooper, Chris Marker (Manchester: Manchester University Press, 2008), 3.

${ }^{15}$ Paul Stoller, The Cinematic Griot : The Ethnography of Jean Rouch (Chicago: The University of Chicago Press, 1992), 23.
} 
that are not necessarily grounded in reality." $" 16$ Timothy Corrigan takes a cue from Aldous Huxley's definition of an essay as moving among the three poles of personal/autobiographical, objective/concrete, and abstract/universal and suggests that an essay film contains three poles of personal expression, public experience, and the process of thinking: "The variable ratio and interactivity of these three dimensions creates a defining representational shape that emerges from the literary heritage of the essay and extends and reformulates itself in the second half of the twentieth century as the essay film." ${ }^{, 17}$ Bazin, referring to Marker's 1957 film in an article printed in a 1958 issue of France-Observateur, similarly wrote:

I'll offer the following tentative description: Lettre de Sibérie is an essay, which takes the form of a filmed report, on the reality of contemporary Siberia. Or, to borrow Jean Vigo's description of A propos de Nice, ('a documented point of view'), we could say it's an essay documented by the film. The key word here is "essay," understood in the same sense as it is in literature, an essay that is both historical and political, though written by a poet. $^{18}$

Meanwhile a review in Sight\&Sound following the release of a collection of some of Marker's

lesser known works suggests that:

Many of these works might be classified as luminous examples of the essay film, but even those nearly half a century old frequently seem like expressions of some encyclopedic and chimerical future form that Marker figured out in solitude. Observed with a gaze as calm as that of his talismanic cat or owl, they're documentaries with the spooky density of science-fiction, meditative and diaristic, shaped by a kind of critique that drifts in and out of reverie. ${ }^{19}$

While there are several themes repeated across the various attempts at describing Marker's oeuvre, the widest swath of critiques and commentaries on Marker's work identify, accurately, the mix of fiction and non-fiction that, while appearing in various forms, remains essential to the

\footnotetext{
${ }_{16}^{16}$ Alter, Chris Marker, 17 (italics original).

${ }^{17}$ Timothy Corrigan, The Essay Film: From Montaigne, After Marker (New York: Oxford University Press, 2011), 14.; for a discussion of the term essay film as applied to other filmmakers as well as Marker, see Laura Rascaroli, "The Essay Film: Problems, Definitions, Textual Commitments," Framework: The Journal of Cinema and Media 49 no. 2 (2008): 24-47.

18 Jean Douchet and Cédric Anger, French New Wave, trans. Robert Bonnono (New York: Distributed Art Publishers, 1999), 111.

${ }^{19}$ Frances Morgan, “In the Discomfort Zone,” Sight and Sound 25 no. 4 (2015): 56-57.
} 
work. Besides film-essay, other terms that have been used are montage, epistolary narrative, documentary video, travelogue, personal essay, even mishmash. While none of these terms is wildly off the mark, they tend (with the exception of mishmash) to emphasize the formality and seriousness of Marker's work without truly capturing the joyful and often playful nature also present. But Marker's films are in fact often whimsical, clever, and even outright funny. While many address essential political and social issues, they are not intended merely as lectures or essays. Indeed, by combining the serious with the humorous Marker imbues the former with greater appeal; it becomes possible, as in Chats perchés, to discuss the threat of terrorism while still appreciating the inherent silliness of chasing both real and cartoon cats around Paris. ${ }^{20}$

In addition to the discussions of genre, scholars have been particularly prolific on representations of time and space and in particular how Marker's treatment of these concepts works to modify our awareness of the world around us, no matter the topic of the film. As many note, Marker is particularly fond of breaking boundaries, not only those of space and time but also of genre and expectation, and then putting the pieces back together. At the outset of her 2005 book Chris Marker: Memories of the Future, the first comprehensive English-language study of Marker, Catherine Lupton identifies Marker as "a towering and seminal figure in the field of contemporary visual culture, but until very recently one of its best-kept secrets." ${ }^{21}$ She suggests that Marker, while rarely a major focus of discussions of the French New Wave, deserves a more thorough reckoning: "When the iconoclastic forces of the New Wave receded in the second half of the 1960s, and many of its directors settled safely back within known cinematic bounds, only Marker and Godard stood out in their parallel, if very differently

\footnotetext{
${ }^{20}$ The English title of Chats perchés is "The Case of the Grinning Cat."

${ }^{21}$ Catherine Lupton, Chris Marker: Memories of the Future (London: Reaktion Books, 2005), 7.
} 
manifested, commitments to both media innovation and political efficacy."22 Lupton echoes previous explorations of genre, noting that Marker himself crosses boundaries: "The different media that Marker has traversed with such breathtaking ease do not provide stable grounds for classifying him, since they are in an important sense only the support, not the essence, of his defining qualities as an artist. ${ }^{, 23}$ Lupton goes on to argue that Marker is fascinated by film in part because of "what he regards as its capacity for revelation: the power to unveil deeper realities that expand and enrich the significance of the everyday world, but remain firmly grounded in its objects and appearances. ${ }^{24}$

In Alter's 2006 biography, Chris Marker, she posits that "[t]he diverse nature of Marker's work parallels his peripatetic journeying around the globe" and notes Marker's awareness of political issues and engagement with the same. ${ }^{25}$ She considers "the translation of emotions...into systems of representation. ${ }^{26}$ Cooper's 2008 overview of Marker's oeuvre focuses specifically on the filmmaker's "treatment of temporality,"27 and further notes that "a fascination with stillness runs throughout Marker's work ... [which] manifests itself principally through the existence of photographs, but also in more diverse ways, through the filming of statuary, painting and other static images, including the film still, in addition to a fondness for fixed frame shooting. ${ }^{28}$ Cooper finds that the tension between still and moving image speaks to much more than just technical play, suggesting that "[f]or Marker, film is not unequivocally on the side of mobility, duration and life, but nor is photography always an avowal of immobility, temporal stasis and death. The pull of stasis, the hesitation between life and death lives on

\footnotetext{
${ }^{22}$ Ibid., 8.

${ }^{23}$ Ibid., 10.

${ }^{24}$ Ibid., 23.

${ }^{25}$ Alter, Chris Marker, 5.

${ }^{26}$ Ibid., 108.

${ }^{27}$ Cooper, Chris Marker, 4.

${ }^{28}$ Ibid., 4-5.
} 
throughout Marker's filmic oeuvre in manifold ways. ${ }^{, 29}$ Beyond the interplay between time passing and time standing still, Cooper identifies the oscillation among past, present, and future in Marker's work as a particularly heady concern:

Temporality in Marker's work is sometimes closed in on itself, the future pre-known, and time impossible to change - a scrambled logic enables us to look back at a future in some films, as we may look at history in others. Dystopias are frequently apparent. At other times, and always mindful of the past in his ceaseless concern with memory, more utopian possibilities are explored in relation to a future that has yet to be invented. ${ }^{30}$

Recent articles on Marker continue to focus on the breaking of boundaries and the relevance of Marker's work to the contemporary political landscape. Elizabeth Cowie posits that "Sans Soleil (1983) can be read as an essay-film on the cultural fetishes - including ethnographic film - by which we sustain ourselves in the face of the undecidable, while it also problematizes the easy assumption of distance from such fetishism that documentary usually affords us." ${ }^{, 31}$ In additional to physical distance, there is also the question of time; Rick Warner suggests that in Marker's oeuvre "montage emerges as a means of historical rescue, of sorting through far-flung, readymade material and marshaling it into an acute, affective examination of the past." 32 And finally, the question of medium: in a 2009 article, Alison J. Murray Levine suggests in relation to Chats perchés that:

Marker's apparent meanderings in fact constitute a tightly woven and meticulously crafted argument about political culture and its primary pillar, that of communication, in the world after the catastrophe. Through a deconstruction of the primary elements of communication - text, sound, and image - he advances a profound critique of all forms of mediated exchange, proposing instead the necessity of direct collective dialogue and action. In elaborating this critique, he undermines the authority of the very medium within which he works, that of the documentary video, explicitly demonstrating its ability to transform and distort reality. ${ }^{33}$

\footnotetext{
${ }^{29}$ Ibid., 9.

${ }^{30}$ Ibid., 8.

${ }^{31}$ Elizabeth Cowie, "Specters of the Real: Documentary Time and Art," differences 18 no. 1 (2007): 102.

${ }^{32}$ Rick Warner, “Go-for-broke games of history: Chris Marker between 'old' and 'new' media," Post Script 29 no. 1 (2009): 17.

${ }^{33}$ Alison J. Murray Levine, “Ghosts on the Skyline: Chris Marker's France after 9/11," From Solidarity to Schisms:

9/11 and After in Fiction and Film from Outside the US, ed. Cara C. Cilano (Amsterdam: Rodopi, 2009 ), 3.
} 
Levine also usefully emphasizes the importance of the $9 / 11$ attacks to the work, despite its near absence from the surface narrative. The wide range of Marker's work makes him a source of fascination not just for film scholars but also for contemporary art enthusiasts: he has recently been the subject of several museum exhibitions, including a 2007 exhibition at Wexner Center For the Arts at the Ohio State University, the catalog of which was published as a book entitled Staring Back, a 2014 exhibition at the Whitechapel Gallery in London also entitled A Grin Without a Cat, and a 2013 retrospective at the Centre Pompidou in Paris, Planète Marker. ${ }^{34}$

\section{Lost in the crowd}

The mix of fiction and non-fiction that distinguishes Marker's films also encourages a critical assessment of the topics featured therein. By including a number of public gatherings in Chats perchés, Marker suggests that we take a closer look at group movements, and in particular the common elements of these gatherings, which tend to include some form of vocal contributions (singing or chanting), coordinated and individual motion (marching or dancing), signage (posters, flags, and banners), and the use of public space (most often streets, but occasionally green spaces). Despite the disparate causes that have gathered people together, these elements remain relatively constant across the movements included in the film. In addition, interlinked with the collective movements discussed in the film is the concept of the anonymous, as the group setting both allows for and relies upon the anonymity of individual members. By the nature of the event, the organizers of popular protests may be known, but the majority of

\footnotetext{
${ }^{34}$ Chris Marker, A Grin Without a Cat (London: Whitechapel Gallery, 2014).;Chris Marker, Staring Back (Columbus: Wexner Center for the Arts, The Ohio State University, 2007). Nora Alter discussed the increasing intersection of the film-essay with contemporary art practices in a recent talk at the 2016 ACLA Conference: Nora M. Alter, "The Moving Essay" (presentation, American Comparative Literature Association Annual Meeting, Cambridge, MA, March 17-20, 2016).
} 
attendees will be on equal footing, their power stemming from the group and not from their individual actions. Much of Chats perchés is concerned with group protests, and in each case, the viewer hears and sees lengthy sequences of protesters acting as a group, often coordinating movements. Each protest features large groups of people speaking, singing, or shouting in unison, clapping, linking arms, and dancing or marching; often the group's chanting or singing is the sole soundtrack of that sequence of the film. The individuals who make up these protests are rarely identified; although the camera occasionally lingers on faces, no one person emerges to become a point of identification for the viewer. Instead, faces are viewed in rapid succession, with the camera panning across the crowd and the crowd moving past the lens. In the opening sequence, for example, the camera often cuts off the frame at shoulder height, completely concealing the participants' identities, a framing that will later be repeated in other group shots (Figure 3.2). Other examples of camera movement that establish anonymity include the many sequences that feature only the feet of marchers in the street, or hands clapping and gesturing, and the emphasis on filming people in masks or costumes, or from the back or side (Figures 3.3, 3.4). Even when faces appear the voices of the people being filmed are often unheard, or are only heard as part of the crowd, indistinguishable on their own. Often faces and bodies are seen through windows, physically separated from the camera not just by the glass of the lens but also that of the window. Several sequences, such as the shot of children chasing a moving light projection along the floor, are lit darkly enough that only silhouettes are visible (Figure 3.5). 


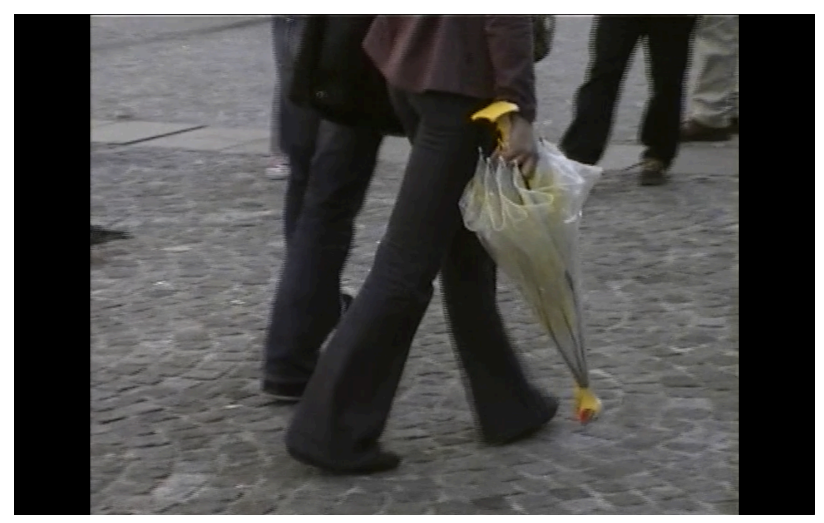

Fig. 3.2

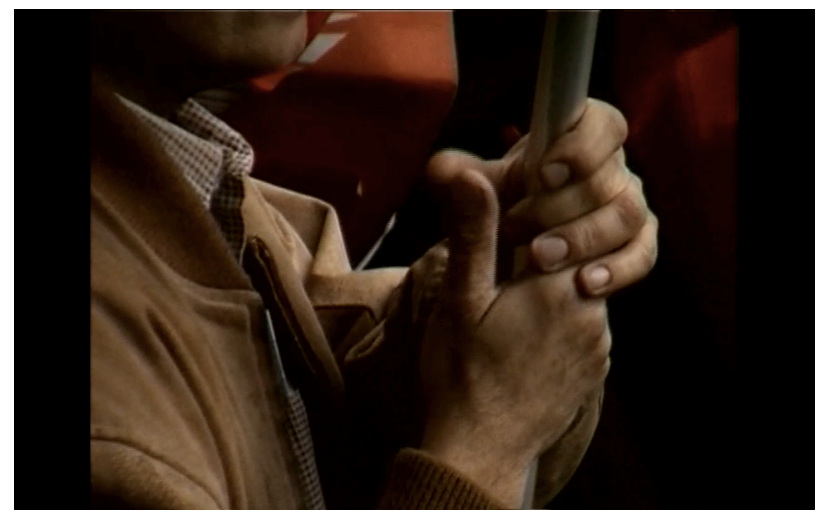

Fig. 3.3

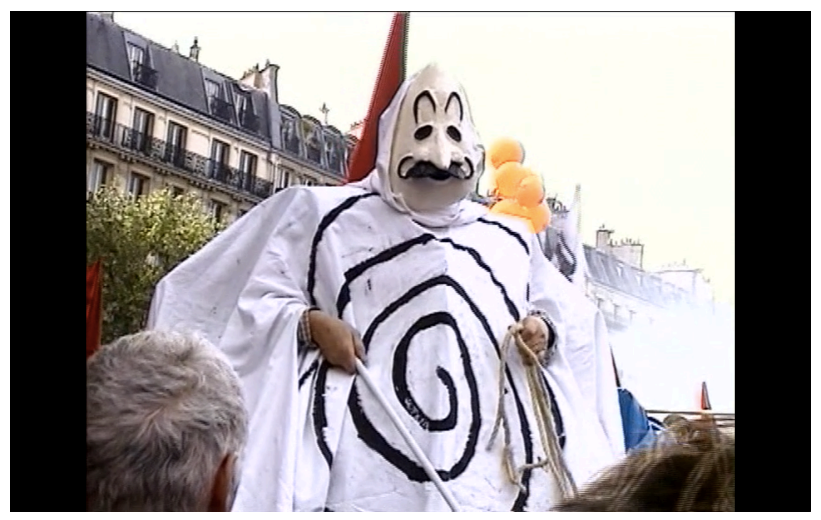

Fig. 3.4 


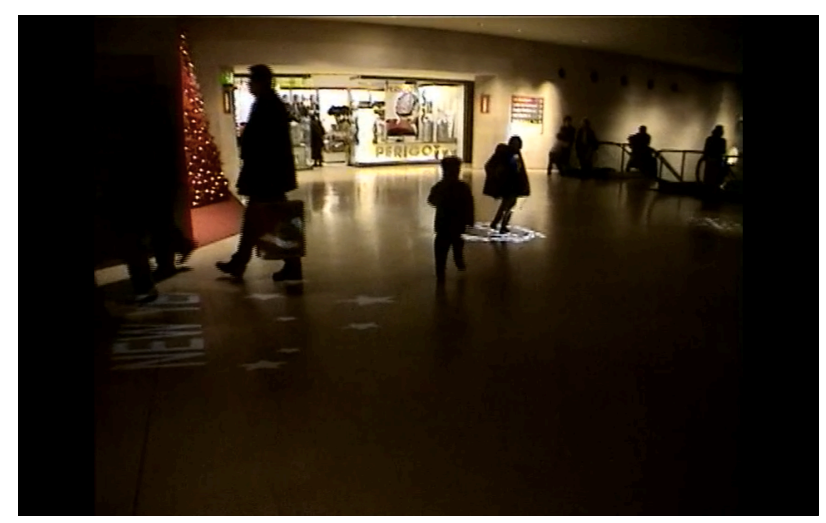

Fig. 3.5

The film opens on what seems to be a rather innocuous public gathering: a flash mob. As documented by the film, in November 2001 a group of people gathered in front of the Centre Pompidou in Paris carrying umbrellas. Following instructions from an unknown flash mob organizer, each person appears walking in circles around a pillar in front of the museum, opening and closing an umbrella every ten seconds. Immediately the question of the intersection of collectivity with the individual comes to the fore. Each individual is in control of his or her own steps and umbrella, and on their own their actions would seem entirely unimportant, if perhaps a little strange, but when a multitude of individuals gather and perform the given action collectively the project given a greater meaning. Whether the comment being made is artistic, social, or something else entirely, the essence is that the group presence affects its surroundings differently than the presence of individuals acting alone. In fact this is the entire premise of the flash mob, which relies on the "mob" aspect to create its effect, and is part of what drove the originator of the contemporary flash mob, Bill Wasik, to organize his initial gathering in 2003; eight years later, he qualifies his idea as "a sort of social experiment" that appropriately enough essentially took on a life of its own. ${ }^{35}$ The importance of the transition from individual to

\footnotetext{
35 "flashmob." OxfordDictionaries.com. 2016. http:/www.oxforddictionaries.com/us/definition/american_english/flash-mob?q=flashmob; Bill Wasik, “\#Riot: Self-Organized, Hyper-Networked Revolts - Coming to a City Near You, "Wired, 2011, http://www.wired.com/2011/12/ff_riots/all/1.
} 
collective in terms of response and even empowerment sets the stage for the remainder of the film, which will investigate this transition over and over again in gatherings of increasing relevance to world affairs.

Following the opening flash mob sequence the film shows a succession of political gatherings. The first, fifteen minutes into the film, is an anti-Front National rally held in May 2002. Filmed in the midst of France's election cycle just after the French had been surprised by Jean-Marie Le Pen's inclusion in the second round of voting, the protest features posters that call for "anti-racisme" policies and deny Le Pen himself as a viable leader. But Le Pen is not the only focus of French anger: the next gathering in the film features protests against George Bush and his threats of war in the Middle-East. Next we see a pro-Kurdish rally, a rally for peace organized by the French Jewish population, several other peace rallies, a march for workers led by the Confédération Générale du Travail (CGT), and another led by the Force Ouvrière. Next, a group of young Muslim women who protest in favor of the veil and sing the French national anthem as proof of their belonging. Later in the film we see other political gatherings, including a rally for peace in Tibet, a rally for "Morts de la Rue" in favor of supporting the homeless population, an "anti-grève" rally and a protest to "Libérez José” (José Bové, who was briefly imprisoned in 2003 for his anti-GMO actions). ${ }^{36}$ Each of these political gatherings features some sort of vocal chant, stickers or signs identifying the organizing group and a succinct message, and some kind of group movement, often walking. ${ }^{37}$ All of these political protests are held in the street, or several streets, if they involve the group walking from one place to another. In addition to political protests, the film also includes other gatherings, such as a rally against AIDS held in

\footnotetext{
${ }^{36}$ Both the anti-Bush and pro-Kurdish rallies are identified as occurring in March 2002, though they appear after the May 2002 rally in the film. While Marker's narrative choices/structure are not the current focus of study, this among other things indicates the "film-essay" approach, in which argument is a part of the narrative structure.

${ }^{37}$ Featured signs include "Non à Le Pen" and "Non à la guerre," as well as the rather less polite "Gréviste, tu nous fais chier!"
} 
the Champs-de-Mars, a crowd watching a World Cup game in front of Hotel de Ville, and two funerals, those of Léon Schwartzenberg and Marie Trintignant.

Each of the group gatherings - which collectively take up a majority of the film features a vocal component, from the straightforward political chants of the anti-Bush march to the Muslim women singing La Marseillaise. ${ }^{38}$ Though not always musical, these vocal components have several functions. They bring the group together in the creation of (more or less) one sound, create a cohesiveness of purpose, and potentially bring outsiders into the group. They also allow members of the group to express themselves, to lend their voices to the cause and become active participants in the process. The physical movements - clapping, walking, etc. - similarly allow the participants to engage with the protest through their actions and to join with a greater whole; only by bringing a critical mass of people together can the effect of marching down the street be of a notable force. The use of public space is also significant; these groups are essentially taking over an area that has been designated for alternate purposes; although many if not all of the protests are likely legal, they are nonetheless disruptive of the normal order of events. Again, few of these elements would be notable if performed by individuals; the presence of a large number of people is essential to the effectiveness of the protest, rally, or event.

But beyond the critical mass of people that makes these gatherings effective, the film insists on the parallels that turn up across all of these gatherings no matter what their purpose or goal. Each group movement is seen through hand-held camera footage, generally filmed from the edge of the crowd so that faces can be clearly seen but are rarely featured within the frame. The soundtrack is made up of the ambient crowd noise, including whatever chants and crowd murmurs happen to occur. The camera usually follows signs and banners long enough that the

\footnotetext{
${ }^{38}$ In the case of the anti-Bush demonstration, the featured chant is a French-accented English-language shout of "one, two, three, four, we don't want your fucking war!"
} 
viewer can read their content, and often shows at one point or another the people leading the protests, standing on elevated surfaces and using megaphones to spur crowd participation, but otherwise remains largely in motion, panning or cutting from focus point to focus point. In other words, while it is possible to distinguish the various movements through their signage and message, in many ways the disparate causes blur together; none appears more than once in the film, and none receives a place of prominence in the film's narrative. All are more or less equal examples of what happens when a group of people (in France) are united by a common desire and want to make their voices heard: they gather in a public space, join together in song or chant or movement, and use additional, often written, visual aids to further their message. And beyond the anonymous faces of the protests lie the equally anonymous faces of the non-protesting people of Paris, who are also observed by the roving camera eye. In particular, the film features several sequences of people in the subway system of the city, either moving through the tunnels connecting various stations, waiting on the platforms, or on the trains themselves. Like the protesters, these faces are seen in medium close-up but are not identified, nor are they given any context; they exist as elements of the collective rather than as individual entities. They quickly become part of the masses; the people of Paris have been subsumed by the zooming, roving, indiscriminate camera-eye into a collective entity lacking (for the most part) individual outlines.

For while mass gatherings can certainly be a productive method for a minority population to make itself heard, it can also be easy to fall into a kind of complacency. In other words, following the crowd can lead to a tendency to accept the prevailing or surrounding opinion, forgetting to think. ${ }^{39}$ At least this is what Marker implies with a sequence that falls near the end of the film and features crowds watching the 2002 World Cup, during which France famously

\footnotetext{
${ }^{39}$ Though Marker does not address the topic, this has more recently resulted in the phenomenon of "flash robs" in which crowds act in violent or socially unacceptable ways. Wasik, "\#Riot," n.p.
} 
failed to score a goal despite having won the entire tournament four years earlier (and despite being, as the intertitles put it, a team made up of "onze milliardaires.") The crowds watching the soccer game, their faces and voices expressing intense emotions, are paired with images of the players plastered as advertisements on buses and on city streets. The gigantic faces of the players loom over the crowds walking past, as the anonymous camera hovers across the street (Figure 3.6). The Speaker points out the incongruity of featuring players who have essentially failed at their job in order to sell consumer items: "Des portraits aux dimensions stalinniennes. . . et pas un but marqué." Here, the mass movement of people is not a tool for social change but rather the opposite, an example of crowdthink where the potential for social and political dialogue has been stifled by the overwhelming desire for, in this case, just one goal. It seems that few, if any, of the spectators consider the implications of the highly commercialized event; certainly the film does not feature any commentary from the crowds on the subject. Further, although the film does not directly address it, the national French soccer team that won the World Cup tournament in 1998 had been widely embraced by the country and vaunted for its diverse racial makeup. ${ }^{40}$ The strangeness of the players of North African descent being widely embraced in a country that at that point had only recently begun calling the 1954-1962 Algerian War of Independence something other than a "law and order maintenance operation" remains unnoted. ${ }^{41}$ By this, the last quarter of the film, Marker is openly problematizing the idea of group movements; the collective can be blinding as well as productive. In fact the film - via the intertitles - openly notes the contradictions that can be inherent within these protests - for example, how it is

\footnotetext{
${ }^{40}$ For an investigation into media coverage of the French national soccer team in 1998 and afterwards, see Jonathan Ervine, "Les banlieues and Les Bleus: Political and media discourse about sport and society in France," French Cultural Studies 25 no. 1 (2014): 70 - 81.

${ }^{41}$ BBC News. "France admits Algerian campaign was 'war,"” BBCNews.com, 1999, http://news.bbc.co.uk/2/hi/africa/365868.stm.; for a discussion on France's terminology of memory regarding the war with Algeria see Jo McCormack, "Social Memories in (Post)colonial France: Remembering the FrancoAlgerian War," Journal of Social History 44 no. 4 (2011): 1129 - 1138.
} 
sometimes difficult to determine what exactly is at stake ("Enfin ils sont pour ou

contre?...Cherchons l'idéologie"), or noting that people are just as willing to chant anti-Raffarin slogans as pro-Raffarin, depending on the occasion. ${ }^{42}$

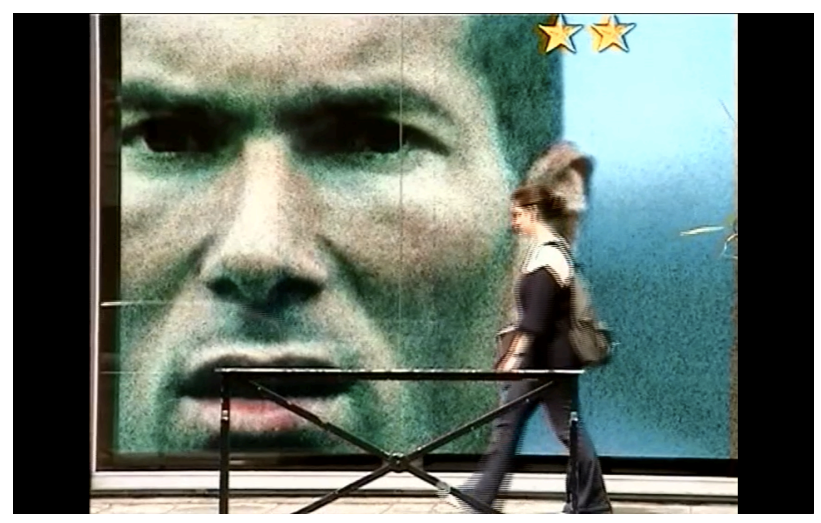

Fig. 3.6

By insisting on the common elements within the protests, and suggesting that occasionally people choose to follow the crowd without putting too much thought into the matter, Marker makes clear that collective movements themselves are not solutions in and of themselves. Yet these movements are clearly a means for a minority, repressed, or otherwise unheard population to be seen and heard publicly, to gather others to their cause, to express deeply held convictions, and perhaps even to inspire change. How to reconcile these two characteristics? The key seems to be in the movements themselves, the physical choices of the individuals who make up the collective. The camera is not interested in finding out more about the masses of people clapping, walking, and singing. They are allowed to go on their way, never to return to the frame. The camera does, however, tend to linger on certain participants. In particular, on several occasions the camera-eye follows or rests on individuals who are dancing either to the music of the protests or to their own beat - for several seconds. In a few cases, the

\footnotetext{
${ }^{42}$ In the background of the former example a male voice can be heard aggressively shouting the single word "liberte" over and over again, an example of a means of communication that is demonstrably more aggravating than effective.
} 
clip is actually slowed down, and the surrounding protest music to which they dance is muted or replaced by a slower, gentler music. In the first instance, seventeen minutes into the film, a young woman sits on a friend's shoulders at a protest. She wears a hat and is seen only in profile, but nonetheless is separate from the crowd, literally sitting apart. The slow-motion clip lasts only a few seconds, but its subject - that individual woman - is unmistakable, and made memorable by the change. Ten minutes later, another woman dancing at a protest is given the same treatment, with the clip slowed down and the protest music once again muted and this time changed to a different soundtrack. She too appears in profile, with the Marianne statue of the Place de la République easily visible in the background (Figure 3.7). It is no accident that Marker includes these dancers in the film, highlighting their presence by letting the camera linger on their faces and bodies; they are the ones who stand out, who have chosen their own path through the crowd. By focusing on these individuals and giving them value within the film, Marker suggests that while the collective is important - indeed, essential - it cannot be a blind choice. Individuality, the ability to dance as well as march, must also be present.

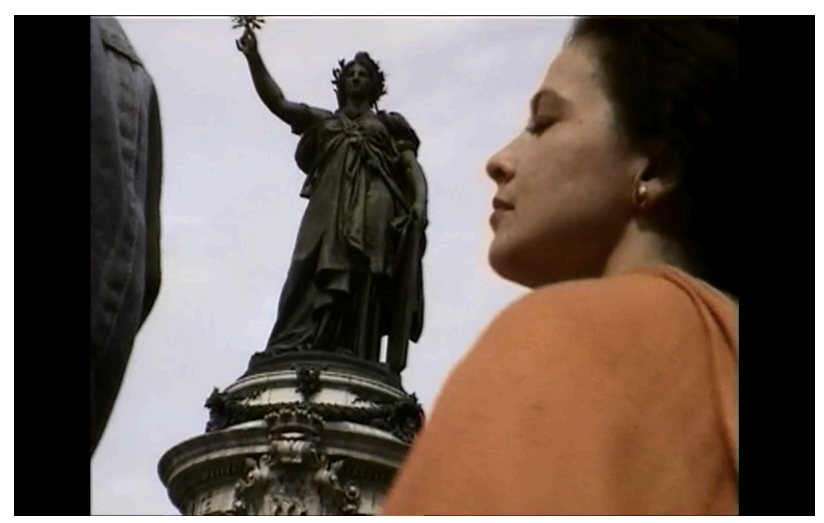

Fig. 3.7 
The dancers are not the only indication of individuality. Certain other moments stand out within the film, moments in which anonymity is not banished but perhaps slightly lessened. These are the moments in which one or another of the people passing in front of the camera accidentally catches the viewer's eye, looking directly into the lens. The contact that occurs in this instant is inherently intriguing; as Marker notes in his 1983 film Sans soleil, one of the earliest rules one learns as a filmmaker is to avoid having your subjects look directly at the camera. Marker, however, relishes these moments, often replaying them in slow-motion or pausing the frame so that the eyes of the stranger remained locked in place. As with the dancers who stand out from the crowd, these strangers become more intimately connected with the viewer, having broken free from their surroundings and differentiated themselves - even if accidentally - from those around them. In fact a third instance of a slow-motion clip with changed soundtrack nearly identical to those described above features a young woman who turns to look directly at the camera, smiling as she moves along with the protest. The music that accompanies the slow-motion clip is the same as that of the second dancer; the moments are therefore both given prominence within the film. Many of Marker's films contain elements like these that offer the audience the chance to personally identify with what they are reading or watching. They are instants - a frame, a scene, a glimpse - in which the audience sees its own reflection. As Marker himself refers to them, they are "moments that quicken the heart.",43

In particular, these moments occur whenever there are brief instances of contact between the camera and the crowd; although both the Speaker and the subject of the camera-eye remain anonymous, a connection is made when strangers accidentally catch the camera's eye. In fact, the sensation is heightened when both sides remain strangers; sharing a smile or brief eye contact, being able to communicate across the distance through these primal methods, can be

\footnotetext{
${ }^{43}$ The quote comes from Sans soleil and is attributed to an 11th century philosopher named Sei Sonagon.
} 
illuminating. For the purposes of this section I will refer to these moments as points of contact.

My use of the term points of contact is inspired both by the idea of contact zones, especially as put forth by Mary Louise Pratt in her 1992 work Imperial Eyes: Travel Writing and Transculturation, ${ }^{44}$ and by the related terms, discussed below, established by animal studies scholars to describe the moments (often characterized by touch) when animals and humans interact. Both types of contact, between cultures and between species, involve physical as well as (or instead of) verbal communication; while the touch in this case may only be haptic, the discussion is nonetheless appropriate to a film that is, after all, about chasing cats.

Sight, and particularly the exchange of gazes, prompts many of the investigations into the contact between human and non-human species. For Jacques Derrida, of course, it is the cat that makes him uneasy: it is via his own reflection in his cat's eyes that he first begins to consider the questions of identity that inspired 'L'animal que donc je suis." Derrida's concept of the point of contact is one of exchange, of potential equality, even co-being. ${ }^{45}$ In true Derridian style he puns on the double meaning of the French suis:

The animal is there before me, there next to me, there in front of me - I who am (following) after it. And also, therefore, since it is before me, it is behind me. It surrounds me. And from the vantage of this being-there-before-me it can allow itself to be looked at, no doubt, but also - something that philosophy perhaps forgets, perhaps being this calculated forgetting itself - it can look at me. It has its point of view regarding me. The point of view of the absolute other, and nothing will have ever given me more food for thinking through this absolute alterity of the neighbor or of the next(-door) than these moments when I see myself seen naked under the gaze of a cat. ${ }^{46}$

\footnotetext{
44 “[S]ocial spaces where disparate cultures meet, clash, and grapple with each other, often in highly asymmetrical relations of domination and subordination - such as colonialism and slavery, or their aftermaths as they are lived out across the globe today." Mary Louise Pratt, Imperial Eyes: Travel Writing and Transculturation (New York:

Routledge, 2008), 7.

${ }^{45}$ See also Deleuze and Guattari's section on "Becoming-Animal” from Mille Plateaux. Gilles Deleuze and Félix Guattari, A Thousand Plateaus: Capitalism and Schizophrenia, trans. Brian Massumi (Minneapolis: University of Minnesota Press, 2008).

${ }^{46}$ Derrida, The Animal That Therefore I Am, 11.
} 
Derrida sees himself being seen, and it startles him. We are not used to the idea of being reflected - or reflected upon - by others, and the experience can and does prompt a reconsideration of the self.

For a more literary representation, animal studies scholars often point to Rainer Maria Rilke's Duino Elegies, published in 1923, as including a particularly lyrical evocation of the animal gaze ${ }^{47}$ The eighth Elegy, which considers animal consciousness, emotion, and perspective against that of man, speaks specifically of the moment when an animal and a human face each other: "some mute animal/ raising its calm eyes and seeing through us,/ and through us. ${ }^{48}$ Giorgio Agamben, citing from the poem, notes that

In the eighth Elegy it is the animal (die Kreatur) that sees the open 'with all its eyes,' in distinct contrast to man, whose eyes have instead been 'turned backward' and placed 'like traps' around him. While man always has the world before him - always only stands 'facing opposite' (gegenüber) and never enters the 'pure space' of the outside - the animal instead moves in the open, in a 'nowhere without the no'..,49

The idea of the Open - the environment and perspective specific to each species and termed Umwelt by Jakob von Uexküll - has since been discussed by everyone from Heidigger to Benjamin, and as Agamben makes clear man has long wondered what he might learn from contact with the animal. ${ }^{50}$

Jean-Christophe Bailly, in his 2007 text The Animal Side, echoes Derrida's conclusion: " $[\mathrm{N}]$ either the mountain nor the pine forest, no object and no plant, can do what any animal can do: see us, and make us understand that we are seen." ${ }^{, 51}$ But Bailly also equates sight - the gaze -

\footnotetext{
${ }^{47}$ Rainer Maria Rilke, Duino Elegies and The Sonnets to Orpheus, trans. A. Poulin (Houghton Mifflin Harcourt, 2005).

${ }^{48}$ Ibid., 57.

${ }^{49}$ Giorgio Agamben, The Open: Man and Animal, trans. Kevin Attell (Stanford: Stanford University Press, 2004), 57.

${ }^{50}$ Agamben offers a lengthy discussion of the development of this term as well as other approaches to human/animal contact in The Open: Man and Animal.

${ }^{51}$ Jean-Christophe Bailly, The Animal Side, trans. Catherine Porter (New York: Fordham University Press, 2011), 16.
} 
as a sort of touch; when he sees a deer emerge from the darkness as he drives down a dark road, he describes it "as if with my eyes, in that instant, for the duration of that instant, I had touched some part of the animal world. Touched, yes, touched with my eyes, despite the impossibility." ${ }^{52}$ His chance experience leads him to conclude that "there is no supremacy, neither of humans nor of beasts, that there are only passages, fleeting sovereignties, occasions, escapes, encounters. The deer was in its night and I in mine, each of us alone. Still. . . I am quite sure of what I touched: . . . that instant opening onto another world. ${ }^{, 53}$ Bailly introduces the term point of contact as a means to make sense of his experience both with the deer and with various other animals, referring to "the close contact, always singular and always consisting of touch, that is the ordinary mode of the bond between them and us - something scarcely formed, always nascent." ${ }^{\text {} 54}$ For him, the gaze - even if it is not returned by the animal - is a shared moment, a non-physical but nonetheless essential connection or communication between the two beings.

Although she reflects upon a different domestic animal, the idea of communication by means of touch is also essential to Donna J. Haraway's When Species Meet, the guiding question of which she states as: "Whom and what do I touch when I touch my dog?"55 Haraway refers to moments of touch as entanglements, knots, or contact zones, the latter in her case also referring to a specified area in dog agility trials which the competing dogs must touch with their paws before continuing on to the next obstacle. ${ }^{56}$ She writes mainly of domestic animals, whose relationships with humans are particularly tangled, practically as well as theoretically speaking. Haraway believes Derrida did not go far enough in his consideration of the cat and that Derrida, despite his enormous powers of inquiry, was not curious enough with regard to the cat's gaze

\footnotetext{
${ }^{52}$ Ibid., 2.

${ }^{53}$ Ibid., 2-3.

${ }^{54}$ Ibid., 5.

${ }^{55}$ Donna J. Haraway, When Species Meet (Minneapolis: University of Minnesota Press, 2008), 3.

${ }^{56}$ For a discussion of the development of the term "contact zone" via Mary Pratt, James Clifford, Juanita Sundberg, Anna Tsing, and Eduardo Kohn see Haraway, When Species Meet, 205 - 246.
} 
back at him. She suggests that Derrida should have considered the possibility of non-verbal communication, thus "delving into the developing knowledges of both cat-cat and cat-human behavioral semiotics when species meet. ${ }^{, 57}$ Although Derrida's turn to the question of whether or not animals suffer offers valuable insights into the human conceptualization of other species, it fails - according to Haraway - to actually adopt an animalistic perspective. Derrida's relationship to his cat is thus less of a knot and more of a true point of contact.

Like Bailly, Haraway is interested in the similarities between touch and sight, particularly touch as mediated by visual technologies. Referring to a photo of a stump that looks remarkably doglike and that a friend had stumbled upon by chance, she writes: "We touch Jim's dog with fingery eyes made possible by a fine digital camera, computers, servers, and e-mail programs through which the high-density jpg was sent to me."58 Given her terminology, she understandably considers the moment of viewing the photograph of the stump-dog as one of "haptic-optic touch." ${ }^{, 59}$ Interestingly, Bailly also compares his vision of the deer in the road to "an image from a film." ${ }^{60}$ Both Haraway and Bailly are echoing the work of Laura Marks, who in The Skin of the Film (2000) coins the term haptic visuality to refer to the "the way vision can be tactile, as though one were touching a film with one's eyes." ${ }^{, 61}$ Marks uses this term as a productive entry into the possibilities for intercultural cinema, which she considers "an international phenomenon, produced wherever people of different cultural backgrounds live together in he power-inflected spaces of diaspora, (post- or neo-) colonialism, and cultural

\footnotetext{
${ }^{57}$ Ibid., 56. One approach to considering what the animal (or insect) might see was put forth by Jakob von Uexküll, who used the term Umwelt to postulate that every species has its own environment, specified by its unique needs and perspectives. Agamben, The Open: Man and Animal, 39-47.

${ }_{58}^{58}$ Haraway, When Species Meet, 5.

${ }^{59}$ Ibid., 6.

${ }^{60}$ Bailly, The Animal Side, 7.

${ }^{61}$ Laura U. Marks, The Skin of the Film: Intercultural Cinema, Embodiment, and the Senses (Durham: Duke University Press, 2000), xi.
} 
apartheid." ${ }^{62}$ In other words, Marks is interested in the moments where one culture finds the ability to "touch" another. Where Marks and Pratt write of intersections among cultures, Bailly and Haraway address the question of those among different species.

Beyond sight and touch, one might even be able to consider contact via the sense of taste, if we stretch our tolerance of wordplay. Haraway writes:

Among beings who recognize one another, who respond to the presence of a significant other, something delicious is at stake. Or, as Barbara Smuts put it after decades of careful scientific field studies of baboons and chimps, cetaceans, and dogs, copresence "is something we taste rather than something we use. In mutuality, we sense that inside this other body, there is 'someone home,' someone so like ourselves that we can co-create a shared reality as equals." 63

"Delicious" is a lovely way to describe that general sense of well-being that comes from identifying a kindred spirit. But generally speaking, despite their relevance to real-world interactions among species, tasting and smelling are not (yet) useful senses when it comes to works of literature, film, or art. Nonetheless, while it is perhaps easiest to perceive our humanness in our reflection in the eyes - or the skin, taste, or smell - of animals, it is also possible to find ourselves reflected by means of non-living entities. In particular, as Bailly notes, Walter Benjamin asserted that even objects could in some way gaze back, writing in his study on the aura that "to perceive the aura of an object we look at means to invest it with the ability to look at us in return." ${ }^{64}$ In fact Benjamin is well known for associating objects and identity, having used his Arcades Project as a means of collecting and understanding Paris and its people. In walking the streets of foreign cities the visitor corresponds with his surroundings, and as countless studies on the flâneur have made clear, by collecting that which he sees the flâneur also defines himself. Charles Baudelaire describes his famous flâneur-observer in "The Painter of

\footnotetext{
62 Ibid.

${ }^{63}$ Haraway, When Species Meet, 236.

${ }^{64}$ Bailly, The Animal Side, 17.
} 
Modern Life" as "a mirror as vast as the crowd itself. . . a kaleidoscope gifted with consciousness;" ${ }^{65}$ his M.C.G. not only recognizes himself in his surroundings, but also in part identifies himself by so doing.

And if we can find ourselves reflected in objects, why not also in images and words? Both are mere representations of reality, but they retain a certain affective power. Harnessing the surroundings - the foreign, the alien, the not-self — in film or photography, in illustration or text, authors and filmmakers bring the other to our living rooms. This is what Marker accomplishes in Chats perchés by gathering images from across Paris and presenting them to our view. Marker's Speaker thus becomes the "eternal[ly] convalescent" Constantin Guys, looking for joy "amid the ebb and flow of movement, in the midst of the fugitive and the infinite," new-world flâneur armed with a camera instead of a pen. Marker's works spring in part from these interactions with the world around him, from the people, animals, and objects he observed and by means of image and/or word transmitted to the audience. The protests filled in Chats perchés are full of sensuous elements, including the eye contact, the chants and other vocal elements, and hands clapping and touching each other. It is via these points of contact, these appeals to the senses, that Marker's films might best resonate with their audience.

And, lest we forget the stated premise of the film - as the intertitles put it, "où sont les chats?" - the various collectives formed by the people of Paris are paralleled by the collective of cats represented by M. Chat and his feline comrades. As with the political protests, whose effect depends on the presence of as many people as possible, as iterations of the M. Chat graffito multiply across the city they begin to take on a larger significance; they must be considered as a

\footnotetext{
${ }^{65}$ Charles Baudelaire, The Painter of Modern Life and Other Essays, trans. and ed. Jonathan Mayne (London: Phaidon Press Limited, 2003), 10.

${ }^{66}$ Ibid., 9 .
} 
movement and not just as individual actions. ${ }^{67}$ Later, the film notes, M. Chat begins to appear in other cities, including Nantes and even Zurich. The significance of this proliferation of images is itself one of the questions of the film: what do all these cat images mean, and do they correspond at all with the political and social milieu of Paris at the time? By the end of the film, the two movements have merged, as protesters begin to use images of M. Chat on signs during marches and protests (Figure 3.8). Once M. Chat appears, it becomes clear that the image has been coopted by the movements as a symbol of liberty and peace: at least one of the accompanying signs reads: "Faites les chats, pas la guerre." However, the cats represent more than a visual marker of these two universal goals, at least as far as the film is concerned. As with the dancers, the camera tends to linger on the cats, even zooming in to get a closer look. They are usually visually centered in the frame, and while on the whole they share certain characteristics, many feature distinguishing details such as hats, flowers, flags, wings, even defined hands and feet. M. Chat and his clones are thus, like the dancers, an opportunity to insert a little bit of whimsy into an important conversation. With their insouciant grins and bright yellow coloring, the cats demand a certain amount of irreverence. As they multiply through the city they suggest the presence of a vitality within the concrete infrastructure; they are illegal but beautiful, participating in the landscape of the city by resurfacing certain small parts of it. As they proliferate across protest signs, they signify the joy still present beneath the angry protests, a sense of peace amidst an atmosphere of war. Whether one cat with many faces, or many cats collected into one, they

\footnotetext{
${ }^{67}$ The originating artist was identified in 2007 as Thoma Vuille but by the end of the film M. Chat has been coopted by others and can be seen on signs, banners, etc. David Finnan, "Chatting with M. Chat at Paris graffiti show," RFI.com. 2010, http://en.rfi.fr/culture/20100316-chatting-monsieur-chat-paris-graffiti-show; Vuille, M.Chat.
} 
wander the streets, observing, smiling silently to themselves, a band of feline flâneurs. And, of course, they are always willing to make eye contact with the camera. ${ }^{68}$

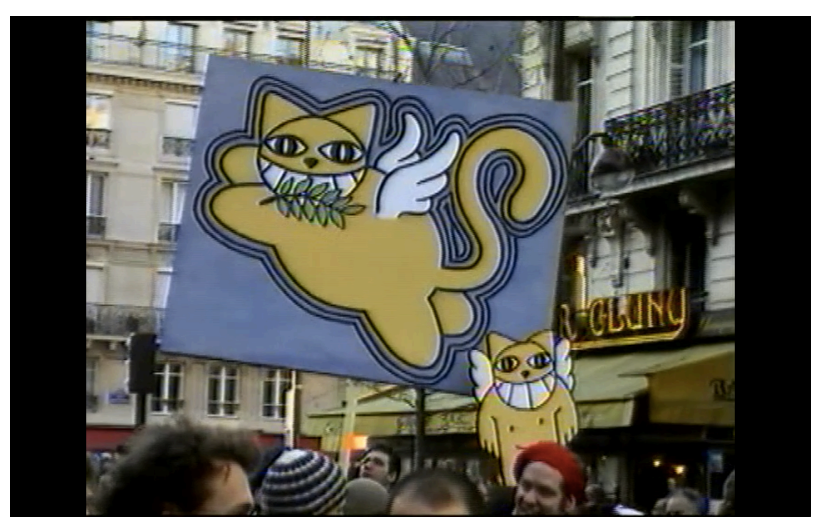

Fig. 3.8

Bailly suggests that points of contact with animals trigger unconscious memories, that “every animal, if we will only watch it exist and move, is the repository of a memory that surpasses the creature itself as it surpasses us, and where every instance in which its species has brushed against our own is inscribed." ${ }^{, 69}$ Bailly's deer, like Derrida's cat the inspiration for a theoretical inquiry into identity, parallels many of Marker's filmed images, in which something some unexpected moment - catches the eye and inspires a thought, a memory, a point of connection. This is the epitome of Marks' haptic moment: the eye touches the film, touches the humans, animals, objects, or images that Marker presents to our gaze. It's just a moment, just a glimpse of a deer on the road or a cat in the metro, but by taking that moment and making it durable - by including it in a film or a text - it becomes transmittable. It quickens the heart. These moments, while perhaps not as immediately accessible to our modern-day, highly attuned visual senses, nonetheless also spur recognition. In essence, by offering a kaleidoscope of reflections to our gaze they tap into the undeniable human urge to search for meaning and purpose beyond the self.

\footnotetext{
68 "Viens, mon beau chat, sur mon coeur amoureux;/ Retiens les griffes de ta patte,/ Et laisse-moi plonger dans tes beaux yeux,/ Mêlés de métal et d'agate. ..." Charles Baudelaire, "Le Chat," The Flowers of Evil, 70.

${ }^{69}$ Bailly, The Animal Side, 10.
} 


\section{Art in the streets: contemporary movements}

Collectivity and anonymity, then, are essential elements of group movement. But as the film suggests, it is all too easy to descend into a kind of groupthink, in which reason and purpose are subsumed by momentum; once we are all marching, clapping, chanting together, it is easier to continue blindly onwards than to change direction. The film therefore highlights the moments in which individuals stand out from the crowd, often by dancing or by looking directly into the camera. The former, in particular, suggests another useful form of protest: the use or creation of art. For intertwined with the film's examples of collective actions and the anonymity of individual subjects we find a meditation on art, in particular on the use of art as a form of protest and as a means of communication. This section will explore the various forms of art that permeate the film and will end with a discussion of the film's self-reflexive elements, the techniques that establish the film itself as a self-aware creative, artistic production.

The foremost example of art within the film is M. Chat himself, a graffito whose presence on the streets of Paris represents the contemporary street art movement. The film does not delve into the details of the artistic effort, instead suggesting that M. Chat is "manifesting" himself on walls (rather than being painted by human hands.) But the graffito's status as art is highlighted by a sequence in which Marker - or rather his investigatory counterpart - attempts to establish a history of the cat figure. The tongue-in-cheek sequence argues that the smiley-faced cat appeared as far back as the Chauvet cave paintings, subsequently appearing in works by everyone from Matisse to Miró to Miyazaki (Figure 3.9). This alternative history of art is humorous, but not irrelevant; street art may not be musealized in the manner of these other works but it does belong within the lineage. ${ }^{70}$ To support this premise this film also offers a sequence

\footnotetext{
${ }^{70}$ It also, incidentally, calls into question the validity of the image as truth, as the pictures of famous art have been rather obviously altered to include $\mathrm{M}$. Chat; however much this topic might interest Marker, here the intent seems to
} 
titled as a visit to the "musées de la rue" that features several wall murals across Paris as well as other street offerings, some elaborate and some as simple as the words "j'aime" or "amour" painted on the sidewalk. Further emphasizing the wide range of art forms available to a contemporary audience, the film's opening sequence, the flash mob, also reflects a newer sort of artistic movement. Flash mobs have been popularized since the early 2000 s as a means for people to express themselves as a group, without necessarily having a purpose or goal in mind beyond the gathering itself, and have been considered an offshoot of performance art. ${ }^{71}$ And Marker also films several sequences that feature street musicians performing in or around the Paris metro system, including a string ensemble, a brass band, and a folk group. Each of these sets of street musicians is featured within the frame and the film as the camera pans from instrument to instrument and their musical offerings often remaining as the soundtrack even once the camera-eye has turned to other things. Each band also gathers an audience, who are also of interest to the camera; many of them clap along or even dance.

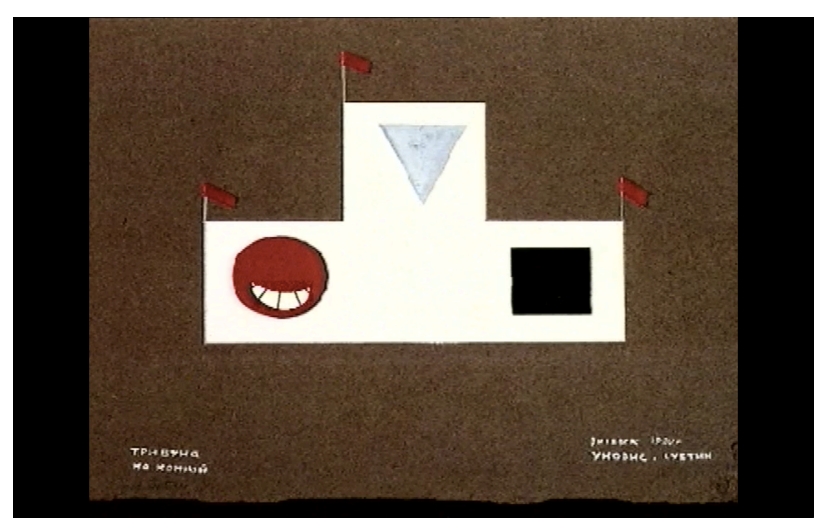

Fig. 3.9

be humor, not cynicism - the silliness of the premise of M. Chat resting on the lap of the Mona Lisa taking all the sting out of the potential critique.

${ }^{71}$ See "A Flash mob Manifesto" as translated and archived at http://web.archive.org/web/20071012195306/aglomerarispontane.weblog.ro/2004-12-05/20168/ManifestulAglomerarilor-Spontane---A-Flashmob-Manifesto.html 
The film thus offers examples of contemporary art in the forms of street murals, street musicians, and flash mobs. However, other art-like elements appear via the advertisements that often appear in the background of the frame and the protest chants that sustain many of the political rallies. ${ }^{72}$ Many of the ads that appear - or at least earn their own place in the frame - are political ads, featuring promotions for one or another of the then-current presidential nominees. These ads, along with the countless examples that line the walls of the metro, quickly become part of the landscape of the film. In fact, the advertisements that feature players from the World Cup team become a brief focus of the film as it notes the disconnect between the size of the ads (and the salary of the players) and the failure of the team itself. The protest chants also quickly become part of the soundtrack of the film due to their almost constant presence. They tend to be rhythmic and repetitive, often featuring simple slogans and very little if any melody or tune. Even the protesters who sing the French national anthem do so with very little musicality, outpacing their accompaniment and shouting more than singing. On the whole while the ads and protest songs are made of similar materials, feature common elements, and are used as means of expression, they are not quite art. As a result, these pairings - street art and advertisement, protest chant and street musician - call into question the very definition of art. In particular it is interesting to look at the pairing of street art and advertisement. Both are visual, often displayed on walls and designed to appeal to the viewer's senses, but one is mass-produced and aimed primarily at selling a product, while the other is hand-painted and intended as a marker of artistic identity. Advertisements are sanctioned by the powers-that-be, while graffiti is an act of defiance. But this, of course, is part of the point: advertisements are not art but rather massproduced art-like things. The ability to differentiate between advertisement and art, between protest song and music, between slogan and street art, and between rally and flash mob is what

\footnotetext{
${ }^{72}$ Unsurprisingly several of the ads seen on screen include cats as part of their appeal to the consumer audience.
} 
elevates the artist out of the crowd. Art gestates in the collective but must rise beyond it. In fact, the art that is featured in the film is not traditional or sanctioned art but rather an art of the people, art of the streets, from the brass band to the cat doodles on the walls.

Given the pairings of art and art-like projects, it is almost surprising that the film never features a clip from a commercial as a comparison to film. ${ }^{73}$ Chats perchés is itself an artistic product, a fact highlighted by the many self-reflexive elements within the film. A film that is self-reflexive or that evinces reflexivity usually demonstrates an awareness of itself through a variety of techniques that include the overt intervention of the director, glimpses of the filmmaking process, asides to the viewer, or anything else that betrays the filmmaker's inherent interest in constantly questioning the mechanisms behind the fixed representation appearing on the screen. As a whole, Chats perchés makes little or no attempt to draw the audience into a cohesive alternate reality. There is no need to suspend disbelief in order to enter into the film, for the film itself prefers that the viewer remain aware of the film's own status as a constructed artifact. In considering reflexivity as a major impetus behind the development of ethnographic film (particularly that of Jean Rouch), Matthias De Groof highlights several of the elements that might create a particular sense of reflexivity:

Self-interrogation and the awareness of the relativity of one's own point of view drove the ethnographic filmmaker to integrate his self-doubt into his representation of the other by means of cinematic devices. Reflexivity was translated into film language and became a cinematic device. It drove him/her also to wonder about the possibility of including the perspective of the other and his self-conception within the representation the former made of the latter, and finally to wonder about how the former would represent himself and his community through cinema. ${ }^{74}$

\footnotetext{
${ }^{73}$ Actually there is one brief mention of a commercial, but it turns out to be a false one that features only a steady stream of M. Chat figures.

${ }^{74}$ Matthias De Groof, "Rouch's Reflexive Turn: Indigenous Film as the Outcome of Reflexivity in Ethnographic Film," Visual Anthropology 26 (2013): 110.
} 
As De Groof insists, the key word to consider is "self." Chats perchés refers back to itself as a film regularly, often by seeming to speak directly to the viewing audience, rather than pretending it does not exist. In particular, it betrays an obvious editing of both image and sound, and a sense of humor that invites the audience to take on a certain perspective in relation to the images on the screen. Both of these are closely tied to the presence of the Speaker, whose voice - accessible through the omnipresent intertitles - gives us a glimpse of the inner workings of the film. The Speaker observes and can comment on the various clips, but also seems to have a hand in choosing them. He is therefore both inside and outside the film, both filmmaker and audience.

The obvious presence of an editor appears most prominently in the use of an effect that manipulates sound and image and that the film terms the MorphEye. The MorphEye device is, in essence, an extreme slow motion effect that also blurs the image on the screen so it remains identifiable, but no longer understandable. The resultant clip appears damaged, almost as if it were a mistake in the film itself. Two notable examples of this are the Morphing of George W. Bush's declaration of forces invading Iraq in 2003 and, later, of his declaration of the success of the invasion in front of the now infamous "Mission Accomplished" banner, both midway through the film. In both cases, the MorphEye removes the images - and the person - from the normal workings of time, making him appear strange, almost but not quite immobilized. To emphasize the disconnect, the sound that accompanies the original footage is played at normal speed. The result is an oddly jumpy, blurry Bush making broad statements about public policy while appearing to be completely outside of reality. This, of course, is the point; without overtly saying so, the film comments on the incongruity of Bush's words to the real world situation, when the invasion of Iraq was still very much a matter of debate. Notably, only politicians get the MorphEye treatment in Chats perchés; without overtly asserting the not-uncommon 
absurdity of official political statements, Marker nonetheless clearly makes his point. ${ }^{75}$ It is also clear that the image has been altered and that there is some editorial power at work behind the scenes.

The MorphEye moments are the film's most extreme cases of sound/image disconnect, but there are plenty of others. The opening sequence quickly establishes some of the highly noticeable camera techniques that are present throughout the film. The first evidence of the hand on the controls is the extreme zoom in on the graffito of M. Chat. The grinning cat looks down on the flash mob converging at the Centre Pompidou; it is so far distant that only an extreme zoom can even reveal its presence. The long zoom is repeated frequently, always zeroing in on a new M. Chat and in the process establishing both the surreptitiousness of the graffiti and its place within the environment. The zoom is particularly jarring given that it is often followed by closer shots of the same image; the camera eye thus reveals the conscious choice to observe M. Chat from a distance, mimicking how he (in theory) is in turn observing the French. ${ }^{76}$ Other examples of the disconnect between sound and image: in covering the Le Pen upset, the viewer sees still shots of the people's reactions and of newspaper headlines while screams are heard in the background; a woman dancing to music at a protest is shown in slow-motion, while the music continues at full speed; M. Chat disappears, but then reappears to the sound of royal fanfare; the AIDS lie-in is paired with the opening music from a film made by one of Marker's friends and colleagues, Alain Resnais, that also deals with death on a large scale and with memory: Hiroshima mon amour. The disconnect between sound and image asks the viewer to note these

\footnotetext{
${ }^{75}$ Other politicians who get Morphed include Pierre Lellouche, Jean-Pierre Raffarin, Jean-Pierre Chevènement and Tony Blair.

${ }^{76}$ It is fascinating to think about the larger implications of Marker also observing the crowd via his camera (which is separate from M. Chat but also a stand-in of sorts.) As of this writing I have not been able to determine who organized the flash mob in front of Centre Pompidou - could it have been Marker himself?
} 
moments, and to consider what might be going on behind the scenes. ${ }^{77}$ A particularly disconcerting sequence shows yet another shot of the men and women of Paris traveling through the subway system on a moving sidewalk, as they have been seen many times before in the film. The soundtrack, however, has been replaced by the sound of explosions and machine-gun fire. The sequence follows the shot of Bush declaring the invasion of Iraq and Tony Blair discussing the threat of weapons of mass destruction; the explosions thus evoke the bombs that (perhaps at that very moment) were falling on Baghdad and other parts of the country. Shots of individuals and couples are intercut with black frames, and the camera pans rapidly back and forth. Finally, advertisements loom overhead, gigantic smiling faces selling something indecipherable (Figure 3.10). As with the advertisements of the soccer players who look down, Stalin-esque, on the passing crowds during the World Cup, something is clearly off. Unable to reconcile the visual and aural elements, the viewer must reflect on the process of putting the film together and on the difference between representation and reality.

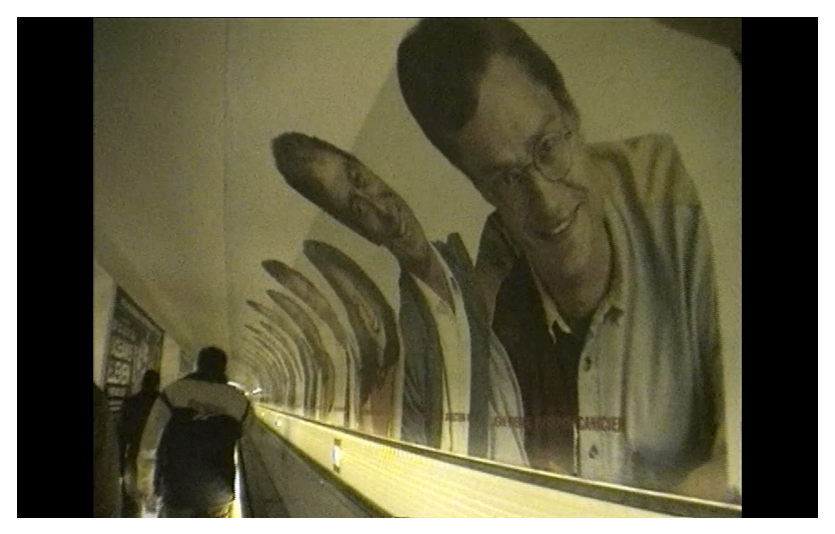

Fig. 3.10

\footnotetext{
${ }^{77}$ This has been widely noted in scholarship on Marker; see e.g. Levine, "Ghosts on the Skyline,"; Alter, Chris Marker, 19.
} 
Another way the Speaker makes his presence known is through the inclusion of a unique, often dark wit or sense of humor, inserting asides - via comical edits or amusing intertitles - that implicate the audience in the events seen on the screen. The intertitles are documentary-like, or even reminiscent of silent films, but Chats perchés is neither. As mentioned above, within minutes of the film's opening the camera zooms in on a graffito in the distance: the grinning cartoon cat, M. Chat. As the camera eye follows the flash mob participants, the film pauses in order to insert the words, in white on a black screen, "Et tout ça sous le regard d'un chat." Next, the long zoom, and a sound effect that sounds vaguely like an electronic slide whistle. Seconds later, echoing the disbelief an audience might well be feeling, the next title: "Un chat?" And this is only the first of many winks at the audience. For the intertitles are frequently funny, even playful, often unexpectedly so given the weight of the political issues in question. Occasionally the intertitles openly refer to the process of editing, terming one sequence of subway musicians "le bande-son du métro" and later excusing a supposed mistake in editing: "petite erreur de bande-son vite réparée.” Or, when watching a sequence of various travelers in the metro, the viewer sees the intertitle: "Un pigéon se change en homme", followed by a shot of the camera slowly following a pigeon as it flies around a corner in an underground tunnel. The camera eye, momentarily blind, turns the corner a few seconds after the bird, only to discover the bird missing and only a man walking slowly ahead. Later, following the film's buildup to the first round of the 2002 elections, the intertitle reads "le 21 avril, catastrophe." Given the wide knowledge of the primary results and the way Le Pen's success has been foreshadowed, the immediate thought must be of the elections, which did indeed occur on April 21 st. Yet the film instead cuts to a shot of Boléro, a cat that lives in the subway ("avec son humaine") and who, the speaker informs us, has caught his paw in an escalator (note the second, linguistic joke inherent 
in the use of the word "catastrophe.") The anonymous speaker continues to entertain throughout the film, commenting at one point, upon M. Chat's having been spotted at a Le Pen protest, “avait-it des ambitions politiques?” At an anti-Le Pen rally, the intertitle gleefully interjects: “un scoop: Le Pen allumé en esperanto" before following up with a wry "Ça se comprend très bien, l'esperanto" after the man's unintelligible comments. Beyond the intertitles, Marker and/or his Speaker also insert humor into other asides: note for example the addressees of the various letters to which M. Chat stamps are affixed, who range from Socrates to George Lucas, or the bilingual joke inherent in an internet search for the word "chat."

Also funny are the other cats that sneak into the film. These include the aforementioned Boléro, one of the few subjects of the film who is properly named and whose disappearance from the subway tunnels causes as much consternation for the speaker as the missing M. Chat. There are cats traced in outline on various surfaces, an advertisement featuring a cat seen through the window of a metro car, a live cat sunning itself in a doorway, another live cat (also given a proper name: Caroline) that gets stuck in a tree. Midway through the film there is a short "geneaologie du chat" which begins with the Cheshire Cat from Alice in Wonderland and works its way through Mizayaki and manga. At the end of the film, M. Chat's face gets superimposed on a cloud which, upon reflection, does look remarkably cat-like (Figure 3.11$){ }^{78}$ These cats are all different from the original graffito and yet they are part and parcel of the search; somehow, the presence of these alternate cats adds joy to the film, a brief respite as the world around them gets darker.

\footnotetext{
78 "Although time prevents it, I would of course have liked to inscribe my whole talk within a reading of Lewis Carroll." Derrida, The Animal That Therefore I Am, 7.
} 


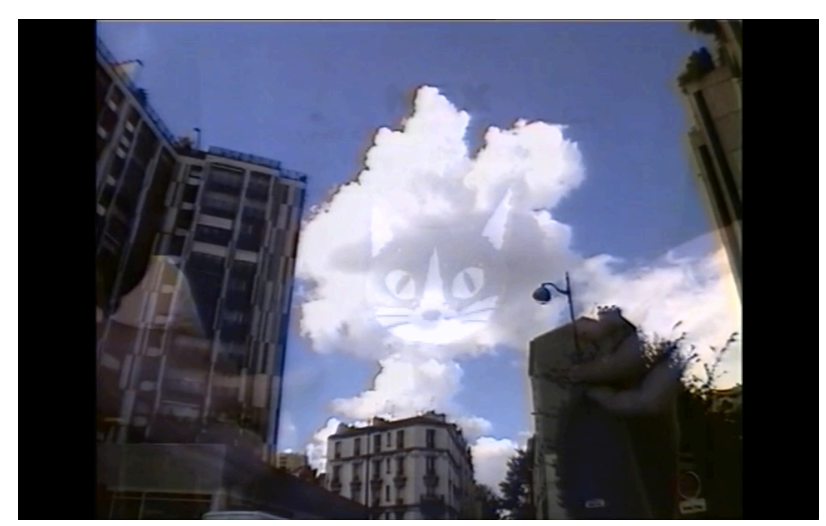

Fig. 3.11

Indeed the wittiness is often, maybe always, shadowed by a somewhat darker commentary. At one point, the Speaker suggests that if given the opportunity to pillage the Louvre he would of course take the Egyptian cats. The comment is accompanied by a reminder of the Baghdad museum that was pillaged following the arrival of American troops, and recalls earlier footage of the Bamiyan Buddhas that were destroyed by the Taliban in 2001. The moment is both indicative of Marker's presence in the film and darkly funny, given the overt obsession with cats throughout the film but also the dismay at the idea of museums being overrun at all. When M. Chat gets subbed into other places he does not belong - informational screens in the subway, stock market reports, popular films, stamps, websites - the initial effect again is humorous; on the website of America's Most Wanted, for example, M. Chat's image is listed as "Unknown Grinning Cat" alongside the crime: "destruction of public property." It makes sense given that M. Chat is, of course, a piece of graffiti illegally painted on walls in public places. Yet upon reflection it is almost unbearably dark, considering the actual lists of "Most Wanted" at the time - both the Ten Most Wanted Fugitives and the Ten Most Wanted Terrorists lists maintained by the FBI in the early 2000s featured Osama Bin Laden, wanted for a very well known act of destruction indeed. 


\section{Nothing to grin at: political underpinnings}

Indeed all of the above - collective, anonymous, artistic movements - are also, in the film, ways to discuss political issues that hold particular significance in France. They suggest the various ways that movement - and movements - may participate in the cultural and political milieu. The mass movements deserve to be filmed and interrogated precisely because they have an intended effect beyond the abilities of most individuals to achieve. With the exception of the flash mob that opens the film, the popular movements covered by the film tend to be focused on highly relevant and central issues of the first few years of the new millennium. Once the film has demonstrated, via the flash mob, that group movements will have a different and more intense effect than (most) individual efforts, the camera goes on to consider several of the divisive topics of the time period. One of these is the French reaction to George W. Bush's decision to invade Iraq in response to the threat of weapons of mass destruction supposedly under the control of Saddam Hussein. Chanting in English ("One, two, three, four, we don't want your fucking war; five, six, seven, eight, organize and demonstrate") the protesters hope at best to change the policies being implemented by America (and, not incidentally, also by France) and at least to register their disapproval. Whether or not the popular protests against the war in Iraq proved effective, another more immediately relevant protest gathered as a result of far-right politician Jean-Marie Le Pen's unexpected success in the first round of the French presidential elections of 2002 and also appears in the film. Le Pen's second-place finish, which put him in a run-off election with then-president Jacques Chirac, spurred massive movements against his election. The film also features a "lie-in" in memory of AIDS victims, held on the Champs de Mars. There is a political aspect to this gathering as well, as the viewer hears an unseen orator lament that the government will spend billions on wars and yet will not offer much money for AIDS research. 
Aside from focusing primarily on political protests, the film consistently works to subtly reinforce the political undertones through the use of cinematographic elements. Being made up primarily of documentary footage, the majority of structural elements are found in Marker's choices of what to film, which pieces of footage to include, and how to juxtapose various shots in order to bring a new understanding to the whole. Marker includes without comment several striking images that reinforce the political environment in which the film was made, many of which can easily pass unnoticed on first viewing. Perhaps the most difficult to watch is the footage of New York City's World Trade Center at the very moment of impact, still standing but burning, which has been superimposed over a shot of the Parisian skyline in the first few minutes of the film. Paris, in the primary image, looks peaceful; only after noticing the almost invisible superimposed image does this calm seem ominous; one thinks, among other things, of the difference between the immense skyscrapers of New York City and the legally mandated height restrictions of (almost) all buildings in Paris. Marker continues to slip reminders of 9/11 into the film, including a violent pan from a plane contrail, high in the sky, to one of the images of M. Chat perched on a rooftop. There is, too, a long shot of one of Paris' "secure" trashcans, put in place after the 1995 subway bombings as part of France's "Vigipirate" alert system and featuring transparent bags that are intended to deter bombs (Figure 3.12). The trashcan footage features a sun low in the sky, resulting in long shadows and sharp lines that are, like the plane contrail, vaguely menacing. Later, in one of the many sequences featuring the Paris metro, the ambient noise includes an announcement from the subway system public address system reminding riders to be attentive and aware. Towards the end of the film, the World Trade Center towers return in another subway graffito, which features the towers and the words "I [heart] NY"; 
heartbreakingly, the scribbled graffito also shows a plane, contrail sketched in, about to hit the tower on the left (Figure 3.13).

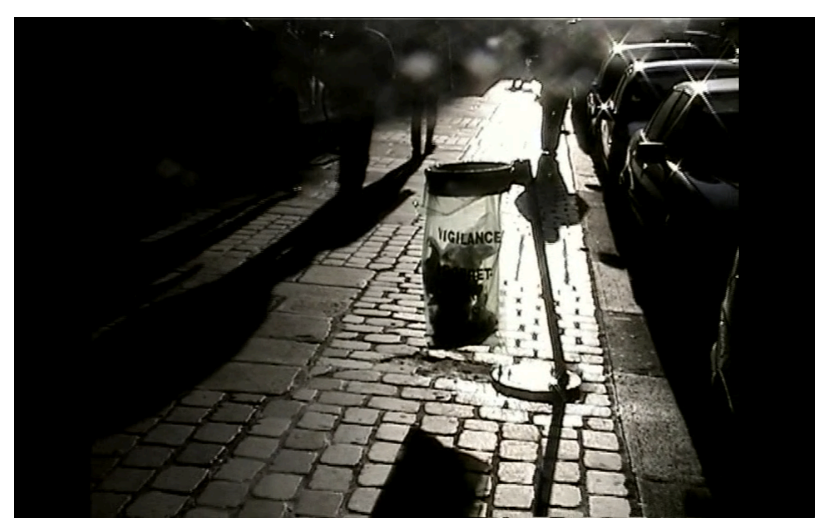

Fig. 3.12

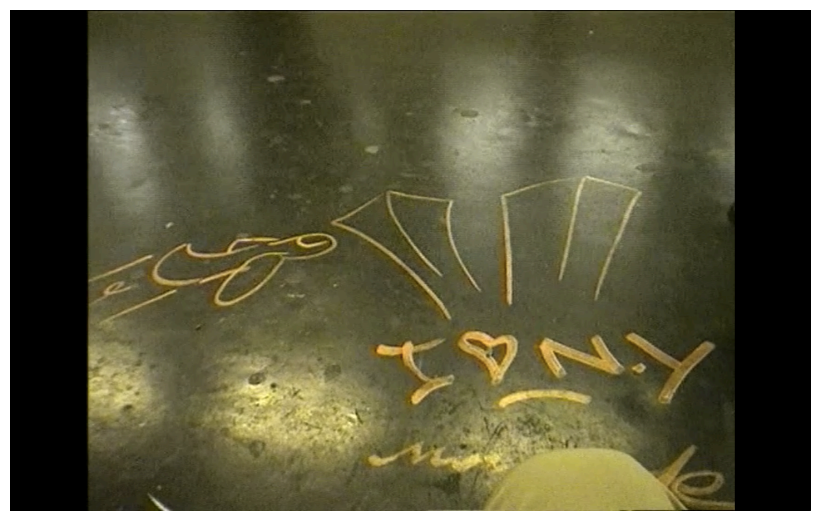

Fig. 3.13

Street art, street protests, and street music: all of these thus come together in a film focused on movements in the Parisian streets. Although the protests met with varying amounts of success, their mere existence is enough for Chats perchés; indeed, Marker never refers to or indicates the actual results. It is enough, one gathers, that the effort has been made to rally against the powers-that-be, whether they are named as the government, the corporation, the more conventional artistic forms. All of these gatherings, however small, are essential elements of contemporary political discourse. 


\section{Conclusion}

In addition to inserting dark humor and a distinct point of view into the film, the Speaker also allows Marker to acknowledge the role of chance in filmmaking and especially in documentary film. Marker's work celebrates chance more than most; for example, Sans soleil's argument in favor of the beauty of individually selected moments relies in part on the unexpected moments that help to create these "choses qui font battre le coeur," while La jetée (1962) is built around a chance encounter that changes one man's life and Le joli mai (1963) relishes the strange words and images that sometimes get caught on camera. Although always highly edited, Marker's films tend to meander from idea to idea, relying on unexpected correspondences to tie together sequences and themes. As a genre documentaries depend, at least in part, on the camera being in the right place at the right time, but rarely are the makings of the film so openly exposed. Indeed the Speaker of Chats perchés openly credits chance at the end of the film for bringing together one last, strange correspondence that takes the film to its darkest moment. The Speaker has just mourned, along with yet another group of anonymous onlookers, the loss of Léon Schwartzenberg, a well-known French activist, who was filmed at one of the protests and shortly thereafter passed away. ${ }^{79}$ As with previous segments, the viewer sees a sequence of still shots of anonymous faces people filmed from the back, images of hands, and handheld signs, no longer signs of protest but signs that celebrate and mourn Schwartzenberg for his work. These include a poster on which the camera rests for several seconds and which reads "Adieu Léon, on t'aimait bien," a far cry from the more combative signs in earlier public gatherings. Then, a flashback. The intertitle reads "le hasard me fait filmer un jeune chanteur," seen at a concert for the sans-papiers, one of the groups Schwartzenberg was known for defending. The singer filmed

\footnotetext{
${ }^{79}$ Douglas Johnson, “Obituary: Léon Schwartzenberg,” The Guardian News and Media, July 2014, http://www.theguardian.com/news/2003/oct/24/guardianobituaries.france.
} 
is Bertrand Cantat, who would soon be arrested for the murder of his girlfriend, the actress Marie Trintignant. Hence the need to film and show another, corresponding funeral. Following this sad confluence, the film repeats the pattern of an earlier sequence in which subway travelers were seen while the sounds of bombs played in the background. Now, however, instead of inserted black frames, the sequence of subway riders is intercut with images of newspapers covering the murder, flashed momentarily onto the screen. Only an eerie tone can be heard in the background. "Pas étonnant que les Chats nous abandonnent," muses the Speaker. Chance here is not a joyful occurrence but an indication of a growing darkness in the world.

The entire film, then, is exposed as a careful balance between chance and purpose, between countless unexpected moments from almost random places and times and the selfreflexive editing techniques that bring an alternate story to the fore. In the very first minutes of the film the viewer sees a series of shots filmed through the windows of a passing subway car: first a young woman waiting for a train, then the advertisement of a cat, then M. Chat himself. Soon afterwards, the viewer is presented with several more instances of things seen through other things: a map, with M. Chat sightings marked, superimposed over city traffic; advertisements seen behind the bodies of people passing; garbage seen through the transparent trashcans marked "vigilance." Often throughout the film one image will be superimposed on another, including the sunflower through which the funeral of Marie Trintignant is seen (yet another round, yellow face.) The anonymous faces who make up a majority of the film are often filmed through or behind windows, including a shot of a museum visitor that calls up a similar image from Marker's film with Alain Resnais Les statues meurent aussi (1953). The film thus returns again and again to the idea of images being mediated in some way. In fact, this is one of the underlying cautions of the film, which encourages an awareness of the difference between 
representation and reality. The MorphEye contributes to this awareness, as do other moments of discord between sound and image, the questioning of advertisements in the subway and surrounding the World Cup, and the various self-reflexive editing techniques that are readily apparent. Do these polished representations - advertisements, political declarations, filmed moments - really convey the truth? The film forces the question, and in doing so hints at the answer. As we consider the potential misrepresentations of the world via the chase for a cartoon cat, the film itself demonstrates the possibilities and pitfalls of mediation, both within its own structure and amidst the protests that make up its subject matter, themselves forms of mediation between people and power.

In the end Chats perchés descends into darkness, as Marker literally darkens the film images, swaps out the ambient noise of the subway for eerie music, and flashes the practically illegible but threatening headlines about Cantat onto the screen. Certain words are visible: "passion", "nuit", "enquête”, “drame” and, repeatedly, "death.” The faces seen through subway windows now appear at strange angles, Boléro goes missing from the subway tunnel, and M. Chat is expunged from the city walls. The intertitle reads: "Nous étions les Chats de la liberté. Si vous ne comprenez pas ce qu'on vous dit débrouillez-vous tous seuls." This, then, is what the speaker imagines the future might be: completely absent of individuality, humor, light. But all is not quite lost, for the next intertitle reads: "Et puis: UN SIGNE." The subsequent shot shows a circle of cat figures traced in outline on the sidewalk and further, a person's face seen through the circle. The circle is the same size and shape as the sunflower that encircled the faces of Trintignant's mourners and, for once, the camera lingers on the stranger's face. This final subway rider is still anonymous, but he has been in essence enfolded into the presence of the cats, as if under their protection. Indeed, the Speaker suggests that these new cats are here "pour veiller sur 
le sommeil du voisinage." All is not lost. The film ends with a time-lapse video of this circle of cats on the corner as numerous, anonymous people and cars pass by. The Speaker, although he fears for the future, still has faith in the M. Chats of the world and, via the intertitles, thanks them for their efforts: "Merci, les Chats." As he walks through the streets of Paris, he is once again able to exchange glances with the watchful cats, hopeful that at least a brief moment of communication has been achieved. 


\section{Conclusion}

\section{Ripples in a pond}

How does one respond to the lingering existential aftermath of large-scale traumatic events? In France, where cinema is considered something of a national hallmark, films are a productive place to look for trends and answers. In at least some films, we see the development of a posttraumatic flâneur, a reinvention of the $19^{\text {th }}$ century figure who strolled through the streets of Paris and became particularly identifiable in the works of Poe, Baudelaire, and Benjamin (not to mention Balzac, Flaubert, and Zola.) The posttraumatic flâneur expresses in a very literal way the need to physically respond to trauma, the common feeling that the trauma has in some way invaded the body and that the body must in some way echo the pain. His or her $19^{\text {th }}$ century ancestor, according to the iconic image most often adopted, was driven by artistic disposition and idleness to wander the streets, peacefully contemplating the hustle and bustle of the crowd. Yet I also read this drive as a kind of malaise on the part of an under-occupied leisure class, whose peripatetic ventures were in part a means to dispel boredom. While flânerie is by no means a cure-all, I argue that there is a correlation in these films between the posttraumatic gloom experienced by a nation of survivors and the impulse to take to the streets in search of something more. Therefore Elle finds solace in walking the paths of Hiroshima and her past, while the vast landscape of southern France gives Mona an environment in which to conceal herself from an unwelcoming gaze and the Speaker finds joy in the momentary points of contact that can abound in Parisian crowds.

Part of the tradition of the $19^{\text {th }}$ century flâneur comes from his tendency, especially if he was of an artistic disposition, to report back on what he saw: Benjamin did so through the 
Arcades Project, his semi-organized notebook on the Parisian streets and populace, while Baudelaire's flâneur (Constantin Guys) painted and Baudelaire himself wrote poems, with an entire series of poems in Fleurs du mal dedicated to Tableaux Parisiens. Although the pursuer does become the narrator of the story, neither of Poe's men of the crowd is particularly artistic. But the posttraumatic flâneurs of this study also report back on their journeys - or rather, the filmmakers who created them do, by presenting them to us. The clearest example is Marker - as an imperfect double of the Speaker, he is of course showing the audience what the Speaker has seen, and heard - essentially creating a contemporary version of a poem or painting, if one can stretch the definition of film-essay that far. By centering their respective films on these figures, Resnais, Varda, and Marker draw attention to their journeys and to the spaces through which they pass.

Another common thread in these films is the mutual gaze, the moment of (eye) contact that occurs between two strangers in the crowd. Poe's convalescent is spurred to action by a stranger's face; though the face was but half-glimpsed, there must be an instant in which that face spoke to him. ${ }^{1}$ Baudelaire himself wrote several poems dedicated to this glimpse, this moment of mutual gazing, including "À une passante" in which the speaker of the poem ecstatically drinks from the eyes of a woman who walks past. ${ }^{2}$ And Benjamin implicitly recognizes the importance of eye contact as he bemoans the rushing crowds who face a sensory overload in a world full of department stores and the like. In Hiroshima mon amour Elle is awoken merely by Lui's gaze brushing across her, and the two lovers regularly find the ability to communicate wordlessly through a glance. When their ability to make eye contact is broken, so

\footnotetext{
${ }^{1}$ So to speak.

2 “... Moi, je buvais, crispé comme un extravagant,/ Dans son oeil, ciel livide où germe l'ouragan, / La douceur qui fascine et le plaisir qui tue..." Charles Baudelaire, "À une passante," The Flowers of Evil, trans. James McGowan (New York : Oxford University Press, 1998), 188.
} 
too is their relationship: towards the end of the film, an old woman in the train station sits between them and speaks in Japanese to Lui. When he looks up from the conversation, Elle has vanished. With the Japanese woman's mere presence breaking the line of sight, the old woman has physically (and linguistically) negated the space of communication between Elle and Lui. Also consider that in Elle's past there is no possibility of eye contact, indeed often no eyes at all, just hands, feet, torsos, and bodies too far distant to see the details of the face. In Hiroshima's past, however, as told by the museum, there are many disconcerting moments of contact: in both re-enactments and documentary footage, the victims of the bomb turn and stare at the camera. These are powerful moments - they connect with Elle, clearly, who finds that her only possible approach to understanding the museum is to cry, and they connect with the audience, who also experiences them as a direct look through the camera lens and into a personal space. Several of Mona's interlocutors also look at the camera, but the most memorable is Assoun, who wordlessly gazes at the audience, Mona's red scarf in his hands. Mona herself isn't one for looking people in the eyes, but she does sit face-to-face with Assoun. Despite the unceremonious goodbye when he kicks her out of his home, Assoun's bond with Mona was a true one, a connection based on their status as outsiders. The best and maybe only way for him to show his sorrow is through making eye contact. And of course, Marker's film is full of moments of contact, in which a stranger catches the camera's eye and through it, our own. What to make of these points of contact? Marker's film suggests that they are the bright spots in a darkening world, and I would add that even for those characters who do not survive - especially Mona, who we know from the start dies - the ability to touch another person, even if only through the briefest of shared glances, does indeed quicken the heart. 
But maybe that is an overly optimistic reading. Consider another film that features an itinerant protagonist: Claire Denis' Beau Travail (1999). Like Resnais, Varda, and Marker, Denis is an extraordinarily proficient filmmaker unafraid to use a variety of visual techniques to convey essential elements of narrative through image and form. Her protagonist in Beau Travail is Sergeant Galoup, an odd and seemingly unhappy soldier in the French Foreign Legion who cannot escape the constantly swirling unease of his undisciplined emotions. Galoup in many ways is a perfect legionnaire, comfortable with and excelling at routine, and is therefore all the more disturbed to find himself unable to control his emotions with regard to two other members of the group, his commander Bruno Forestier and the new recruit Gilles Sentain. Even when reflecting on events in his past Galoup finds himself unable to understand how he has failed to impose discipline on his own emotions, and his voiceover, initially intending to provide an explanation for or at least a coherent narrative of past events, instead increasingly mixes past and present, truth and fiction. Time and space thus get more and more entangled as the film progresses, and by the final two scenes it is almost impossible to identify Galoup's location, let alone his motives. Interestingly, an analogous sense of entangled, circular motion emerges in the repetitive training exercises of the legionnaires and of Galoup himself. One after another the men navigate obstacles, crawling under barbed wire, leaping over poles, and scrambling up and down pits. Their movements have no defined endpoint or purpose; when the legionnaires navigate their set of rails, they must race back and forth along a tightly described metal path. Often the men appear to double back on themselves: two men will cross from right to left using a set of wires, followed by two men moving from left to right, the visual redundancy of the training overwhelming any sense of physical rationale. More disturbingly, the exercises never start or finish; instead, the camera always shows the men mid-action, in constant motion but never going 
anywhere. The rhythms of routine, for the legionnaires, thus appear highly constricted and often even circular, with many training rituals involving two men circling each other or grasping each other to form an almost spherical being. In one sequence, men swim tight circles around each other; later, they practice martial arts movements in which one man and then the other is thrown to the ground. Group stretching leads to images of circles traced in the sand and circular movements of the body and muscles. The sense of circularity extends to the movements of the camera; at one point, while filming the men marching from right to left through the frame, the camera spins so far that they almost walk back towards the right again, a visual bending of a straight line. The spinning duel/dance between Galoup and his rival Sentain is the culmination of the film's obsession with circularity, as the two men spiral around each other, moving closer and closer until they are face to face.

Galoup's movements are therefore perhaps another type of flânerie - a hopelessly mangled, perverted sort. Not only do his movements have no fixed destination, but he cannot seem to get anywhere at all. Instead, he becomes locked into the repetitive routine: train, eat, sleep, clean, watch. For part of the soldier's routine, of course, is to stand watch, to become a careful observer of his surroundings. And while there is no distinct trauma in the immediate background of this film, the Foreign Legion is intended to be sent to war; a conflict will always be recently past, or just on the horizon. Galoup, too, cannot quite manage his personal demons, which seem to stem from his past, his homosexuality, or some combination of the two. Beau Travail therefore becomes a film of movement, but also of tortured stasis embodied by a character who lives perpetually in motion but who is unable to move purposely from point to point, succeeding only in circling back on himself. The entire film can only be understood through Galoup's own tortured experience, the twists and turns of his memory alongside the 
actual twists and turns of his physical body and the camera that follows it. Like Elle, Mona, and the Speaker he finds some relief in being on the move, relishing and excelling at the routines of the legionnaire. Once he is deprived of this outlet, however, he has no other recourse; he wanders through the streets of Marseille but finds it no substitute for the life of the legionnaire. His is a stunted flânerie that ends with him lying on a bed, pistol in hand, unwilling to take another step. It is difficult to find, in Beau Travail's sparse crowd of soldiers, anything akin to Poe's intriguing face, or the sweetness of Baudelaire's passing woman. But here too there is a correlation between movement and trauma, with Galoup's pain embodied in his twisting, tortuous paths, and at the very end of the film there is finally a change, as Galoup - either in a dream or in an afterlife - channels his torment into an incredible, exhilarating dance. He spins and weaves in an empty room, surrounded by mirrors, accompanied by the flamboyant sounds of Corona's 1994 dance hit "The Rhythm of the Night." He seems happy, or at least more at peace with himself. After a film's worth of slow, deliberate motions, this astonishing ending brings a smile to the face. A moment that quickens the heart, after all.

Writing about her experience in New York City following the September $11^{\text {th }}$ terrorist attacks, E. Ann Kaplan describes the multitude of ways that people around her reacted to the event and the resultant sadness, pain, and fear: "There is an entire spectrum of responses to the attacks, a diversity of interpretations. It has become its own phenomenon, with circles spreading out like those from a stone thrown into a pond." ${ }^{3}$ Needless to say the same observation applies to any of the traumas experienced in these films, both for the fictional characters and their realworld equivalents. This study has examined one very small subset of responses in a selection of fictional representations of trauma, and I have sketched out the figure of the posttraumatic

\footnotetext{
${ }^{3}$ E. Ann Kaplan, Trauma Culture: The Politics of Terror and Loss in Media and Literature (New Brunswick: Rutgers University Press, 2005), 17.
} 
flâneur as an example of one possible ripple of response. It remains to be seen where else the posttraumatic flâneur walks - in what other films, essays, novels, poems, and memoirs he or she might be found. 


\section{Filmography}

Beau Travail. Directed by Claire Denis. 1999. New York : New Yorker Video, 2002. DVD.

Chat écoutant la musique (Cat Listening to Music). Directed by Chris Marker. 1990. Available on YouTube: https://www.youtube.com/watch?v=MrEHvDdEPrI.

Chats perchés (The Case of the Grinning Cat). Directed by Chris Marker. 2004. Brooklyn: Icarus Films, 2008. DVD.

Cléo de 5 à 7 (Cleo from 5 to 7). Directed by Agnès Varda. 1962. Irvington: The Criterion Collection, 2007. DVD.

Hiroshima mon amour. Directed by Alain Resnais. 1959. New York: The Criterion Collection, 2003. DVD.

La jetée. Directed by Chris Marker. 1962. New York: The Criterion Collection, 2007. DVD.

L'année dernière à Marienbad (Last Year at Marienbad). Directed by Alain Resnais. 1961. Irvington: The Criterion Collection, 2009. DVD

Le joli mai (The Lovely Month of May). Directed by Chris Marker. 1962. Issy-les-Moulineaux: ARTE France, 2013. DVD.

Le fond de l'air est rouge (Grin Without a Cat). Directed by Chris Marker. 1977. Issy-lesMoulineaux: ARTE France, 2013. DVD.

Le tombeau d'Alexandre (The Last Bolshevik). Directed by Chris Marker. 1993. Issy-lesMoulineaux: ARTE France, 2013. DVD.

Les Statues Meurent Aussi (Statues Also Die). Directed by Alain Resnais, Chris Marker, and Ghislain Cloquet. 1953. New York: The Criterion Collection, 2003. DVD.

Muriel ou Le temps d'un retour (Muriel, or, The Time of Return). Directed by Alain Resnais. 1963. Port Washington, NY : Koch Lorber Films, 2007. DVD.

Music and Dolly Shots. Directed by Agnès Varda. 2003. New York: The Criterion Collection, 2007. DVD.

Nuit et brouillard (Night and Fog). Directed by Alain Resnais. 1956. New York: The Criterion Collection, 2003. DVD.

Providence. Directed by Alain Resnais. 1977. Action-Films, Société française de production, FR 3, Citel Films, 2011. DVD. 
Sans soleil (Sunless). Directed by Chris Marker. 1983. New York: The Criterion Collection, 2007. DVD.

Sans toit ni loi (Vagabond). Directed by Agnès Varda. 1985. New York: The Criterion Collection, 2007. DVD.

Si j'avais quatre dromedaires (If I Had Four Camels). Directed by Chris Marker. 1966. Available on YouTube: https://www.youtube.com/watch?v=yIVU6TDLFFg. 2007.

Toute la mémoire du monde. Directed by Alain Resnais. 1956. New York: Criterion Collection, 2013. Available on YouTube: https://www.youtube.com/watch?v=i0RVSZ_yDjs. 


\section{Bibliography}

Agamben, Giorgio. The Open: Man and Animal. Translated by Kevin Attell. Stanford: Stanford University Press, 2004.

Alter, Nora. Chris Marker. Urbana: University of Illinois Press, 2006.

Alter, Nora M. "The Moving Essay." Presentation at the American Comparative Literature Association Annual Meeting, Cambridge, MA, March 17-20, 2016.

American Psychiatric Association. Diagnostic and statistical manual of mental disorders (DSM5). Arlington: American Psychiatric Pub, 2013.

Anderst, Leah. "Cinematic Free Indirect Style: Represented Memory in Hiroshima mon amour." Narrative 19, no. 3 (2011): 358-382.

Armes, Roy. The Ambiguous Image: Narrative Style in Modern European Cinema. Bloomington: Indiana University Press, 1976.

— The Cinema of Alain Resnais. London: A. Zwemmer Limited, 1968.

Astruc, Alexandre. "Naissance d'une nouvelle avant-garde: la caméra-stylo." Ecran français 144 (1948): 5.

Babcock, Arthur E. The New Novel in France: Theory and Practice of the Nouveau Roman. New York: Twayne Publishers, 1997.

Baker, Geoff. "The Predication of Violence: Reconstructing Hiroshima with Duras and Resnais." Dialectical Anthropology 24 no. 3 (1999): 387 - 406.

Bailly, Jean-Christophe. Le Versant animal. Paris: Bayard, 2007.

The Animal Side. Translated by Catherine Porter. New York: Fordham University Press, 2011.

Barthes, Roland. Mythologies. Paris: Éditions du Seuil, 1957.

_ S/Z: An Essay. Translated by Richard Miller. New York: Hill and Wang, 1974.

Baudelaire, Charles. "Le Peintre de la Vie Moderne." Oeuvres Complètes de Charles Baudelaire, Edited by Jacques Crépet. Vol. 3. Paris: Louis Conard, 1925. 49-110.

_Les Fleurs du mal. Genève: Slatkine, 1968.

___ Petits Poèmes en Prose: Le Spleen de Paris. Gloucester: Dodo Press, 2009. 
- - The Flowers of Evil. Translated by James McGowan. New York : Oxford University Press, 1998.

- - - The Painter of Modern Life and Other Essays. Translated and edited by Jonathan Mayne. London: Phaidon Press Limited, 2003.

Baudelaire, Charles and E. A. Poe. Nouvelles histoires extraordinaires. Gallimard, 1974.

Baudrillard, Jean. Simulations. New York: Semiotext(e), 1983.

— The System of Objects. Translated by James Benedict. London: Verso, 1996.

Bazin, André. What is Cinema? Translated by Hugh Gray. Berkeley : University of California Press, 2005.

BBC News. "France admits Algerian campaign was 'war.” BBCNews.com, 1999. http://news.bbc.co.uk/2/hi/africa/365868.stm

Benayoun, Robert. Alain Resnais: arpenteur de l'imaginaire. Paris: Editions Stock, 1980.

Bénézet, Delphine. "Spatial dialectic and political poetics in Agnès Varda's expatriate cinema." Journal of Romance Studies 9, no. 2 (2009): 85-100.

Benjamin, Walter. Charles Baudelaire: A Lyric Poet in the Era of High Capitalism. London: Verso, 1983.

The Arcades Project. Translated by Howard Eiland and Kevin McLaughlin. Cambridge: The Belknap Press of Harvard University Press, 1999.

- Illuminations: Essays and Reflections, Edited by Hannah Arendt. Translated by Harry Zohn. New York: Schocken Books, 1968.

— The Writer of Modern Life: Essays on Charles Baudelaire. Cambridge: Harvard, 2006.

Berger, James. "Trauma and Literary Theory." Contemporary Literature 38 no. 3 (1997): 589 582.

Bickerton, Emilie. A Short History of Cahiers du Cinéma. London: Verso, 2009.

Binion, Rudolph. Traumatic Reliving in History, Literature and Film. London: Karnac Books, 2011.

Blanchard, Marc Eli. In Search of the City: Engels, Baudelaire, Rimbaud. Saratoga: AMNA Libri and Company, 1985. 
Boutin, Aimée. "Rethinking the Flâneur: Flânerie and the Senses.”Dix-Neuf 16 no. 2 (2012): 124-132.

Burgin, Victor. In/Different Spaces: Place and Memory in Visual Culture. Berkeley: University of California Press, 1996.

Butler, Judith. Bodies that Matter: On the Discursive Limits of "Sex". New York: Routledge, 1993.

Careri, Francesco. Walkscapes: walking as an aesthetic practice. Barcelona: Gustavo Gili Land\&Scape Series, 2002.

Carlier, Christophe. Etudes Littéraires: Marguerite Duras, Alain Resnais, Hiroshima mon amour. Paris: Presses Universitaires de France, 1994.

Caruth, Cathy. Trauma: Explorations in memory. Baltimore: The Johns Hopkins University Press, 1995.

- Unclaimed Experience: Trauma, Narrative, and History. Baltimore: The Johns Hopkins University Press, 1996.

Cauville, Joëlle and Josette Déléas. "Fragments orphiques dans Hiroshima mon amour de Marguerite Duras et d'Alain Resnais." Cinémas: revue d'études cinématographiques 9 no. 2-3 (1999):159-173.

de Certeau, Michel. "Walking in the City." The Cultural Studies Reader, Edited by Simon Durang. London: Routledge, 1993.

Cléder, Jean and Gilles Mouëllic, eds. Nouvelle vague, nouveaux rivages: permanences du récit au cinéma, 1950 - 1970. Rennes: Presses Universitaire de Rennes, 2001.

Clifford, James. "On collecting art and culture." The Cultural Studies Reader, Edited by Simon During. London: Routledge, 1993. 49-73.

Cooper, Sarah. Chris Marker. Manchester: Manchester University Press, 2008.

Cordua, Christian Hermansen, ed. Manifestoes and transformations in the early modernist city. Burlington: Ashgate Publishing, Ltd., 2010.

Corrigan, Timothy. The Essay Film: From Montaigne, After Marker. New York: Oxford University Press, 2011.

Cowie, Elizabeth. "Specters of the Real: Documentary Time and Art." differences 18 no. 1 (2007): 87-127. 
Daire, Joël. "Estate Chris Marker: Where are we at with the inventory?" Chris Marker: Notes from the Era of Imperfect Memory. 2015. http://chrismarker.org/2015/06/state-of-theestate/

De Groof, Matthias. "Rouch's Reflexive Turn: Indigenous Film as the Outcome of Reflexivity in Ethnographic Film.” Visual Anthropology 26 (2013): 109-131.

Deleuze, Gilles. Cinema 1: The movement-image. Translated by Hugh Tomlinson and Barbara Habberjam. Minneapolis: University of Minnesota Press, 2009.

Cinema 2: The time-image. Translated by Hugh Tomlinson and Robert Galeta. Minneapolis: University of Minnesota Press, 1989.

Deleuze, Gilles and Felix Guattari. A Thousand Plateaus: Capitalism and Schizophrenia. Translated by Brian Massumi. Minneapolis: University of Minnesota Press, 2008.

Kafka: Toward a Minor Literature. Translated by Dana Polan. Minneapolis: University of Minnesota Press, 1986.

Derrida, Jacques. L'animal que donc je suis. Paris: Editions Galilée, 2006.

The Animal That Therefore I Am, Edited by Marie-Louise Mallet. Translated by David Wills. New York: Fordham University Press, 2008.

Douchet, Jean and Cédric Anger. French New Wave. Translated by Robert Bonnono. New York: Distributed Art Publishers, 1999.

Duras, Marguerite. Hiroshima mon amour: scénario et dialogue. Paris : Gallimard, 1960.

Eagleton, Terry. Literary Theory: An Introduction Anniversary Edition. Malden: Blackwell Publishing, 2008.

Elsaesser, Thomas. "Postmodernism as Mourning Work.” Screen 42 no. 2 (2001): 193- 201.

Ervine, Jonathan. "Les banlieues and Les Bleus: Political and media discourse about sport and society in France." French Cultural Studies 25 no. 1 (2014): 70 - 81.

Featherstone, Mike. "Postmodernism and the aestheticization of everyday life." Modernity and Identity. Scott Lash and Jonathan Friedman, eds. Oxford: Blackwell, 1992.

Fenton, James. “The Pitts-River Museum, Oxford." Newsletter (museum Ethnographers Group) 16 (1984): 37-40.

Finnan, David. "Chatting with M. Chat at Paris graffiti show." RFI.com. 2010. http://en.rfi.fr/culture/20100316-chatting-monsieur-chat-paris-graffiti-show 
“flashmob." OxfordDictionaries.com. 2016. http://www.oxforddictionaries.com/us/definition/ american_english/flash-mob?q=flashmob

Flitterman-Lewis, Sandy. To Desire Differently: Feminism and the French Cinema. Urbana: University of Illinois Press, 1990.

Forster, E.M. Aspects of the Novel. San Diego: Harcourt Inc, 1955.

Freedman, Jane. Immigration and Insecurity in France. Burlington: Ashgate, 2004.

Freud, Sigmund. The Uncanny. Translated by David McClintock. New York: Penguin Books, 2003.

Friedberg, Anne. "Les Flâneurs Du Mal(1): Cinema and the Postmodern Condition". PMLA 106 no. 3 (1991): 419-431.

Window Shopping: Cinema and the Postmodern. Berkeley: University of California Press, 1993.

Genette, Gérard. Narrative Discourse: An Essay in Method. Translated by Jane E. Lewin. Ithaca: Cornell University Press, 1980.

- Narrative Discourse Revisited. Translated by Jane E. Lewin. Ithaca: Cornell University Press, 1988.

Gill, Miranda. Eccentricity and the Cultural Imagination in Nineteenth-Century Paris. New York: Oxford University Press, 2009.

Goldie, Matthew Boyd. "The Rhetoric of Grief: Hiroshima mon amour." English Language Notes 46 no. 1 (2008): 61-74.

Gronhovd, Anne-Marie and William C. VanderWolk. "Memory as Ontological Disruption: Hiroshima mon amour as a Postmodern work." In Language and In Love, Marguerite Duras: The Unspeakable, edited by Michael Cranston. Potomac: Scripta Humanistica, 1992. 119 - 138.

Guiney, M. Martin. "'Total Cinema', Literature, and Testimonial in the Early Films of Alain Resnais." Adaptation 5 no. 2 (2011): 137 - 151.

Hanssen, Beatrice, ed. Walter Benjamin and The Arcades Project. London: Continuum, 2006.

Haraway, Donna J. When Species Meet. Minneapolis: University of Minnesota Press, 2008.

Hargreaves, Alec G. Immigration, 'Race' and Ethnicity in Contemporary France. London and New York: Routledge, 1995. 
Harvey, David. Paris, Capital of Modernity. London: Routledge, 1999.

Hayward, Susan. "Beyond the gaze and into femme-filmécriture: Agnès Varda's Sans toit ni loi (1985)." French Film: Texts and Contexts, edited by Susan Hayward and Ginette Vincendeau. London: Routledge, 1990. 285-296.

Higgins, Lynn A. New Novel, New Wave, New Politics: Fiction and Representation of History in Postwar France. Lincoln: University of Nebraska Press, 1996.

Hillier, Jim, ed. Cahiers du Cinéma: The 1950s: Neo-Realism, Hollywood, New Wave. Cambridge: Harvard University Press, 1985.

"Hiroshima Peace Memorial Museum.” Hiroshima Peace Site. 2011. http://www.pcf.city.hiroshima.jp/top_e.html

Hirsch, Joshua Francis. Afterimage: Film, Trauma, and the Holocaust. Philadelphia: Temple University Press, 2004.

Hoffman, Martin L. "Empathy, Justice, and the Law." Empathy: Philosophical and Psychological Perspectives. Edited by Amy Coplan and Peter Goldie. New York: Oxford University Press, 2011.

Horne, Alistair. A Savage War of Peace: Algeria 1954 - 1962. New York: New York Review of Books, 2006.

Hottell, Ruth A. "Flying Through Southern France: Sans toit ni loi by Agnès Varda." Women's Studies 28 (1999): 675-696.

Huyssen, Andreas. Twilight Memories: Marking Time in a Culture of Amnesia. New York: Routledge, 1995.

Ince, Kate. "Feminist Phenomenology and the Film World of Agnès Varda." Hypatia 28 no. 3 (2013): 602-617.

Jenks, Chris. "Watching Your Step: The history and practice of the flâneur." Visual Culture. London: Routledge, 1995. $142-160$.

Jenson, Deborah. Trauma and its Representations: The Social Life of Mimesis in PostRevolutionary France. Baltimore: The Johns Hopkins University Press, 2001.

Johnson, Douglas. “Obituary: Léon Schwartzenberg.” The Guardian News and Media. July 2014. http://www.theguardian.com/news/2003/oct/24/guardianobituaries.france.

Jones, Kent. "Hiroshima mon amour: Time Indefinite." New York: The Criterion Collection, 2003. 
Kaplan, E. Ann. “Melodrama, cinema and trauma.” Screen 42, no. 2 (2001): 201 - 205.

- Trauma Culture: The Politics of Terror and Loss in Media and Literature. New Brunswick: Rutgers University Press, 2005.

Kline, T. Jefferson, ed. Agnès Varda: Interviews. Jackson: University Press of Mississippi, 2014.

- Screening the Text: Intertextuality in New Wave French Cinema. Baltimore: Johns Hopkins University Press, 1992.

Kreidl, John Francis. Alain Resnais. Boston: Twayne Publishers, 1977.

Kristeva, Julia. Black Sun: Depression and Melancholia. Translated by Leon S. Roudiez. New York: Columbia University Press, 1989.

- Strangers to Ourselves. Translated by Leon S. Roudiez. New York: Columbia University Press, 1991.

Lauster, Martina. "Walter Benjamin's Myth of the "flâneur"'”. The Modern Language Review 102 no. 1 (2007): 139-156.

Levine, Alison J. Murray. "Ghosts on the Skyline: Chris Marker’s France after 9/11.” From Solidarity to Schisms: $9 / 11$ and After in Fiction and Film from Outside the US, edited by Cara C. Cilano. Amsterdam: Rodopi, 2009.

Lopate, Phillip. "In Search of the Centaur: The Essay-Film.” The Threepenny Review 48 (1992): 19-22.

Lucas, Raymond. "Inscribing the city: a flâneur in Tokyo." Anthropology Matters 6 no. 1 (2004): $1-11$.

Lupton, Catherine. Chris Marker: Memories of the Future. London: Reaktion Books, 2005.

Mallan, Kerry. "Strolling Through the (Post)modern City: Modes of Being a Flâneur in Picture Books." The Lion and the Unicorn 36 no. 1 (2012): 56 - 74.

Marker, Chris. A Grin Without a Cat. London: Whitechapel Gallery, 2014.

—La Jetée: ciné-roman. Brooklyn: Zone Books, 1992.

— Staring Back. Columbus: Wexner Center for the Arts, The Ohio State University, 2007.

Marks, Laura U. The Skin of the Film: Intercultural Cinema, Embodiment, and the Senses.

Durham: Duke University Press, 2000. 
Marie, Michel. The French New Wave: An Artistic School. Translated by Richard Neupert. Malden: Blackwell Publishing, 2003.

Martin, Marcel. Le Cinéma français depuis la guerre. Paris: Edilig, 1984.

Mavor, Carol. Black and Blue: The Bruising Passion of Camera Lucida, La Jetée, Sans soleil, and Hiroshima mon amour. Durham: Duke University Press, 2012.

"“Summer Was Inside the Marble': Marguerite Duras and Alain Resnais's Hiroshima mon amour." Photography \& Culture 1 no. 1 (2008): 27-50.

McCormack, Jo. "Social Memories in (Post)colonial France: Remembering the Franco-Algerian War." Journal of Social History 44 no. 4 (2011): 1129 - 1138.

Morgan, Frances. “In the Discomfort Zone.” Sight and Sound 25 no. 4 (2015): 56-57.

Mouton, Janice. "From Feminine Masquerade to Flâneuse: Agnès Varda's Cléo in the City." Cinema Journal 40 no. 2 (2001): 3-16.

Mulvey, Laura. Visual and Other Pleasures. Bloomington: Indiana University Press, 1989.

Naficy, Hamid. An Accented Cinema: Exilic and Diasporic Filmmaking. Princeton: Princeton University Press, 2001.

Neupert, Richard. A History of the French New Wave Cinema. Madison: University of Wisconsin Press, 2002.

Nichols, Bill, ed. Movies and Methods: An Anthology. Berkeley: University of California Press, 1976.

- Representing Reality: Issues and Concepts in Documentary. Bloomington: Indiana University Press, 1994.

Nuvolati, Giampaolo. "The Flâneur: A Way of Walking, Exploring and Interpreting the City." Walking in the European City, Edited by Timothy Shortell and Evrick Brown. Farnham: Ashgate, 2014.

Poe, Edgar Allan. "The Man of the Crowd." The Complete Tales and Poems of Edgar Allan Poe. New York: Race Point Publishing, 2014. 414 - 420.

Poppe, Sandra. "The Aesthetics of Death and Mourning in American Literature and Film." Morbidity of Culture: Melancholy, Trauma, Illness and Dying in Literature and Film, edited by Stephanie Siewert and Antonia Mehnert. Frankfurt: Peter Lang, 2012.

Pratt, Mary Louise. Imperial Eyes: Travel Writing and Transculturation. New York: Routledge, 2008. 
Radstone, Susannah. "Trauma and Screen Studies: Opening the Debate." Screen 42 no. 2 (2001): $188-193$.

Rascaroli, Laura. "The Essay Film: Problems, Definitions, Textual Commitments." Framework: The Journal of Cinema and Media 49 no. 2 (2008): 24-47.

Reynolds, Anthony. "Toward a Sovereign Cinema: George Bataille's Hiroshima mon amour." Literature Film Quarterly 38 no. 4 (2010): 311-322.

Rignall, John. "Benjamin's flâneur and the problem of realism." The Problems of Modernity. Edited by Andrew Benjamin. London: Routledge, 1989.

Rilke, Rainer Maria. Duino Elegies and The Sonnets to Orpheus. Translated by A. Poulin. Houghton Mifflin Harcourt, 2005.

Rivoire, Annick. “Interview: Chris Marker et M. Chat: Chats discutent.” Liberation. 2004. http://next.liberation.fr/arts/2004/12/04/chats-discutent_501770.

Ropars-Wuilleumier, Marie-Claire. "How history begets meaning: Alain Resnais' Hiroshima mon amour (1959)." French Film: Texts and Contexts, edited by Susan Hayward and Ginette Vincendeau. London: Routledge, 1990.

Sarraute, Nathalie. L'ère du soupçon. Paris, Gallimard, 1956.

Siewert, Stephanie and Antonia Mehnert, eds. Morbidity of Culture: Melancholy, Trauma, Illness and Dying in Literature and Film. Frankfurt: Peter Lang, 2012.

Smith, Alison. Agnès Varda. Manchester: Manchester University Press, 1998.

Sontag, Susan. On Photography. New York: Picador, 1977.

Regarding the Pain of Others. New York: Picador, 2003.

Stoller, Paul. The Cinematic Griot : The Ethnography of Jean Rouch. Chicago: The University of Chicago Press, 1992.

Stora, Benjamin. Ils Venaient d'Algérie : L'immigration algérienne en France (1912-1992).

Paris : Fayard, 1992.

Tassone, Aldo, ed. Que reste-t-il de la nouvelle vague? Paris : Éditions Stock, 2003.

Truffaut, François. "Une certaine tendance du cinéma français." Cahiers du cinéma 31 (1954): $15-29$. 
Turim, Maureen. “The trauma of history: flashbacks upon flashbacks." Screen 42, no 2 (2001): $205-210$.

Varsava, Nina. "Processions of trauma in Hiroshima mon amour: Towards an ethics of representation.” Studies in French Cinema 11 no. 2 (2011): 111-123.

Vaughan, Hunter. Where Film Meets Philosophy: Godard, Resnais, and Experiments in Cinematic Thinking. New York: Columbia University Press, 2013.

Vuille, Thoma. M.Chat. Paris: Éditions Alternatives, 2010.

Warner, Rick. "Go-for-broke games of history: Chris Marker between 'old' and 'new' media." Post Script 29 no. 1 (2009): 14-27.

Wasik, Bill. "\#Riot: Self-Organized, Hyper-Networked Revolts - Coming to a City Near You." Wired. 2011. http://www.wired.com/2011/12/ff_riots/all/1.

Wilson, Emma. Alain Resnais. Manchester: Manchester United Press, 2006. 